\title{
Aircraft Noise Prediction
}

\author{
Antonio Filippone ${ }^{1}$ \\ The University of Manchester
}

\begin{abstract}
This contribution addresses the state-of-the-art in the field of aircraft noise prediction, simulation and minimisation. The point of view taken in this context is that of comprehensive models that couple the various aircraft systems with the acoustic sources, the propagation and the flight trajectories. After an exhaustive review of the present predictive technologies in the relevant fields (airframe, propulsion, propagation, aircraft operations, trajectory optimisation), the paper addresses items for further research and development. Examples are shown for several airplanes, including the Airbus A319-100 (CFM engines), the Bombardier Dash8-Q400 (PW150 engines, Dowty R408 propellers) and the Boeing B737-800 (CFM engines). Predictions are done with the flight mechanics code FLIGHT. The transfer function between flight mechanics and the noise prediction is discussed in some details, along with the numerical procedures for validation and verification. Some code-to-code comparisons are shown. It is contended that the field of aircraft noise prediction has yet not reached a sufficient level of maturity. In particular, some parametric effects cannot be investigated, issues of accuracy are not currently addressed, and validation standards are still lacking.
\end{abstract}

Keywords: Aircraft operations, aircraft noise, community noise, engine noise, airframe noise, noise footprints, noise abatement procedure, sound propagation.

\section{Contents}

1 Introduction $\mathbf{5}$

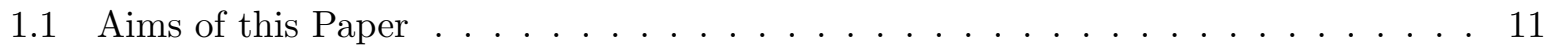

1.2 Aircraft Noise Metrics . . . . . . . . . . . . . . . . . . . . . . . . 12

1.3 Environmental Effects . . . . . . . . . . . . . . . . . . . . . . . 14

1.4 The Case for Airport Expansion _ . . . . . . . . . . . . . . . . 16

1.5 Aircraft Noise Prediction Models . . . . . . . . . . . . . . . . . . . . 17

2 Computational Methods for Aircraft Noise Prediction 22

2.1 Airframe Noise . . . . . . . . . . . . . . . . . . . . . . 24

2.1 .1 High-Lift Systems Noise . . . . . . . . . . . . . . . . . . . . 26

2.1 .2 Landing Gear Noise . . . . . . . . . . . . . . . . . . . . . . . . . . . . . 29

2.2 Propulsive Noise . . . . . . . . . . . . . . . . . . . . . . . . . . 33

2.3 Propeller Noise . . . . . . . . . . . . . . . . . . . . . . . . 41

Email address: a.filippone@manchester.ac.uk (Antonio Filippone)

${ }^{1}$ School of MACE, George Begg Building, Manchester M13 9PL, United Kingdom 
2.4 Acoustic Liners . . . . . . . . . . . . . . . . . . . . . . . . . . 43

2.5 Noise Shielding and Other Source Effects _ . . . . . . . . . . . . . . . . 44

2.6 Far-Field Noise Propagation . . . . . . . . . . . . . . . . . . . . . . 45

2.7 Engine Models . . . . . . . . . . . . . . . . . . . . . . . . . . . . . . 49

3 Aircraft Noise Calculations $\quad \mathbf{5 0}$

3.1 Transfer Function for Aircraft Noise . . . . . . . . . . . . . . . . . 51

3.2 Fly-over Trajectories . . . . . . . . . . . . . . . . . . . . . 54

3.3 Spectral Analysis . . . . . . . . . . . . . . . . . . . . 57

3.4 Fly-over Trajectories . . . . . . . . . . . . . . . . . . . . . . 61

3.5 Noise Directivities . . . . . . . . . . . . . . . . . . . . 63

3.6 Noise Footprints . . . . . . . . . . . . . . . . . . . . . . . . . 64

3.7 The Need for Validation Standards . . . . . . . . . . . . . . . . . . 65

3.8 Systems Analysis . . . . . . . . . . . . . . . . . . . . . . . 67

3.9 Code-to-Code Comparisons . . . . . . . . . . . . . . . . . 71

4 Perspectives in Noise Reduction $\quad \mathbf{7 1}$

4.1 Noise Trajectory Optimisation _ . . . . . . . . . . . . . . . . . 72

5 Conclusions $\quad 78$ 


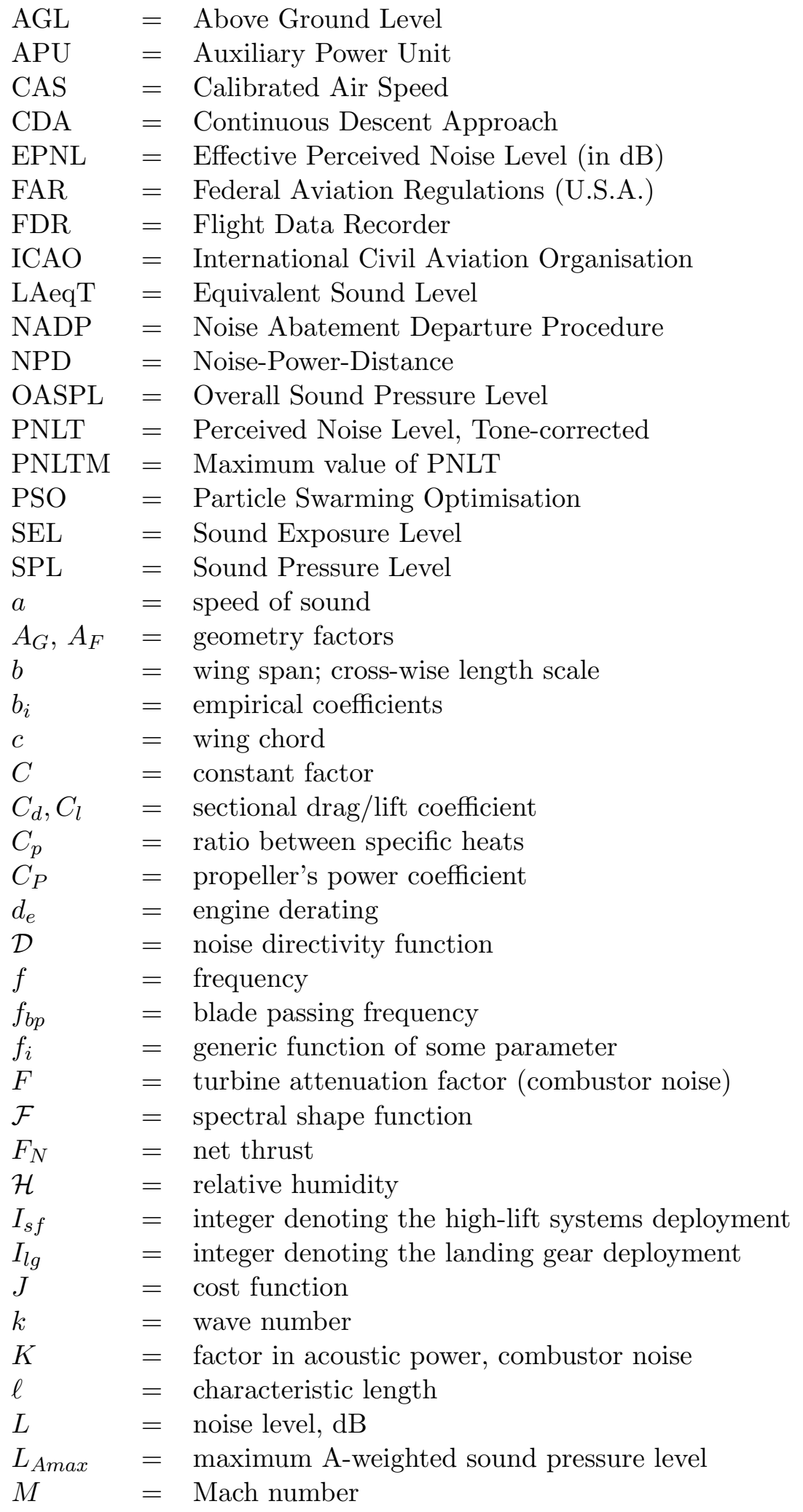




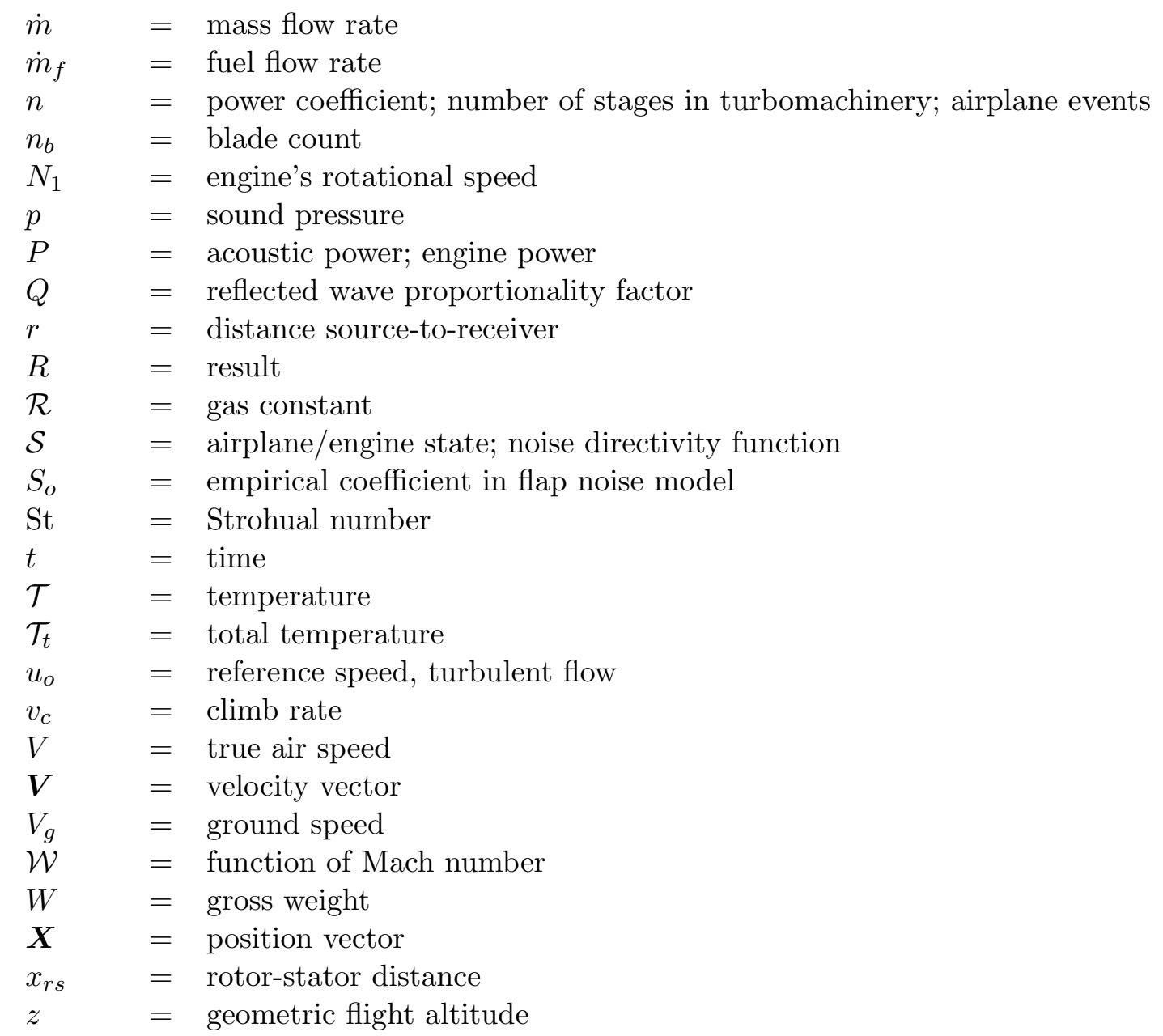

\section{Greek Symbols}

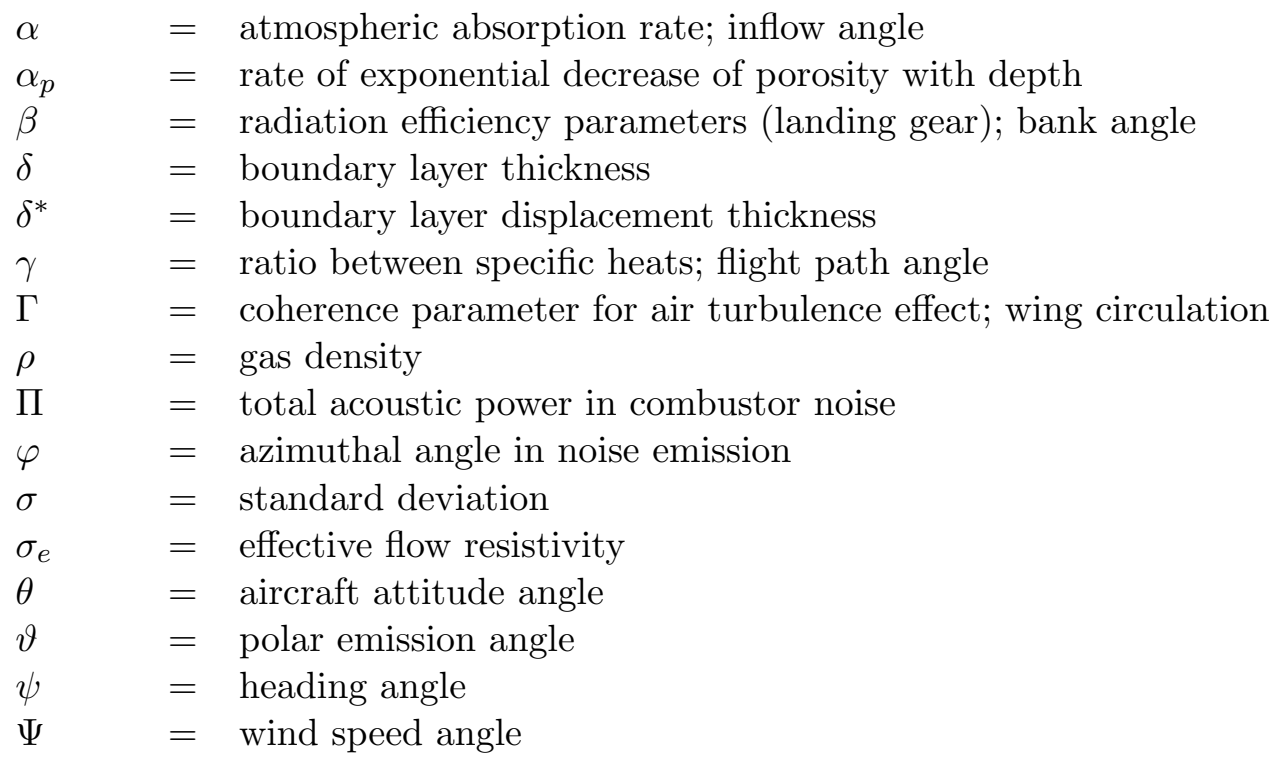




\section{Subscripts \& Superscripts}

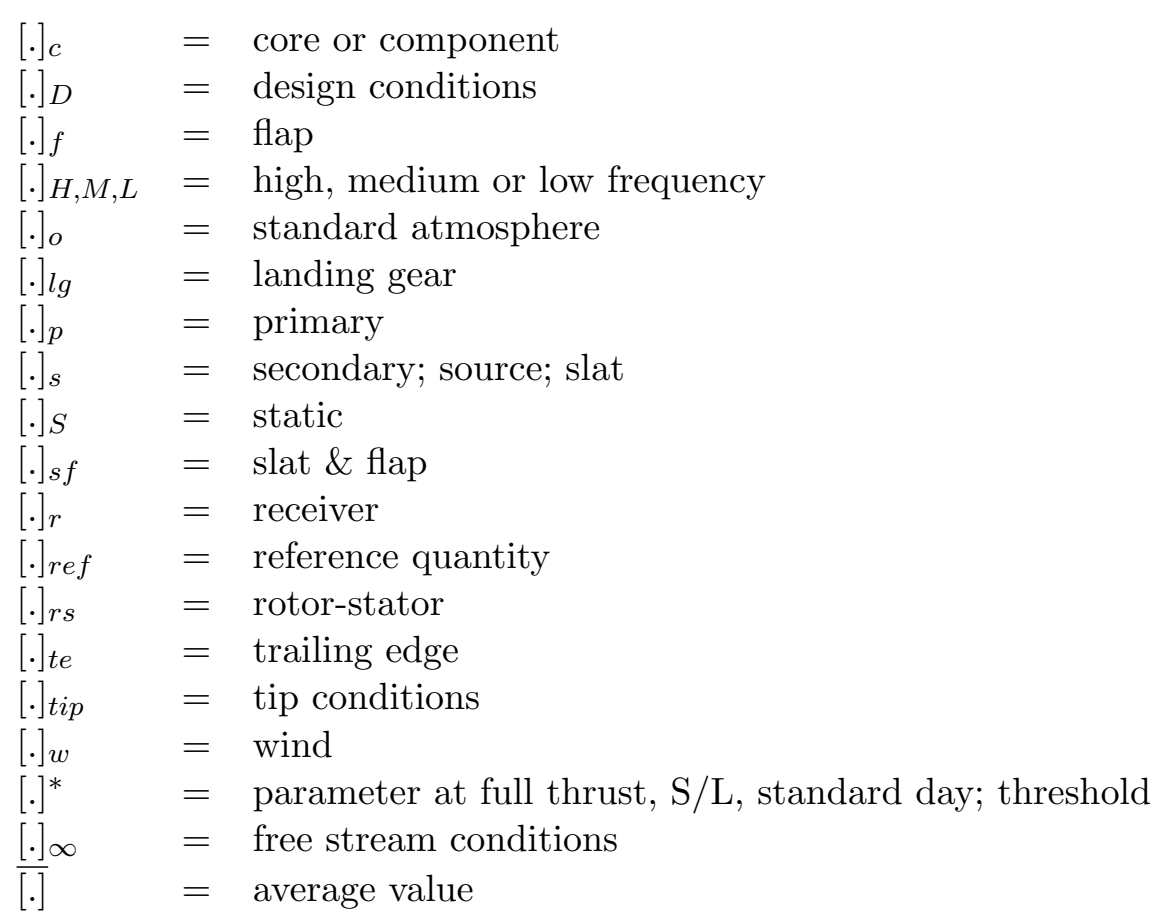

\section{Introduction}

Aircraft noise has significant effects at many airports around the world. Although at the basic level these effects are classified as "annoyance", there are more serious health-related effects which have generated a considerable amount of academic work. As a result, aircraft noise is a highprofile issue that commands the attention of experts in the aviation industry, airframe and engine manufacturers, airline operators, the general public, health and occupational services. Efforts to bring down aircraft noise have been largely driven by regulations in response to concerns from various communities. These regulations have been developed by the International Civil Aviation Organisation (ICAO) and other organisations over the course of many years; the ICAO took into considerations complex aspects beyond noise itself, which eventually led to the so-called "Annex 16"; these regulations first entered into force in 1971. Even today, the noise regulations cannot be considered a closed business, as clauses are updated through continual review by a number of committees, in particular the Committee on Aviation Environmental Protection (CAEP). A summary of such historical events is recorded by Heller ${ }^{1}$ and Smith ${ }^{2}$, among others. In brief, the ICAO regulations underwent a series of major updates and enforcements called Chapters. The current regulations, at the date of this contribution, are represented by Chapter 4; these 
regulations were enforced in 2006, following a decision by the CAEP in June 2001. By then, most of the commercial fleet was within the regulatory bounds; presently, there are wide margins at all the required points. An analysis of the most recent noise certification data indicates that across the commercial airplanes there is an average margin of $5.1 \mathrm{EPNL}(\mathrm{dB})$ on approach, 6.9 $\operatorname{EPNL}(\mathrm{dB})$ on fly-over and 3.6 $\operatorname{EPNL}(\mathrm{dB})$ at lateral points. On average, there is a cumulative margin of $15.8 \mathrm{EPNL}(\mathrm{dB})$ over the Chapter 4 regulations, as shown in Figure 1. In some cases, the cumulative margin exceeds $20 \mathrm{~dB}$. Therefore, we are well below the current limits, and certainly open to further restrictions in the near future. The next ICAO chapter is likely to demand a further cumulative reduction by $7 \mathrm{EPNL}(\mathrm{dB})$, which appears to be a retrospective acceptance of the current noise levels (Figure 1). Even then, the feeling of "annoyance" will not disappear.

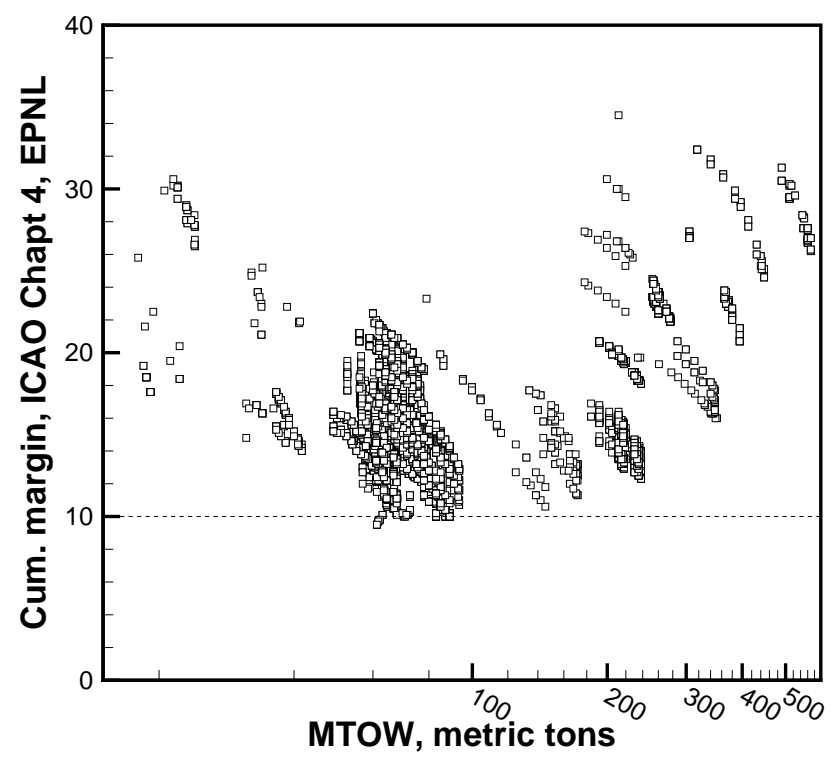

Figure 1: Cumulative noise margin (approach, fly-over, lateral) of commercial aircraft over ICAO Chapter 4 limits. Data source: EASA.

Figure 2 shows that the noise on approach is always higher than at other reference points; this result depends on a combination of factors, including duration, contribution from multiple sources, and distance from receivers on the ground.

Figure 3 shows the conventional ICAO/FAR reference points for community noise. Note that "take-off" and "fly-over" are synonymous, as are "sideline" and "lateral". Noise data at this reference points were shown in Figure 1 and 2.

One general statement that can be extracted from the large body of noise regulations is that 


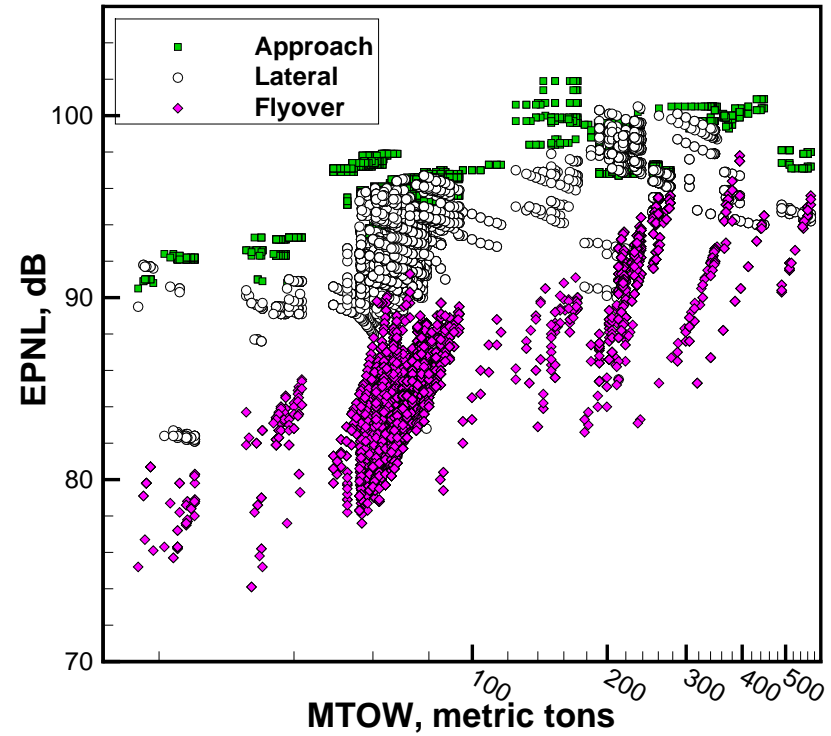

Figure 2: Recorded EPNL on approach, fly-over, lateral. Data source: EASA.

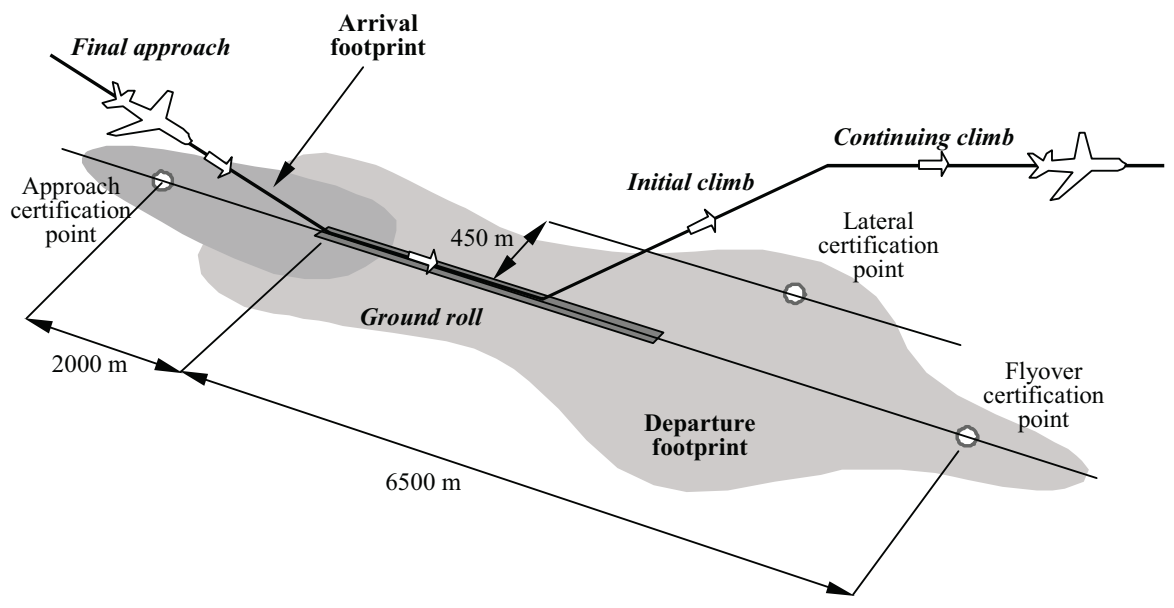

Figure 3: Community reference points for noise certification and typical noise footprints on arrival and departure. Adapted from Ref. ${ }^{3}$

the effects are considered in a cumulative manner, and thus refer to "community annoyance"; this is a long-term effect in a statistical sense. Noise annoyance is rather subjective and dependent on the time (day or night), which is an inconvenient fact for a quantitative analyst. A characterisation of such annoyance was published by $\mathrm{Schultz}^{4}$ on the basis of social survey data, which have been updated over time ${ }^{5,6}$; this approach to quantification of noise annoyance is now of widespread use in various aircraft noise prediction, specifically in trajectory optimization. 
Table 1: Airports with noise restrictions in 2013.

\begin{tabular}{lc}
\hline & No. Airports \\
\hline Noise Restrictions & $\mathbf{6 5 1}$ \\
Noise abatement procedures & 517 \\
Engine run-up restrictions & 414 \\
Use of preferential runways & 366 \\
Curfew & 241 \\
APU use & 137 \\
Noise surcharge & 128 \\
Flight Quotas & 55 \\
\hline
\end{tabular}

When we consider all the restrictions arising from noise regulations, land use, technology level and operational costs, we conclude that aircraft noise has to be dealt with at several levels. At the operational level, we must aim to improve the use of existing fleets through optimal flight paths, careful ground operations, retrofit technologies, where possible, and other procedures that limit noise exposure. The view taken by the ICAO recognises the complexity of the problem, and is thus is aligned with this holistic or balanced approach; this includes:

- Noise reduction at the source (engine and aircraft).

- Improvements in land use and urban development.

- Improvements in flight procedures.

- Restriction of operations (quotas).

The operational aspect is not emphasised enough: in an ideal world, we would design and manufacture better airplanes that will replace the existing fleet. We recognise that this is not realistic as we enter an age of expansion of commercial airplanes consisting of new and conventional aircraft that will operate beyond 2050 (Airbus A350, A320NEO, A380; Boeing B787, B737NG, B747-800).

Where are the opportunities for getting the most benefit from existing airplanes? — Flight path management is one important option. Fundamental to the determination of optimal flight paths is the accurate predictions of noise measured by microphones on the ground. If such methods become available, then it is possible to develop a flight management computer that handles noise constraints as part of the flight control system. Thus, there is a need for holistic methods that are sufficiently accurate, reliable and fast. Fast means calculation times of the same 
order as the duration of the flight: a flight maneuver lasting say one minute should be analyzed in a similar amount of time. Let us call this computational time a single unit $t$. When we expand our analysis to the estimation of noise carpets from a single aircraft movement, we need a few hundred receiver points to extract a meaningful noise map, which leads to a few hundred units of computation time, e.g. $\sim 10^{2} t$. If we further extend this analysis to a complete take-off and landing cycle, then the number of receivers would be several hundreds, and the calculation times run a thousand units, $10^{3} t$. Finally, if we wish to determine the noise maps created by multiple aircraft movements over a long period of time (for example, a full day) at a busy airfield, computation times run into several thousand units, $10^{4}-10^{5} t$. It does not take long to verify that the problem grows exponentially in both complexity and computational burden. As this burden increases, it is inevitable that sacrifices have to be done in terms of accuracy at some point in the calculation chain.

Numerical methods that do not satisfy these basic requirements on computing times cannot be part of comprehensive models. At present, physical acoustic methods requiring field solutions are neither suitable, nor realistic. The requirements currently are clearly rather strict, because they direct the choice toward low-order methods, which are necessarily limited in both scope and generality; finer details of airframe or engine parameters cannot be assessed with confidence when using these reduced methods.

A comprehensive approach to aircraft noise produces a large matrix of time-resolved data of individual noise sources for specific events, e.g., during departures or arrivals. These data can be manipulated to generate a variety of noise metrics. For instance, instantaneous noise metrics can be presented in terms of annoyance, noisiness, or loudness; metrics for single events are commonly presented using Effective Perceived Noise Levels (EPNL) or Sound Exposure Levels (SEL). Higher level applications include noise footprints around airports, noise histories throughout the flight, detailed noise data at specific receiver locations, and comparisons between individual sources.

In spite of these apparent limitations, the potential for a comprehensive analysis of aircraft noise is enormous, and does include applications in aircraft design, when there is a need to predict noise at the very early stages, when the amount of data is modest and their quality is uncertain.

Figure 4 shows the current needs in aircraft noise prediction. At the fundamental level, we need physics-based field models, including computational fluid dynamics, computational aeroacoustics (for jets, fans, compressors, combustors, high-lift systems). The work published in Ref. ${ }^{7}$ 


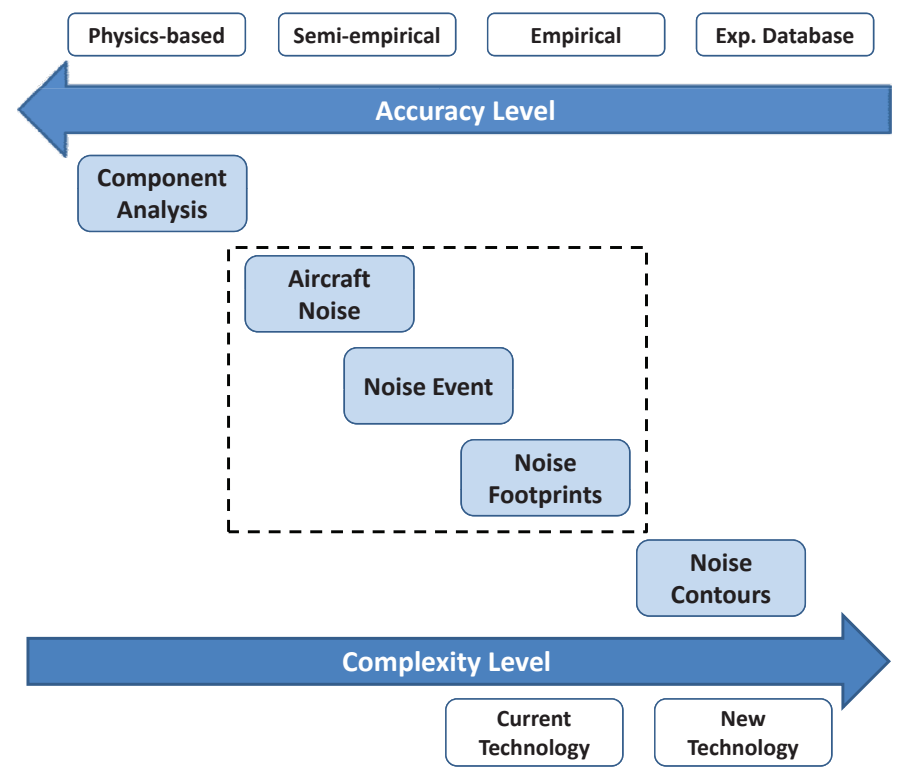

Figure 4: Flowchart indicating needs and applications at several levels.

shows the typical computational efforts required on a real aircraft, as well as some shortcomings that even the most sophisticated models suffer. However, there are also powerful boundarybased methods, such as the boundary element methods, which have been successfully used in applications in which the ratio between solid boundaries and flow domain is small (for example, fans, propellers, ducted propellers, airframe shielding). There is scope for some boundary element methods to be incorporated into a comprehensive model, as discussed later.

The intermediate level (framed by a dashed line) includes the aircraft (interpreted as a noiseproducing system), a noise event (interpreted as the noise emitted during a single flight trajectory at a microphone location) and a noise footprint (interpreted as the noise received by several microphones over a large area). This is the target research domain of this paper, and the domain of a scientific approach to aircraft noise prediction. Unfortunately, this research is still dominated by empirical and semi-empirical methods, with little, albeit increasing, support from physicsbased methods.

At a higher level, there is a need to predict noise contours at an airfield; these contours are short- to long-time averages (from 24 hours to one year, including seasonal variations) and result from multiple operations (several thousands) from different airplane types at different times of the day and night. 
As we move toward more integration and higher levels of complexity, we must sacrifice details and accuracy for the sake of an "average" noise metric resulting from a variety of events. Noise prediction in this area is done exclusively by using experimental databases, aided by some basic theoretical support to interpolate and extrapolate data.

The final issue that needs clarification in Figure 4 centers around the use of these methods to particular aircraft types. It will be argued that the dominant drive in this effort is the current technology, because of the large fleet of commercial airplanes already in service; however, there is now increased emphasis on multi-disciplinary design, with minimum environmental impact as a cost function; the latter effort is to drive the next generation of commercial aircraft. For these cases, there is little experience and data to go by; therefore, aircraft noise prediction must produce step changes in simulation capability.

\subsection{Aims of this Paper}

In light of the previous introduction, this paper aims at demonstrating state-of-the-art and progress in comprehensive aircraft noise in a number of areas, including the following:

- To review and propose theoretical methods for the prediction of aircraft noise, including specifically all the integral noise metrics, the overall sound pressure levels and the noise footprints caused by single and multiple aircraft movements. This contribution deals with the areas of research and applications noted by the dashed box in Figure 4 .

- To propose methods for verification and validation of the noise simulation with experimental noise measurements that are synchronised with aircraft trajectories.

- To identify the noise sources from aircraft operations through the use of sensitivity analysis; this allows us to focus on noise reduction strategies for those items that contribute to the highest noise levels.

- To study the effects of atmospheric conditions and boundary conditions, including winds, ground effect and temperature gradients.

- To review the options for noise trajectory optimization, and how they can be used to reduce operational aircraft noise.

On the basis of the above, we aim to establish a benchmark for the validation of aircraft noise simulation, to be used in all engineering analysis. Due to the immense technical literature in 
this field, we need to set some limiters to the scope of our work. The presentation is limited to civil fixed-wing aircraft powered by high by-pass turbofan engines or turboprop-propeller systems. Helicopter noise, internal (cabin) noise and noise from supersonic flight (for example, sonic boom) are not considered. Likewise, health effects cannot be the subject of the present analysis. A few items need review because many trajectory optimisation methods rely on functions such "awakenings", which have now been codified by the ANSI $^{8}$ after extensive field studies. With regards to the latter issue, the Dutch Division of Public Health published an exhaustive report ${ }^{9}$. This field of research is outside our scope ${ }^{\dagger}$. However, we wish to mention that there studies as varied as the effect of sleep deprivation ${ }^{10}$ and on learning effectiveness of school-children in London ${ }^{11,12}$.

\subsection{Aircraft Noise Metrics}

As anticipated, aircraft noise relies on a level of "annoyance". It is essential to clarify what this means and how subjective feelings can be quantified to provide metrics that are of engineering value. Annoyance is rather different than a physical measure of acoustic pressure (sound pressure level): the acoustic pressure can be measured, annoyance can only be interpreted. Unlike other acoustic events attributed to machines and human activities, aircraft noise is characterised by cumbersome measures, whose definition requires in many cases numerical operations, tone corrections, weighting, and integration. The ANSI ${ }^{13}$ define at least sixteen metrics, which are exposure-based, time-based, time-audible, and maximum value. Each of these categories can be A-weighted, C-weighted or tone-corrected. A full analysis and classification is available in Schultz ${ }^{14}$.

For the purpose of the analysis shown later, we will refer to the OASPL, which can be raw or A-weighted. We then refer to the following integral metrics: 1.) EPNL; 2.) $L_{A E}$ (or SEL); 3.) $L_{A e q T}$ (or LAEQ, or Equivalent Sound Level); 4.) $L_{A S m x}$ (or LAmax, A-weighted maximum sound level).

To be more specific, the EPNL metric is used for noise certification of commercial airplanes (both propeller and jet-driven, Figure 2), the SEL is used for certification of light airplanes, the $L_{\text {Amax }}$ is used in studies such as awakening functions. EPNL, like other flight integral metrics, cannot be measured directly, but it must be calculated following a procedure specified by the

\footnotetext{
${ }^{\dagger}$ The Federal Interagency Committee on Aviation Noise (FICAN), through their website, provide further recommendations.
} 
ICAO (Annexe 16, Appendix 2). Noise measurement, monitoring and selection of sites at airfields are regulated in the $\mathrm{UK}^{15}$ and possibly in other countries. Some major airports, including London and Frankfurt, produce real-time noise levels accessible to the public via the Internet. Noise threshold levels are around $60 \mathrm{~dB}$; lower noise levels do not trigger the recording devices.

Aside from the integral metrics for a single aircraft movement, there is a number of exposurebased metrics that refer to noise exposure over a specified time limit (day-time, night-time, full day) at a reference location during an average day.

Aircraft noise exposure contours are calculated from $57 \mathrm{dBA}$ Leq to $72 \mathrm{dBA}$ Leq at $3 \mathrm{~dB}$ intervals. Long-term effects are measured with day-night sound level (DNL) and the equivalent noise level $L_{e q}$. The DNL (or $L_{d n}$ ) is the A-weighted $L_{e q}$ over a 24-hour period; a correction of +10 $\mathrm{dB}$ is added to night-time events (23:00 to 07:00). The metric used to calculate the population affected by aircraft noise is $L_{d e n}$ (or CNEL, Community Noise Equivalent Level). Estimation of the people affected by aircraft noise is done with $L_{d e n} \geq 55 \mathrm{dBA}$; for London Heathrow, this corresponds to about 750,000 people exposed to noise ${ }^{16}$. This "exposure" consideration has led to a higher-level noise measure, named quota count. This is a noise parameter dependent on the exposure area above a certain EPNL and the number of people affected. By comparison, the noise inside London Heathrow Terminal Five is 60 to 65 dBA (measured by the Author at London Heathrow, Terminal 5, at the central passenger lounge; reference time: 2 minutes).

In aircraft noise most spectral analysis is done in the $1 / 3$ octave band frequencies ${ }^{17}$, although in many instances a finer frequency spectrum must be considered (for example, broadband noise). However, since we need to provide a sum of several contributions, the contributions must be correlated in frequency; hence the sums are done in the octave band frequencies. In this spectrum, the lowest frequency is $20 \mathrm{~Hz}$ and the highest is $20 \mathrm{kHz}$. Aircraft noise prediction is often restricted to an even narrower band; for example, the EPNL is calculated at frequencies greater than 50 $\mathrm{Hz}$.

As a final comment to the role of the noise metrics, the logarithmic scale implies that a " $50 \%$ noise reduction" must be interpreted as a $50 \%$ reduction in the acoustic pressure $\left\langle p^{2}\right\rangle$; this means that the actual reduction in SPL is about $-3 \mathrm{~dB}$. This is one of the most important aspects of working with the log-scale. Assume that the overall sound pressure level is due to a combination of three sources $L_{i}=90 \mathrm{~dB}$, The resulting noise $L$ is 


$$
L=10 \log _{10}\left(10^{L_{1} / 10}+10^{L_{3} / 10}+10^{L_{3} / 10}\right)=94.8 \mathrm{~dB}
$$

A reduction of $L_{1}$ to $85 \mathrm{~dB}$ would cause a reduction in $L$ by only $1.4 \mathrm{~dB}$. By extending the analysis to a large number of noise sources, we can demonstrate that is it not effective to reduce noise sources which are $15 \mathrm{~dB}$ below the highest contribution; furthermore, if there are several contributions of comparable levels, a reduction is required on all of them in order to effectively reduce the overall noise level. The effort required depends on whether the flight trajectory is an approach or a departure.

The relationship between the reduction in $\left\langle p^{2}\right\rangle$ and the corresponding reduction in EPNL is not straightforward, and cannot be predicted in the general case, because is depends on the tonal components and the duration of the acoustic signals. Thus, there is widespread use (and confusion) about the term "quiet". Recently, some empirical corrections have been proposed ${ }^{18}$ that correlate well the certified EPNL with the key aircraft flight parameters (thrust, gross weight, fan diameter, lift-to-drag ratio).

For those cases where the maximum noise level $L_{\max }$ is the relevant metrics, there is a straightforward relationship between noise level and flight quotas. Consider for example the following

$$
\bar{L}_{\text {max }}=10 \log _{10}\left[\frac{1}{n} \sum_{i=1}^{n} 10^{L_{\max , i} / 10}\right]
$$

where $n$ is the number of movements. One way of looking at congestion problems and noise limitations can be based on the

$$
L_{2}-L_{1}=10 \log _{10}\left(\frac{n_{1}}{n_{2}}\right)
$$

If we assume $\Delta L=\Delta L_{A E}=-1 \mathrm{~dB}$, then $n_{2}=1.2 n_{1}$. In other words, a decrease by one $\mathrm{dB}$ in the equivalent noise level over a full day allows an increase in aircraft movements by $20 \%$.

\subsection{Environmental Effects}

A number of environmental effects must be considered when measuring aircraft noise or comparing simulations with noise measurements. These effects include the background noise, the wind and the ground reflection. With reference to the former, airfields are generally around build-up areas with considerable ground transportation traffic and other noise arising from human activities. Although simple correlations exists to provide a rough estimate of the OASPL as a function 
of the average population density, more accurate measurements are generally required; these data will inevitably depend on the airfield, on the location of the microphones and on the time of day. Figure 5 shows an example of background noise measured near Manchester airport, using one location on the departure side and two locations on the arrival/approach side. Integration of the $1 / 3$ octave band SPL shown in Figure 5 leads to background noise levels of almost $60 \mathrm{~dB}$. Lim et al. ${ }^{19}$ contend that background noise is an important in the determination of subjective annoyance, even in cases when the aircraft noise levels are nominally the same.

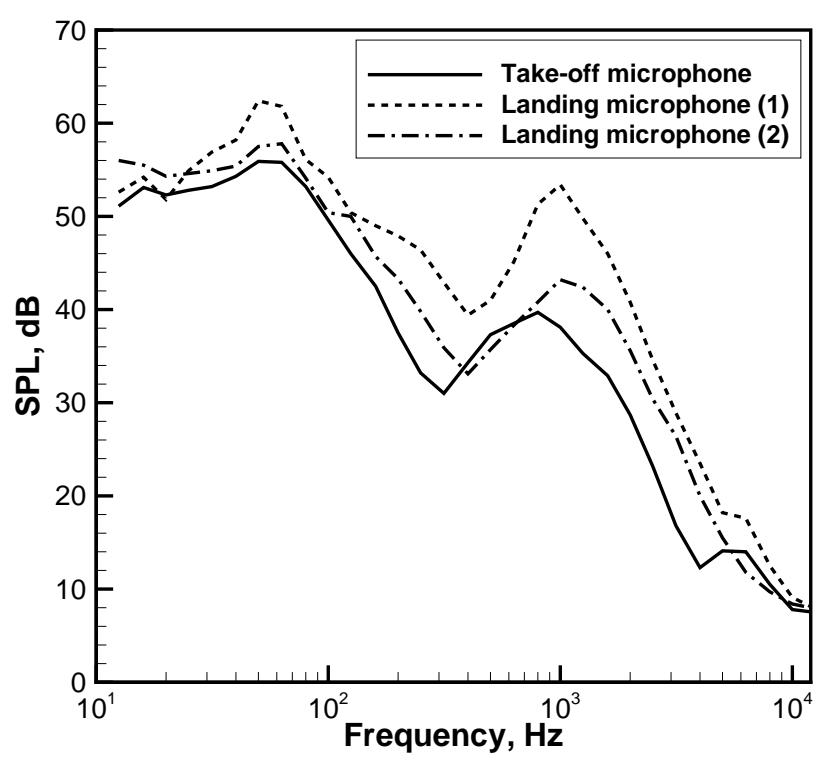

Figure 5: Background noise measurements at a large international airport at three selected microphone locations.

At certain microphone locations, the noise from ground transportation systems can obscure aircraft events. Such cases occur when microphones are placed near motorways and railways. The passing of a train can be as noisy as an approaching aircraft. However, it has been noted that the problem of aircraft noise is anomalous in comparison with other forms of transportation such as rail, due to an innate overcompensation of the aircraft noise. This anomaly has led the International Standards Organisation ${ }^{20}$ to include a $3 \mathrm{~dB}$ penalty to aircraft noise and a $6 \mathrm{~dB}$ bonus for rail noise (aircraft malus, train bonus). There are differing opinions as to why aircraft noise is penalised; for example, Berglund et al. ${ }^{21}$ contend that one cause of concern is the relatively high acoustic energy within the low-frequency spectrum $(<1 \mathrm{kHz})$, something that is true even for the most modern aircraft.

It is contented here that as humans, we are not used to noise coming from the sky, with the 
possible exception of thunder, which in any case is rare. On clear days it is possible to hear aircraft noise at cruise conditions; it sounds like a frequent thunder, annoying on its own way.

\subsection{The Case for Airport Expansion}

The case for airport expansion is not new. In a legal paper appeared in 1948, it was stated that:

"airfields, which were once properly located in marginal farm and wasteland areas outside of larger cities, now find that a relatively short period of postwar building expansion has placed them within the more restricted business and residential districts ..." ${ }^{22}$.

This assessment was made in the post-war years in the U.S., when there was still relatively large land available for development, and when aviation was still dominated by the propeller engine. The impact of aviation has increased exponentially since then. Therefore, choosing a location for a new airport, or expanding an existing one, has become a near-impossible proposition. Studies of the impact of noise around airports include studies for individual airports (too many to cite), single countries and groups of countries. We reiterate that robust and verified aircraft noise prediction methods are needed to provide forecasts and convince all the affected lobbies.

From the point of view of noise emissions alone, London Heathrow airport is in the wrong place, since most approaches are performed from the East. The 20 -year average is $76 \%$ westerly operations, although in some years the westerly operations can exceed $80 \%^{23}$. This airport currently extends over $12 \mathrm{~km}^{2}$ and is virtually surrounded by residential and commercial areas. The daytime $L_{e q}=57 \mathrm{dBA}$ is about $35 \mathrm{~km}$ (19 n-miles) long in the East-West direction ${ }^{24}$. Issues of compensation to residents have been known for sometime ${ }^{25}$, and not adequately resolved. A decrease in noise emission by a few $\mathrm{dB}$ is unlikely to change the public's acceptance of airport existence or even expansion. One option, albeit a costly one, is to move the airport to the sea. For example, Chubu and Kansai airports in Japan are islands in the sea connected by rail and road causeway. These airports currently allow 24 hour flight operations. It is for policy makers to decide whether to relocate the worst-affected residents. In any case, the highest benefit from noise reduction would require shrinking the noise footprint of all aircraft within the airport boundaries; this reduction, as we shall see, is not obvious, because it depends on the interpretation of annoyance. 


\subsection{Aircraft Noise Prediction Models}

There have been efforts to produce various aircraft noise prediction tools, each catered towards differing objectives, which are now clear from the diagram in Figure 4. For civil aviation operators, the needs for such tools are focused on those that provide cumulative noise metrics for operations (e.g. single and multiple fly-over events) near airports to comply with regulations. For designers, the desire to reduce the noise of individual sources requires the development of comprehensive tools that provide detailed answers.

In brief, the methods capable of predicting aircraft noise can be classified into two broad categories: 1.) theoretical methods. 2.) best practice methods. Theoretical methods rely on some form of physical model of noise production and propagation. By contrast, best-practice methods rely almost exclusively on measurement databases (fly-over or other measurements), which are augmented with other sub-models, including the prediction of flight trajectories.

Theoretical Methods. Theoretical methods have reached a relatively modest progress in comparison to other branches of aerospace engineering (for example, computational fluid dynamics, finite element methods); they still rely on empirical data for at least some aspects. The aim of these methods is the ability, at some point in the future, to predict reliably the noise emissions from both conventional and unconventional aircraft. The terms "reliable" and "high fidelity" can be disputed, because they have not been fully demonstrated in the technical literature. Even within the domain of "conventional" aircraft, there are parametric changes in airframe and engine design that are beyond the matrix of validity of many empirical models.

Validation tests are fairly complex and must rely on a variety of data, including fly-over tests; for new designs and unconventional configurations these data are non existent. The issue of validation is discussed separately in $\S 3.7$.

Research on the theoretical prediction of aircraft noise started in the early 1970s. At that time, efforts were driven by the Federal Aviation Administration and NASA ${ }^{26,27}$ to predict noise for single fly-over events. The first computer code was ANOPP (or NASA Langley's noise prediction program); in this computer program, the aircraft flight dynamics is integrated with semi-empirical models for noise propagation and generation for individual sources, e.g., fan, compressor, jet, wing, landing gear, and so on ${ }^{28,29,30,31}$. The noise propagation models handle the effects of spherical spreading, atmospheric attenuation, and ground reflection on the received noise. The noise propagation models are rather elementary with respect to advances made in such models. 
Updates on some of these noise source models ensure continuous improvement upon ANOPP's predictive accuracy, while the program is being used by several organisations in the U.S.A.

Major upgrades have been announced ${ }^{32}$ on a second generation model, ANOPP2, which partly uses computationally-intensive higher fidelity methods. The majority of the source and propagation models has been studied and developed independently, each requiring a substantial number of input parameters. Therefore, the integrated program handles a large group of input parameters (numbering in the hundreds), making it suitable for research-oriented applications. The amount of efforts being expended on this research is evidenced by the size of some research teams and the growing number of publications in this area.

NASA's newer noise technology has relied on FOOTPR/RADIUS, a code developed by NASA Glenn Research Center and private syndicates. This framework focuses more on high speed jets with complex engine geometry and complex jet interaction ${ }^{33}$, but is has been used as a platform for development and validation of new noise models under NASA contracts.

In addition to the tools for existing aircraft, there is a need for high fidelity noise models within a multidisciplinary framework of designing unconventional conceptual aircraft. One objective for such effort is to design aircraft with radical noise reductions, particularly the airframe noise. This approach was undertaken by the Silent Aircraft Initiative (SAI). The project aimed at making aircraft noise inaudible outside a typical airport perimeter, resulting in a blended-wing-body concept aircraft. ${ }^{34,35}$ The blended wing-body design offers a more streamlined integration of the fuselage, the wings, and the control surfaces. The engines are placed above the airframe to take the advantage of noise shielding properties of the airframe itself. Careful treatment of the airframe shielding effect demands computationally-intensive methods such as three-dimensional ray-tracing ${ }^{36}$.

A more recent effort by DLR is the PANAM code ${ }^{37}$, which was developed in the context of providing a design tool with noise as an additional constraint ${ }^{38}$. The focus is mainly to enable comparative noise evaluation for various aircraft designs; thus, precision in noise prediction not the key objective. To provide rapid solutions and analysis capabilities, PANAM recognizes that only dominant noise contributions count towards the overall aircraft noise, and thus calculates only the jet and the fan noise to represent the engine noise. The airframe noise comprises semi-empirical formulations on the noise of high-lift devices, wings, control surfaces, and landing gears. PANAM can be integrated into larger simulation processes, including multidisciplinary analysis. Individual 
and task-specific process chains can be assembled via a distributed simulation environment ${ }^{39}$. Another DLR model is called SIMUL ${ }^{40,41,42}$; this program splits the major noise components and attempts to use some physical modelling, although it uses databases from laboratory testing and fly-over measurements. For this reason, it must be classified as a hybrid method.

Other computer codes exist, but none is documented in the technical literature as the ones previously cited. Notable, among these, are the industry's proprietary programs, such as Airbus' own noise calculation program (provided to commercial clients) and the results of national and international research programmes: SILENCE(R), SOURDINE, AWIATOR ${ }^{43}$, RAIN, LAnAb ${ }^{44,45}$, Environmentally Responsible Aviation (ERA) in the U.S. Information on these projects can be found by keyword search on the Internet.

The need for physics-based aircraft noise prediction extends to the design level ${ }^{46}$. All the manufacturers have access to some aircraft noise simulation problem ${ }^{47}$. However, the interest in noise prediction and reduction is not limited to the commercial aviation. There have been efforts to address noise from military aircraft ${ }^{48,49}$, as well as the effects of topography around the airfield $^{50}$. For this purpose, another comprehensive model (NOISEMAP) was developed by the U.S. Air Force ${ }^{51}$. On a similar vein, ESDU ${ }^{52}$ proposes a series of empirical methods based on numerical implementations of various sub-models, although not in organic form.

Most of the results discussed in this paper have been produced with the comprehensive flightmechanics and aircraft noise computer program FLIGHT, which has been developed and documented in several instances in recent years $53,54,55,56,57,58$. This software is a completely integrated framework that provides geometric configuration, mass and inertia properties, configuration aerodynamics, flight mechanics, steady-state trim, flight trajectories, gas-turbine engine modelling, propeller aerodynamics, thermo-structural analysis and aircraft noise prediction. The latter item is discussed in this paper.

Notwithstanding the existing predictive capabilities for aircraft noise in the industry, it is desirable to improve upon the limitations inherent in the tools currently available as described above. One of the main challenges is to integrate various models and current techniques into a robust application capable of predicting noise with desirable accuracy in real-time. Further, it would be advantageous to produce a more holistic and comprehensive application by integrating the noise aspect of an aircraft operation with its other aspects, e.g., flight dynamics and performance, engine operation, fuel consumption and gas emission. Such an effort allows for 
multi-disciplinary design, analysis, and optimization capability.

Best Practice Methods. The immediate needs of the civil aviation require a faster and more practical approach. An Integrated Noise Model, INM ${ }^{59}$, was promoted by the Federal Aviation Authority (FAA) in 1978 to fulfill such needs. Its development continues to this day; the program is now used at several airports around the world and by various national authorities. This computer program provides a straightforward application with a small set of inputs to determine aircraft noise in the vicinity of airports and its impact on surrounding areas. Its approach is largely empirical and based on the framework of the SAE-AIR-1845 document ${ }^{60}$. The core of the INM modeling relies on the Noise-Power-Distance (NPD) data of an aircraft to estimate its noise for a given receiver location, engine thrust, and atmospheric conditions. INM also builds on the best practice method "for the calculation of noise in the vicinity of airports" issued by the ICAO as a guidance in the late $1980 \mathrm{~s}^{61}$. This is now somewhat outdated. Eurocontrol produces a database of "Aircraft Noise and Performance" (ANP) for aircraft noise modellers* for those who wish to use the procedures described in a similar document by the European Civil Aviation Conference $^{3,62}$. The capability and accuracy of INM is limited by the applicability of the NPD data for individual aircraft. Another disadvantage is that the predicted overall noise cannot be categorized into individual components.

$\operatorname{ANCON}^{63,64}$, another empirical-based software developed over many years, suffers similar limitations. However, this is the "standard" model in the United Kingdom, where its has been defined as the "ultimate word" in aircraft noise prediction. The purpose of this method is to generate annually updated noise contours at major UK airports in order to provide reference noise levels for zoning and planning applications. The main noise metric is the day-time $L_{e q}$ over a period of 16 hours over an average summer day (mid-June to mid-September). Three levels are considered; 57, 63, and $69 \mathrm{dBA}$. ANCON uses an NPD database, performance tables provided by manufacturers and updated accordingly, and lateral sound attenuation models. The database benefits from a large set of historical data, including radar tracks and sound exposure levels.

On a similar vein, the FLULA program ${ }^{65}$, developed in Switzerland, is based on measured directivity data and a database of aircraft trajectories measured at one airport and over a limited length of time. The noise prediction is in fact based on existing statistics and allow for long-

\footnotetext{
${ }^{*}$ This database is accessible on the Internet from the Eurocontrol web site.
} 
term average noise exposure predictions ${ }^{66}$. In the same category there is the SIMUL ${ }^{42}$ and AzB codes developed at DLR in Germany ${ }^{67}$, and used for noise prediction at German airports. Other national authorities, including Japan, have their own implementations, sometimes based on INM, such as the case of Denmark, Norway and France. In the latter case, there is top-level platform called IESTA, which includes both environmental emissions and aircraft noise around an airfield $^{68,69,70}$. This area of application is not documented in the academic community, therefore it will not be considered further. Ref. ${ }^{3}$ has a review of national best practice methods in major European countries.

A flowchart of a best-practice noise program is shown in Figure 6. Many airports keep updated databases of noise measurements and flight tracks; the latter data are recorded with ground radars, which combine the trajectory with the registration number, aircraft type and the destination/origin. The destination/origin is used to infer the take-off weight, and hence to estimate the thrust and power settings from basic flight mechanics equations and aircraft performance data (which are inferred). Thus, the lower block is a database of airplanes. Due to the requirements of creating noise maps (and to estimate the population within each contour level), considerable approximations are done at several levels, including NPD and various attenuation calculations.

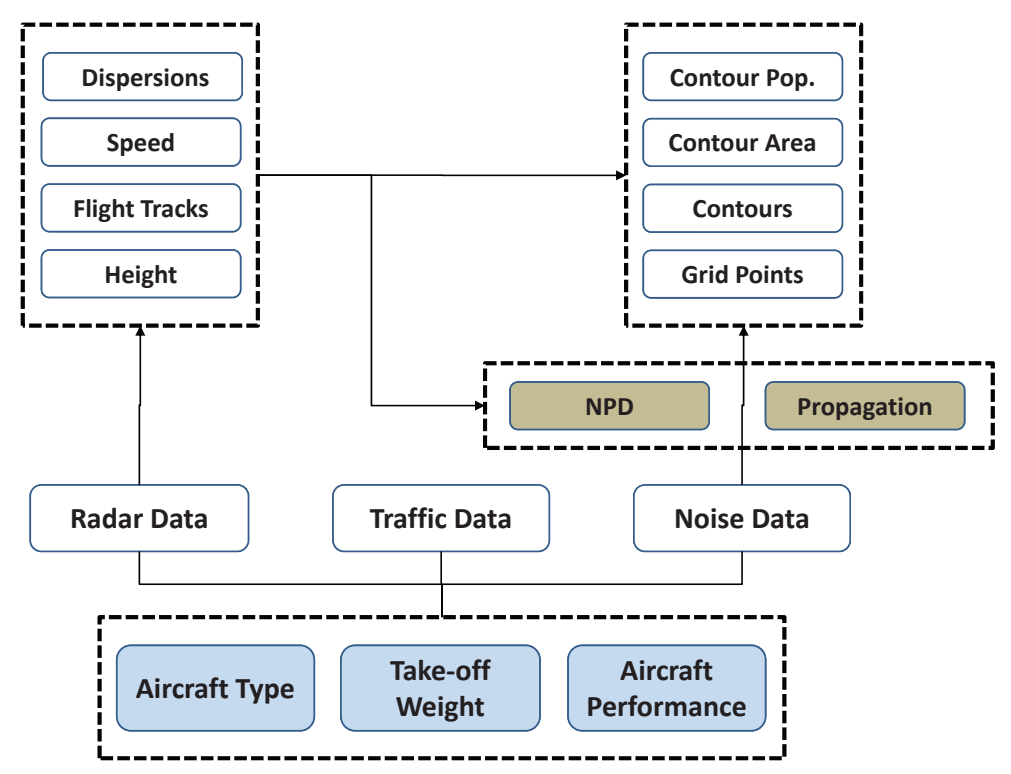

Figure 6: Flowchart of a typical best-practice noise method.

The NPD relationships are used for normalisation of aircraft noise data. This is done by 
reducing a single event (represented by tabulated data) to a standard flight speed but different power settings. This is generally done by using reference microphones below the flight path. None of this methods is capable of differentiating between noise sources, and the result is given as a cumulative measure, meaning that it is not possible to identify critical noise sources. An additional review of this matter is available in Bertsch et al. ${ }^{71}$

As reported in Ref. ${ }^{24}$ : "for a given airport and a given set of operations, it is possible to produce notably different contours, in terms of both size and shape, from the two models". Furthermore, Ref. ${ }^{3}$ reports that: "in practice, to determine cumulative sound levels at appropriate locations by measurement, it is necessary to estimate them statistically from analysis of data samples.". Therefore, there are fundamental issues that are not resolved, even with a large data set of measurements. It is important to note that the accuracy of the noise contours has implications on decision-making, complaint handling, zoning, curfews, noise taxes. For these reasons, noise has become a commodity.

With reference to the noise tax, it is now widespread practice at several large airports to charge a levy based on the amount of noise caused, or for noise emitted above a threshold decided locally. The case for noise taxes has been reviewed in several instances starting in the $1980 \mathrm{~s}^{72}$ and more recently by Girvin ${ }^{73}$, who also shows the different noise tax regimes enforced at various large airports. In all cases the tax levy depends on the noise level and the aircraft's gross weight. Ref. ${ }^{72}$ proposed an equation correlating the noise tax to the cost of retrofitting the aircraft with noise reduction technologies and the life-time of the new technology.

\section{Computational Methods for Aircraft Noise Prediction}

Since the physics of acoustic emissions from solid surfaces and aero-engine components is not amenable to a simple treatment ${ }^{74}$, alternative strategies have been proposed. In the first place, to overcome the limitations of the theory there has been an effort, not all organic, in producing experimental data. These data can be classified as follows: 1.) laboratory tests of single components or sub-systems with a limited number of geometry configurations and operational conditions (for example, co-axial jets, flaps, landing gear); 2.) flight (or fly-over) tests. The former includes several contributions that are cited as relevant in the following sub-sections. The latter category is discussed separately in the validation analysis $(\S 3.7)$.

The method of components has become the prevalent method for predicting aircraft noise. 


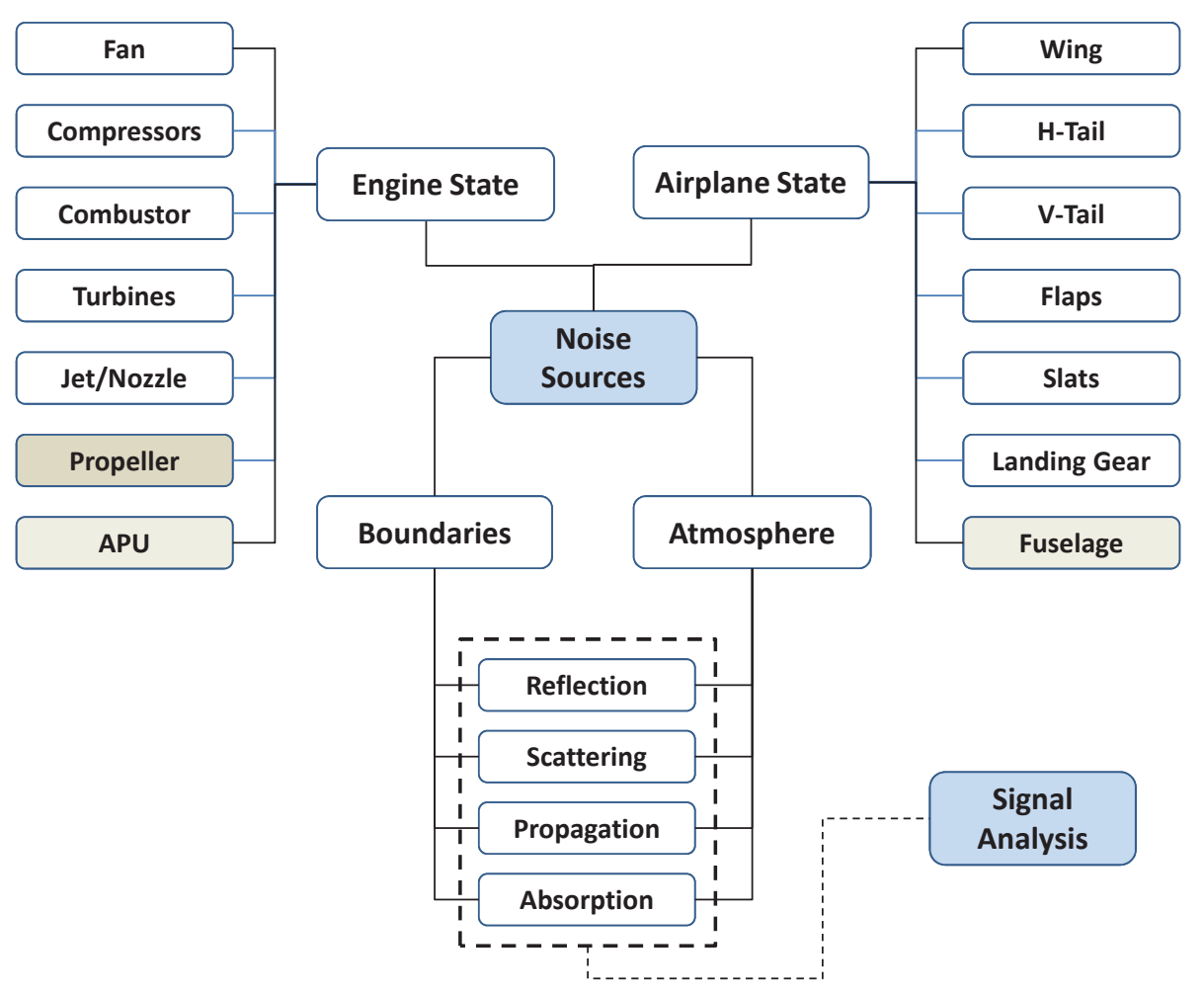

Figure 7: Flowchart of aircraft noise model. Adapted from Ref. ${ }^{58}$

This method is based on the assumption that each noise source is uncorrelated to other noise sources and hence independent. The resulting noise at one frequency is calculated by summing all the components at the same frequency. This assumption is very powerful and does a good service in most cases of conventional aircraft configurations. Issues of noise scattering, reflection and shielding occur in some operational conditions for the current generation of airplanes, and is due to be a dominant aspect of noise in a projected step change in configuration (wing-body, over-the-wing engines, prop-fan engines). The flowchart in Figure 7 shows the key elements of a comprehensive noise model. The noise sources are classified as propulsive and non propulsive (airframe). The both depend on configuration and operational conditions. Then there corrections due to the presence of boundaries within the airplane (noise shielding) and outside the airplane (ground topography). The propagation from the sources to the receiver takes place over very long distances (up to several $\mathrm{km}$ ), which makes aircraft noise a peculiar problem within the field of acoustics. During long-distance propagation, the acoustic waves travel through layers of the atmosphere affected by changes in density, pressure, temperature, relative humidity, and wind gusts. The problem of noise propagation is no less important than the determination of the 
sources themselves, with the possible exception of the FAR/ICAO landing noise at the standard certification point. This is because the source-receiver distance is relatively small $(\sim 120 \mathrm{~m})$.

The position of the noise sources is calculated from the airplane geometry model. For sourcereceiver distances $r>10 \ell_{\text {fuse }}\left(\ell_{\text {fuse }}\right.$ is the fuselage length) the aircraft can be considered as a lumped mass and all the acoustic sources are concentrated on the airplane's centre of gravity. For shorter distances, there will be a distinction between left and right sides of the airplane (leftright engine, left-right main landing gear). The physical distance between source and receiver is calculated from the magnitude of the vector $\boldsymbol{r}$

$$
\boldsymbol{r}=\boldsymbol{r}_{c g}+\boldsymbol{r}_{a}
$$

where $\boldsymbol{r}_{a}$ is the vector between the CG and the noise source. For example, on a Boeing B777-300, the distance between the centre of the nose and main landing gears is $\sim 33 \mathrm{~m}$; when the airplane's $\mathrm{CG}$ is right above the ICAO/FAR microphone during a conventional approach, this distance is more than $1 / 4$ of the microphone-airplane distance. Fuselage shielding effects occur when the source component is out of the line of sight of the receiver. This event only occurs in very limited cases, when the receiver is away from the ground track.

\subsection{Airframe Noise}

For several years, research on airframe noise lagged that on engine noise. This area of research was first populated in the 1970s, when there was interest on minimum theoretical noise levels of an airborne vehicle, from birds to gliders ${ }^{75}$ and Boeing airplanes ${ }^{76}$. There is now a wide body of experimental evidence, including sub-systems (discussed separately) and scaled airplane models ${ }^{77,78}$ using phased microphone arrays. A review of the aerodynamic principles of noise was published by Crighton on this Journal in $1975^{79}$, at a time when research in this area was rapidly expanding. The prediction methods for airframe noise are divided into the following categories, in increasing order of complexity: 1.) semi-empirical methods; 2.) fully analytical methods; 3.) CFD methods coupled with the acoustic analogy; 4.) fully numerical methods. This classification is available in Farassat \& Casper $^{80}$. We will be concerned with models in the first two categories. The simplest models are those adopted in the aircraft noise codes mentioned earlier (§ 1.5). The fully analytical methods are applied to canonical shapes, such as trailing-edge noise generation.

To begin with the semi-empirical models, work done at the FAA, and published by Fink and others ${ }^{81,82}$ led to the first semi-empirical or fully empirical methods, which were based on sparse 
experimental data from various sources. A full review of airframe noise methods is available in Crighton $^{83}$, Rackl et al. ${ }^{84}$, Farassat \& Casper ${ }^{80}$, Casalino et al. ${ }^{85}$ and Dobrzynski et al. ${ }^{86,87}$ All these reports point to additional technical literature; $\mathrm{ESDU}^{88,89}$ give a practical introduction to the empirical methods currently used in many engineering applications.

In the past twenty years there has been renewed interest at several levels, including industry, national research centres and academia. Clear priorities are on landing gear noise and highlift systems noise. For a long time, this field of research was dominated by empirical evidence, with limited physics, even when the results appear to be plausible. In order to provide a more meaningful background to the evolution of this research, the methods proposed by Fink and many followers relied on the assumption that high-lift noise was derived from the turbulent scattering of the boundary layer at the trailing edge ${ }^{90}$. The experimental data were calibrated, and further assumptions were proposed in order to provide scaling laws, spectra and directivities. A typical equation for the mean-square acoustic pressure is

$$
<p^{2}>=\frac{P b^{2} \mathcal{D} \mathcal{F}}{4 \pi r^{2}(1-M \cos \vartheta)^{4}}
$$

In Eq. $5 P$ is the acoustic power, $b$ is a cross-wise characteristic length (span), $\mathcal{D}$ is the acoustic directivity and $\mathcal{F}$ is a spectrum function of the Strouhal number. Eq. 5 also has a spherical propagation factor $4 \pi r^{2}$ and a source amplification factor (Doppler effect), which jointly provide a convective factor. The product $P b^{2}$ is a function of the flight Mach number and several empirical parameters depending on the geometrical configuration of the item. The directivity function in Eq. 5 depends on the polar emission angle $\vartheta$. The Strouhal number involved in the method is in fact a "corrected" Strouhal number, given by the following expression

$$
\mathrm{St}=\frac{f \ell}{V}(1-M \cos \vartheta)
$$

where $\ell$ is a characteristic length, and $V=a M$ is the true air speed. Therefore, this method is intended to capture the source and the convective effects by means of simple geometric relationships and a number of coefficients which are determined from curve-fitting of empirical data.

In spite of the theoretical shortcomings, specifically the misunderstanding that most of the noise was generated at the trailing edge, this method remains widely used and (until recently) seldom criticised. The development of more advanced measurement techniques, such as phased array microphone technology, has led to some considerable progress in the determination of the 
noise sources, their locations and spectra. The bulk of evidence indicates that the two main sources of concern are high-lift systems (collectively) and landing gears. Progress can be achieved if noise is correlated with the main aerodynamic characteristics, as well as their main dimensions.

\subsubsection{High-Lift Systems Noise}

There are three main items of interest: 1.) trailing-edge noise; 2.) flap-edge noise; 3.) leading-edge slat noise; these items are collectively named "high-lift" systems. They operate in combination or isolation. Experimental data are available in the technical literature for basic understanding, model calibration, design optimisation, and CFD validation. Among the recent data, we report basic flaps ${ }^{91,92}$, parametric studies of various flap edges ${ }^{93}$, scaled models of a DC-10 aircraft ${ }^{94,95}$ (including several parametric analyses), multi-element wings ${ }^{96,97}$.

The methods currently available for high-lift noise prediction have some important gaps. This is due to two basic reasons: 1.) the geometrical details of the high-lift systems (leading-edge slats and trailing-edge flaps) are often unknown; hence, no accurate computational methods are applicable; 2.) the noise prediction methods are based on empirical evidence, partly as a result of the previous shortcoming, and rely on a limited set of parameters such as a cross-wise length scale, a streamwise length scale and a variety of empirical factors to determine Strouhal numbers and directivities. These methods essentially go back to the original work published by Fink ${ }^{81}$ and proposed in practical form by ESDU ${ }^{89}$. Trailing-edge noise was considered important, and following from the work of Howe ${ }^{98,99}$, Amiet ${ }^{90}$ and others on the trailing-edge diffraction noise due to scattering of the boundary layer and flap-edge noise, these methods were proposed to provide at least a first-order estimate of this acoustic contribution.

A number of technologies exist to address, at least partially, some airframe noise sources, both at the level of basic research and in the real-life airplane. These strategies consist in retrofits that cannot be predicted by any of the methods described in this paper (flow tripping devices, seals, lips, spoilers, cowlings).

Flap-Edge Noise. Some investigations have highlighted the role of the flap edges, the tip vortex strength and its location, which eventually led to new strategies for noise alleviation from this component. In brief, the flap edge is an inevitable cause of flow separation due to large cross-wise and stream-wise pressure gradients. This separation evolves into vortical regions, wherein two unsteady tip vortices (primary and secondary vortex) grow, eventually merge downstream, and contribute to acoustic disturbances. The actual nature and shape of these vortices depend on 
the geometrical configuration and the aerodynamic loading. The spectral shape of the acoustic disturbances seems to indicate that there are two distinct mechanisms operating at low- and high frequency. The exact source mechanism is described in a number of papers, including, among others, Ref. ${ }^{93,100,101}$.

With reference to empirical and semi-empirical models, there have been developments in the past few years, including the work of Rossignol ${ }^{102}$, which shows incomplete directivity functions at low frequency. The method proposed by Guo et al. ${ }^{103}$ consists of an algebraic equation for the SPL that is based on the correlation of aerodynamic data including flap-edge effects:

$$
L=S_{o} \mathcal{F} \mathcal{D} M^{b_{1}} C_{L}^{b_{2}}(\ell / r)^{b_{3}}(\sin \alpha)^{b_{4}}\left(\sin \delta_{f}\right)^{b_{5}}
$$

where $S_{o}$ and $b_{i}$ are empirical coefficients; $\alpha$ is the wing inflow angle; $\delta_{f}$ is the flap deflection; $\ell$ is a length scale and $r$ is an emission distance. The coefficients depend on the flap type (inboard/outboard). For this model, also reported by Sen et al. ${ }^{104}$, there are some unclear issues. First, the key parametric values were developed for a specific condition at the overhead location during approach (this corresponds effectively to the certification conditions). Second, it is mentioned that the far-field extrapolation of the data is unreliable and "involves many unresolved issues". Third, the far-field spherical spreading, which was determined by empirical means, is not correctly captured. Finally, inconsistencies exist in the description of the model in both studies, e.g., disagreements in the numerical values of identical parameters and in the definitions of some fundamental variables.

More recently, Guo ${ }^{105,106}$ has proposed a two-component model for the flap edge noise, including a low- and a high-frequency domain. The high frequency noise is associated to the flow separation from sharp corners; the low frequency noise is associated to the large-scale vortex interaction. This formulation has several aspects in common with the landing gear noise model, and specifically its dependence on the ambient medium, on the convective spreading on the spectrum and directivity functions.

$$
P_{H, L}=\left(\rho_{o} a^{2}\right)^{2} A_{G} A_{F} \mathcal{W}(M) \mathcal{F} \mathcal{D}(\vartheta, \varphi) \frac{\ell}{a_{o}} \frac{\ell c_{f}}{(1-M \cos \vartheta)^{2} r^{2}}
$$

where $A_{G}$ and $A_{F}$ are a geometry- and a flow-related noise amplitude, respectively; $\mathcal{W}(M)$ is a function of the flight Mach number; $\mathcal{F}$ is a spectral shape function (defined by unspecified values of some free parameters); $\mathcal{D}$ is a directivity function of the polar and azimuthal angles $(\vartheta$ 
and $\varphi$, respectively). Several parameters remain unspecified in this paper. Corrected parameter values have been proposed by Rossignol ${ }^{92}$ on the basis of additional experimental data, and on the consideration that a relevant length scale is the vortex core diameter.

More sophisticated methods, such as those of Brooks \& Humphreys ${ }^{93}$ require the determination of the aerodynamic loads, in particular the unsteady pressure distribution at the wing tips, which is not readily available for comprehensive noise models. However, it is possible to determine a first-order aerodynamic load and pressure distribution by using a lifting surface method, as shown by Rackl et al. ${ }^{84}$. Finer effects, such as rough edges, porous edges ${ }^{107}$, round edges and the effects of tip fences can only be determined with higher order methods. Further studies on flap edge-effects ${ }^{108}$, though potentially important, have not found adoption into a comprehensive noise model. Inboard-outboard flap sealing with round edges is already applied to some airplanes such as the Airbus A320.

Slat Noise. The slat aerodynamics is more complicated than the trailing-edge flap, because of the flow separation in the cove area ${ }^{109,110}$. Main features include the cove itself (cavity noise), the slat gap (turbulence-induced noise, vortex shedding), the general features of the slat (incidence, upper side curvature) and the slat edges (lateral flow separation due to pressure jumps). Secondorder effects are attributed to the slat tracks, although the latter ones have not been properly investigated. Considerable research exists in this area, particularly with CFD and computational aero-acoustics, which highlighted several geometrical effects ${ }^{110}$. In brief, experimental data show that often the slat noise is characterised by a tonal component arising from from the cove's main vortex, which appears to be a general feature with oscillating characteristics. It has been suggested that the fluid mechanic oscillations are associated to the acoustic pressure (Rossiter modes), although there could be issues of resonance as well. Only recently there have been publications showing good quality experimental data. We mention in particular the data from Refs. ${ }^{111,112}$ and fly-over measurements on an Airbus A340 by using beam-forming techniques ${ }^{113}$.

The model developed at DLR for slats ${ }^{111,114}$ is similarly based on semi-empirical evidence, although sometimes there appears to be incomplete reporting of the parameters used. Specifically, the model proposed by Dobrzynski ${ }^{111}$ provides the following algebraic expression for the slat noise:

$$
\begin{cases}L_{1}=k_{1}+3 \log (S t)+\Delta L_{s f} & \text { St }>\mathrm{St}^{*} \\ L_{2}=k_{2}-18 \log (S t) & \text { St }>\mathrm{St}^{*}\end{cases}
$$

where $k_{1}$ and $k_{2}$ are two numerical parameters; $\mathrm{St}^{*}$ is a threshold Strouhal number which deter- 
mines the limits of validity of the correlation with selected experimental data; $\Delta L_{s f}$ is a correction term that takes into account the slat and flap deflection angles.

In line with the formulation of Eq. 8 for the flap edge noise, Guo ${ }^{115}$ proposed a similar formulation for the slat noise, except that in this case there is one power spectral density function operating on the full spectrum of frequencies. The near-field power spectral density is

$$
P=\left(\rho_{o} a^{2}\right)^{2} A_{G} A_{F} \mathcal{W}(M) \mathcal{F} \mathcal{D}(\vartheta, \varphi) \frac{b_{s} c_{s}}{(1-M \cos \vartheta)^{2} r^{2}}
$$

The model accounts for several scaling factors, including length scales, convective factors, wavenumbers, and so on. One of the key results is that the acoustic pressures scale like $M^{5}$.

\subsubsection{Landing Gear Noise}

Models for landing gear noise are necessarily empirical, although some attempts exist in theoretical modelling, with field methods, including RANS, LES, Boltzmann lattice methods, all with various degrees of complexity and success ${ }^{116}$. These methods are important for fundamental understanding of landing gear noise, but cannot be used in comprehensive computer models.

In recent years, experimental data have been published at an increasing pace, for both scaled and full-scale landing gears, and include a variety of situations: fly-over noise, wind tunnel experiments with real-life models, scaled models, canonical models; landing gears have been considered in isolation or coupled with their relative bays, wings and flaps. It has been shown in several instances that rudimental models are not a reliable indicator of real-life landing gears, because the lack of geometrical details may cause a change in some tonal components and highfrequency acoustic emissions. Scaling is likewise problematic. In any case, the maximum noise is exhibited at medium frequencies, 0.5 to $2.5 \mathrm{kHz}$.

Experimental data for scaled models are available from Humphreys \& Brooks ${ }^{117}$, Zawodny et al. ${ }^{118,119}$ (Gulfstream G550), Smith et al. ${ }^{120}$ (A340); full-scale data are available from Dobrzynski et al. ${ }^{121}$ (Airbus A340), Dobrzynski \& Buchholz ${ }^{122}$, Guo et al. ${ }^{123}$ (Boeing B737), Ravetta et al. ${ }^{124}$, Horner et al. ${ }^{78}$ (Boeing B777), Dedoussi et al. ${ }^{125}$ (Boeing B747-400), among others. There are specific studies that address landing gear noise directivity ${ }^{117,126}$ and landing-gear wake interaction with a flap ${ }^{127,114}$.

On the noise prediction side, there are now a number of models with some similarities, but also important differences. These models are all empirical in nature, and are afferent to the methods proposed by Fink (as cited, adopted by ANOPP): Molin et al. ${ }^{128}$, Smith \& Chow ${ }^{129}$, 
Guo ${ }^{130,131,132}$ (Boeing), Zawodny et al. ${ }^{118}$ Many of these models attempt to break down the noise sources from sub-components and within certain frequency ranges by using some form of scaling laws and corrections for complexity and installation. Typically, noise emission from landing gear has a large broadband content, but also some tonal components associated to coherent vortex shedding. Broadband contributions arise from turbulent flow separation, bluff-body wakes and interaction of these wakes with downstream surfaces, such as shown in Figure 8. Dobrzynski ${ }^{87}$ provides a good review of these issues. In this instance, the inflow velocity is affected by the circulation around the wing system. With the spanwise distribution of wing circulation $\Gamma$, it is possible to estimate the sectional lift at the location of the shock struts and hence the line vortex that induces the velocity $V=\Gamma / 2 \pi r$ (this approximation is only valid at some distance from the circulation source). The circulation effect reduces the inflow velocity and hence contributes to a reduction in noise by several $\mathrm{dB}$, as also pointed out in Ref. ${ }^{114}$.

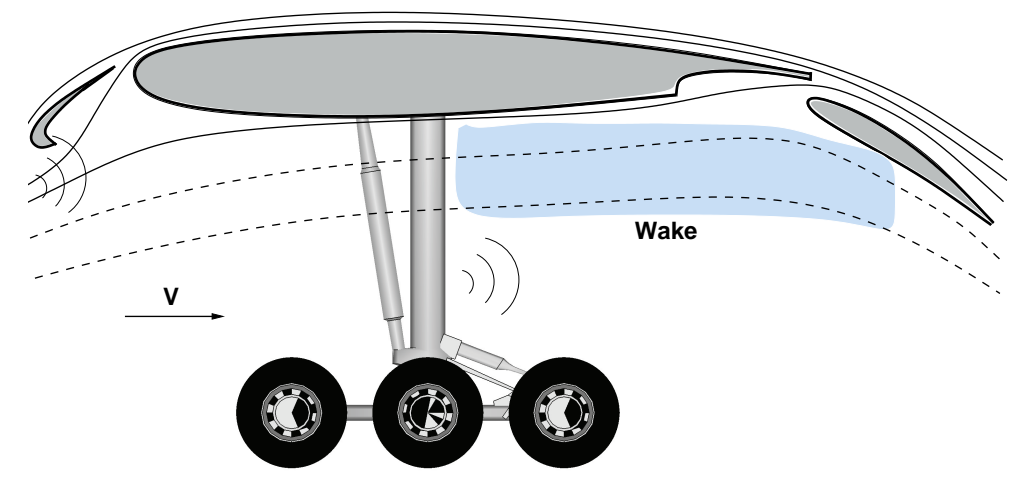

Figure 8: Landing gear interaction with high lift surfaces, upstream and downstream.

The model proposed by Guo breaks down the landing gear noise into low-, medium- and high frequency contributions, each being derived by separate sub-systems. Each sub-system is characterised by a length scale. The near-field RMS of the acoustic pressure is

$$
<p>^{2}=\frac{\left(\rho_{o} a_{o}^{2}\right)^{2} M^{6} \mathcal{D}(\vartheta)}{r^{2}(1-M \cos \vartheta)^{4}} P
$$

where $P$ is the acoustic power (for each of the contributions: low-, mid-, high-frequency). Eq. 11 also contains terms for the Doppler effect and the convective amplification (at the denominator). This method has been demonstrated to provide sufficiently accurate results in several cases, although doubts remain as to the credibility of some empirical parameters and the directivity 
(the empirical data provided by Guo ${ }^{130,132}$ cannot replicate all the experimental data). Eq. 11 is not too different from the method proposed earlier by Fink ${ }^{81}$, although in the former case the Strouhal scaling is done by using various landing gear parameters and complexity factors. A comparison between the two models is shown by Burley et al. ${ }^{133}$ The experimental data by Heller \& Dobrzynski ${ }^{134}$ were used for correlation by Fink himself. An earlier model by Smith $\&$ Chow ${ }^{129}$ on the basis of fly-over data, provided reasonable predictions only for the overhead aircraft position. An alternative landing gear noise model was proposed by Lopes et al. ${ }^{135}$ and demonstrated on scale landing gear model data of the B777-300 ${ }^{136}$. This is again a semi-empirical model using acoustic elements consisting of the main components of the landing gear unit (cylinders, wheels, trailing edges, doors). Considerable efforts have been devoted to the determination of scaling factors. Guo ${ }^{123}$ shows a $V^{6}$ (or $M^{6}$ ) scaling. Other studies indicate that the SPL scales with $\sim V^{6}$ frequencies $f<1 \mathrm{kHz}$ and $\sim V^{7}$ at frequencies $f>1 \mathrm{kHz}$. In other words, spectral contributions at different air speeds can almost be reduced to a single curve by using a correction $\log _{10}\left(V^{n}\right), n=6,7$.

Installation effects are the subject of separate studies which can include the effects of a deployed flap downstream, the wheel cavities, the flow distortion caused by changes in circulation and fore-bodies ${ }^{137,138}$. It is variously reported that the effects of a deployed flap behind a landing gear can increase the noise level by 5 to $10 \mathrm{~dB}$, due to the interaction of the landing gear strut system with the downstream flap. For example, in Ref. ${ }^{125}$ it is shown an increase of 5-6 dB over the full spectrum with a flap angle of 25 degrees. It is unclear what is the actual contribution of the flap and what is the interference contribution. The speed effect, noted as $\sim V^{n}$, would decrease as a result of the circulation effect shown in Figure 8.

To reduce the complexity effects, modern landing gear systems include various fairings (toboggan and other details), circular doors, and minimal landing gear bays (which can be partially closed during deployment). There are no studies in the open literature that address the benefits of circular- versus rectangular cavities from the point of view of acoustic emission. Some recent studies have addressed the fundamental role of circular cavities ${ }^{139}$, as well as gaps and holes ${ }^{140}$.

In any case, modelling of these additional details cannot be reliably undertaken with any of the models proposed. Tonal components appear in some cases at one or more discrete frequencies, depending on the landing gear; these tonal contributions are generally attributed to vortex shedding from struts and bars. Some experimental data indicate that these contributions can be 
reduced or eliminated by increasing the air speed or the roughness of the components. Furthermore, there are second-order effects, such as the scattering due to the wing and the distortion of the free-stream due to wing circulation and fuselage blockage ${ }^{138}$.

Some elastic fairing proposed by Ravetta et al. ${ }^{141}$ promise a $2 \mathrm{~dB}$ cut in noise level across the full spectrum of frequencies. These and other sophisticated design methods require a continuous upgrading of the landing gear models currently in use.

None of the landing gear models proposed consider the effect of tyre noise on the ground, which easily exceeds $90 \mathrm{~dB}$. Several studies are available in the field of motor vehicle noise, which could be extended to aircraft tyres, although corrections would have to be included to account for the propagation of acoustic waves near the ground and over long distances. Tyre noise only affects ground operations.

Other Sources of Noise. External noise from the fuselage is neglected by virtually all noise prediction programs. The reason for this lies in the belief, not fully justified, that noise radiated by fuselage panels is the order of $10 \mathrm{~dB}$ below that of the high-lift systems. The study by Liu \& Dowling ${ }^{142}$ proved that for a certain range of frequencies this might not be the case. Much of the research on fuselage noise remains confined to cabin noise, with the possible exception of research going back to the 1970s (and earlier), which focussed on boundary layers and their effects on cabin noise. At least two main sources are identified: 1.) the effect of the turbulent boundary layer over a rough surface; 2.) the effect of vibrations, which cause perturbations to the boundary layer itself and amplify the results of the former effect.

Lower Bounds in Airframe Noise. Questions about the limits of aircraft noise have become popular in recent times. One of the most intriguing aspects of this problem was proposed by Lilley ${ }^{143}$, who took as an example the flight of the Owl Strix varia to illustrate the generation of acoustic disturbances above a lifting surface. These findings were later expanded to full scale ${ }^{144,145}$; more recently, the flight of the owl was revisited and accurate flyover measurements were published by Sarradj et al. ${ }^{146}$

In Lilley's analysis, following the half-plane theory initially proposed by Howe ${ }^{98}$, the noise intensity level of an infinite lifting surface is written as

$$
I=\frac{1.7}{2 \pi^{3}} \frac{\rho A V^{3} M^{2}}{z^{2}}\left[\left(\frac{u_{o}}{V}\right)^{5}\left(\frac{\delta}{\delta^{*}}\right)\right]_{t e} \cos (\vartheta / 2)
$$


where $u_{o}$ is the reference speed for the turbulent flow; $u_{o} / V$ is interpreted as a turbulence level in the streamwise direction; $\delta$ and $\delta^{*}$ are the boundary layer thickness and boundary layer displacement thickness at the trailing edge, respectively; $z$ is the flight altitude of the lifting surface. One drawback of the formulation in Eq. 12 is the lack of a spectral content. A quick calculation indicates that the lower bound of lifting surface noise scales with the wing loading. Thus, the owl's noise performance cannot be replicated with the current technology.

\subsection{Propulsive Noise}

In the early days of jet propulsion, the main noise source was seen to be associated with various mechanisms in the jet nozzle itself. Noise generation related to the compressor was deemed to be important only in limited regions directly ahead of the engine and over limited operating conditions. The development of the turbofan engine was a major breakthrough in dealing with the problems of jet noise. The turbofan derives a significant portion of its thrust from the fan. While this caused a major reduction in jet noise and an increase in propulsive efficiency, it had the side-effect of an increase in fan-compressor noise. Jet and fan noise are now comparable in some flight conditions; compressor noise is bound to increase further as the compression ratios are pushed higher in new engine designs.

The technical literature generally refers to contributions from the fan, the jet and the core, which includes all the remaining sub-systems (compressor stages, combustor, turbine stages). Since each sub-system works in synergy with the others, isolation of one contribution from the remaining systems is difficult, although technology exists for separating coherent and incoherent noise sources. For this reason, specific research is done with fan and jet rigs to investigate fan and jet noise, respectively.

Essential to the development of realistic noise prediction models is the availability of gas turbine engine performance. These models do exist in various forms and have been developed by organisations such as $\mathrm{NASA}^{147}$ and $\mathrm{NLR}^{148}$. Without going into the details of the process of generating such a model, we note that the essential features are the correct relationships between the aero-thermodynamic parameters, and specifically the relationship between fuel flow (or engine speed) and thrust/power.

Engine noise can be broadly categorised into: 1.) tonal noise generated by regular rotation of turbomachinery blades; 2.) broadband noise which is caused by pressure fluctuations that are associated with turbulence in the flow field. Under normal conditions, broadband noise in fans 
arises from vortex shedding at the blade trailing edges with the possibility of an increase in noise due to the occurrence of any large-scale turbulence in the flow. The noise from multi-stage fans was found to arise from the aerodynamic interaction between fixed and moving blades, with the axial spacing between rows and stator area being a significant parameter. All the models currently in use for aircraft noise prediction are limited to steady-state conditions. It is not possible to predict transient noise, except as a series of steady-state segments (quasi-steady approach).

Fan Noise. Fan noise dominates most flight conditions; depending on the flight direction with respect to the microphone, it can be higher than jet noise. Research in this field has highlighted the importance of tip Mach numbers, fan compression ratio, blade and vane numbers, rotor-stator spacing, leaning and sweep angles, inlet design as key parameters in overall noise performance ${ }^{149,150}$. At subsonic Mach numbers, the interaction with stator blades becomes important. At supersonic Mach numbers there is the "buzz-saw" noise arising from supersonic speeds in parts of the fan blades. Finally there is the effect of inlet duct noise attenuation, which is done actively done with the use of "acoustic liners". We cannot mention all the design efforts in fan noise reduction, but rather the methods that are available to make a first-order estimate of the acoustic pressures arising from a fan specified by a limited number of design parameters: diameter, tip chord, number of blades, rotational speed, fan-stator distance, pressure ratio, mass flow ratio, temperature rise across the fan. The work of Ganz et al. ${ }^{151}$ provided extensive measurements on a fan rig, aimed at investigating various parametric effects (tip clearance, inlet boundary layer, exit guide vanes, rpm) on the broadband noise. This is an area of research increasingly dominated by CFD, which fully addresses the "Component Analysis" requirements in Figure 4. This is the top level of modelling capabilities that has yet not entered the domain of aircraft noise.

The bottom level of the modelling capabilities is the fully empirical approach, which with all its limitations and caveats is still widely used. Specifically, the method proposed by Heidmann ${ }^{152}$ in the mid 1970s has come to dominate the arena of empirical fan and single-stage compressor noise prediction. Some improvements to this method have been proposed over the years, with updates to the coefficients (inlet tone noise spectral function, acoustic power). Numerical modifications were made to include predictions on small engines ${ }^{31}$. A compilation of other improvements were reported in ESDU ${ }^{153}$. These improvements were also coded in the FLIGHT program and validated with data from Kontos et al. ${ }^{30}$. 
Computational models using the boundary element method ${ }^{154}$ allow the computation of the effects of hard- and soft ducts in a combined numerical solution. In this model, the sources are monopoles and dipoles concentrated in single points. Higher-level models (inviscid field models, duct propagation and radiation) are discussed by Nark et al. ${ }^{155}$, which again have been used in the development of the ANOPP code. A further analytical development from the 1980s onwards at NASA and Pratt \& Whitney was a rotor/stator wake interaction model in duct ${ }^{156,157}$. The basis for this fan noise model is a simplified geometry with zero-thickness blades, infinite duct length (to remove reflection events at the ends). This program calculates the duct acoustics and provides both tonal and broadband contributions (code V072).

A typical prediction equation for the broadband noise is the following:

$$
L=20 \log \left(\frac{\Delta \mathcal{T}}{\Delta \mathcal{T}_{o}}\right)+10 \log \left(\frac{\dot{m}}{\dot{m}_{o}}\right)+f_{1}\left(M_{t i p}, M_{t i p D}\right)+f_{2}\left(x_{r s}\right)+f_{3}(\vartheta)+f_{4}\left(\frac{f}{f_{b p}}\right)+C
$$

where the first term denotes the effect of temperature rise across the fan with respect to a conventional value $\Delta \mathcal{T}_{o}$; the second term denotes the effect of mass flow rate relative to a conventional value $\dot{m}_{o}$. The remaining contributions are functions of the design and operational tip Mach numbers, of the rotor-stator separation distance $x_{r s}$, of the emission angle $\vartheta$, of the frequency (relative to the blade passing frequency $f_{b p}$ ). The final term $C$ is a bias depending on the type of engine. Equation 13 shows a linear combination of the main factors and relies on several functions $f_{i}$ that would need to be determined experimentally for each engine class. It is possible that some contributions are dominant compared to others, but this depends on the operating conditions. The discrete-tone noise equation is similar to Eq. 13, without the function $f_{4}$. Additional terms should be added to take into account effects such as fan and stator blade sweep and lean angles. Note that the linear split in Eq. 13 does not take into account the implicit relationship between mass flow rates and temperature rise across the fan.

The fan working conditions include a temperature jump across the rotor, for simplicity assumed to be the same for the core and duct sides. The tip Mach number and blade passing frequency are determined from the rpm of the relevant spool, in this case $N_{1}$. Several tests indicated that the fan noise is critically dependent on the temperature rise across the fan; on turns, this quantity depends on the fan pressure ratio (core- and duct-side). A small reduction in fan pressure ratio, for example from 1.6 to 1.55 can lead to a few $\mathrm{dB}$ reduction in fan noise, and thence to a sensible reduction in the integral noise metrics. A sensitivity test is shown in $\S 3.8$. 
Supersonic tip speeds are not specifically addressed by Eq. 13, unless empirical factors are derived separately for both subsonic and supersonic conditions. One important supersonic effect is the so-called "buzz-saw" noise, encountered at high engine rpm, particularly at certain locations of the receivers (those facing the engine). Work on the buzz-saw was published in Refs. ${ }^{158,159}$.

The analytical models are placed between the empirical and the computational models. They require an "acoustic analogy", wherein the aerodynamic pressures are separated from the acoustic pressures. The model equations are essentially wave equations relying on the aerodynamic loads. Although such methods are used for propeller noise, fan noise prediction relies on algebraic equations such as Eq. 13.

A similar method is used to calculate the noise performance of axial compressor stages. To adapt such a method, we need a detailed engine thermodynamics and some degree of knowledge of the geometrical configuration (diameters, blade count, rotor-stator distances). In absence of detailed engine data, constant pressure ratios can be used for all compressor stages. Currently, there is no recognised method for the prediction of noise from centrifugal compressors, as they may be found in turboprop and turboshaft engines.

Jet Noise. Jet noise is the most widely studied among the aircraft noise sources. Initial studies go back to the 1950 s for the single jet ${ }^{160}$, which are no longer representative of an aircraft engine. The technical literature in this area is vast; a number of periodic reviews from the 1980s to the present time are available ${ }^{161,162}$.

Gas turbine engines have evolved into turbofan engines with increasing by-pass ratios. This has prompted the need for prediction models of co-axial jets with a variety of mass flow ratios (ratio between the core and the bypass flow), velocity ratios and temperature ratios. For this purpose, several methods have become available in the past twenty years. The basis of these methods is a combination of experimental and empirical approaches, with experimental data sets that cover the operational envelope of the jet; these are the velocity and temperature ratio between hot and cold flows, emission angles, by-pass ratios, the spectral contributions, and so on. Not all the data produced in recent years are of the same quality ${ }^{163}$.

An earlier method for predicting noise from cold and hot co-axial jets is due to Balsa \& Gliebe $^{164}$. A later method proposed by Fisher \& Preston ${ }^{165,166}$ operates over a relatively limited matrix of parameter ratios, because it uses experimental data that are likewise limited (such database is available from ESDU ${ }^{167}$ ). At present, the most comprehensive method for coaxial 
jet noise is that of Stone et al. ${ }^{168,169}$, which has been validated over the years ${ }^{170}$ (CF6, CF34, CFM56, GE90) and extended to include details such as chevrons ${ }^{171}$ and various geometrical details of the nozzle and the plug. Other empirical models exist, such as the standard SAE ARP $876^{172}$. Ref. ${ }^{173}$ provides a summary of jet noise models tested by NASA.

Studies on the chevrons have been documented in the literature ${ }^{174,175,176,177}$; this technology is likely to become standard on all the new-generation turbofan engines. The model proposed in Ref. ${ }^{169}$ accounts for the chevron effects by defining two additional parameters: the suppressedto-unsuppressed wetted perimeter ratio of both core and duct side. These quantities are used to correct the radiation distance of the large-scale radiation noise and the mixing velocity.

Jet noise data for very high by-pass ratio engines have been published by Low ${ }^{178}$ and compared with the SAE prediction method. As in many other cases, there are important side-effects to be considered, such as the possible loss in net thrust as a result of forced jet mixing. An extensive database for model validation is available in Viswanathan et al. ${ }^{179}$; this database includes spectra, area ratios, velocity ratios, flight Mach numbers. There are prediction codes based on some form of RANS, but these are computationally more demanding and unlikely to be adopted soon.

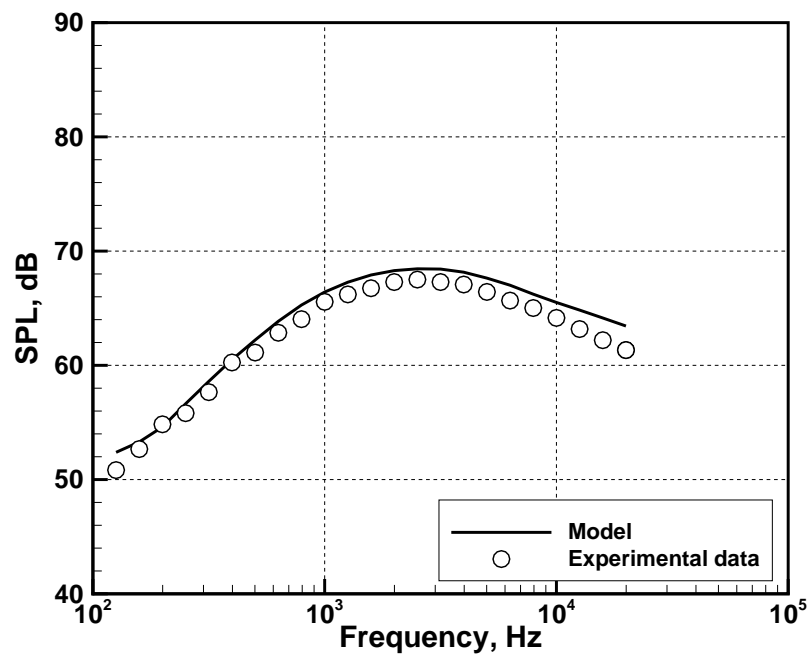

Figure 9: Hot jet $\left(\mathcal{T}_{p}=800 \mathrm{~K} ; V_{p}=215 \mathrm{~m} / \mathrm{s}\right)$ noise prediction and comparison with laboratory data ${ }^{166}$.

The FLIGHT program incorporates numerical implementations of both the Fisher et al. (Figure 9) and Stone models (Figure 10), with the latter one used as a default, due to the more extensive database. The model in Refs. ${ }^{165,166}$ uses the single-jet analogy to model the noise produced in different regions using mean velocity and temperature ratios. The model in Refs. ${ }^{169}$ 


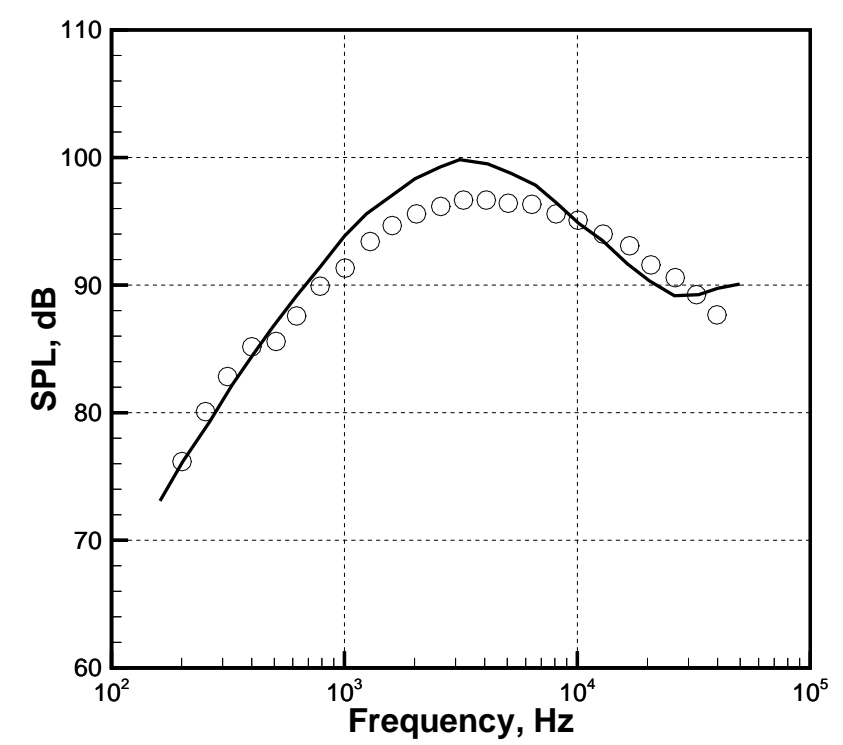

Figure 10: Near-field jet noise prediction $\left(M_{j}=0.98, M=0.05, \vartheta=135\right.$ degs $)$ and comparison with laboratory $\operatorname{data}^{169}$.

uses the concept of component correlation, including large-, small- and transitional scale mixing noise, inner plug separation and shock noise, outer stream shock noise.

There are comparatively few modern studies on jet noise with a thrust reverser ${ }^{180}$. The effort is on reduction of use of thrust reversers, with strict policies being enforced at many airfields ${ }^{181}$.

Engine Core Noise. Under this header we include noise from the rotating machinery (compressor and turbine stages), the combustor and from forced mechanical vibrations. These noise components are grouped together into what is known as "core nose", which generally refers to the noise sources not directly attributable to fan and jet; yet, there is no universal agreement on this definition. The core sub-systems are at best ill-defined from a geometry point of view. For example, a typical compressor and turbine stage would require the knowledge of parameters such as diameters, number of blades, blade chords, rotor-stator distance. Experimental data are few and not always reliable; these sub-systems never work in isolation. Therefore, their analysis cannot be carried out in isolation. Early experimental data on core noise were published by Matta et al. ${ }^{182}$ Attempts at separating the noise sources are available in Mendoza et al. ${ }^{183}$ A need for research in this area was articulated by Hultgren ${ }^{184}$, in particular the need to include more physics into the semi-empirical models, on the basis of experimental data and diagnostics systems ${ }^{185}$. 
Combustor Noise Model. It has been established that there are two distinct source mechanisms ${ }^{186}$ : direct combustion noise and indirect noise from the hot gas expansion in the turbines and nozzle. A review of combustor noise models has been published by Hultgren ${ }^{187}$, whilst Stone et al. ${ }^{188}$ published a core noise correlation that is split according to frequency range. This model has been implemented in the FOOTPR prediction code, previously discussed in $\S 1.5$. An empirical method for combustor noise is published by the ESDU ${ }^{189}$, and is claimed to be accurate within $5 \mathrm{~dB}$, although it is not validated with any data and appears to be superseded by Stone et al. ${ }^{188}$ Basic models for axial compressors are available from ESDU ${ }^{153}$, on the basis of a modified Heidmann's method, whilst there is no model currently available for centrifugal compressors. A prevailing semi-empirical model for the acoustic pressures (in $1 / 3$ octave bands) of an engine combustor is based on the formula

$$
<p^{2}>=\frac{(\rho a)_{\infty}}{4 \pi r^{2}} \Pi \mathcal{D}(\vartheta, f) \mathcal{S}(f)
$$

where $\Pi$ is the total acoustic power, $\mathcal{D}$ and $\mathcal{S}$ are directivity and spectral functions, respectively (determined empirically). Various normalisations can be carried out, but the determination of the total acoustic power is critical. For this purpose, it has been proposed to use the following:

$$
\Pi=10^{K / 10} a^{2} \dot{m}\left(\frac{\mathcal{T}_{t e}}{\mathcal{T}_{t i}-1}\right)\left(\frac{p_{t i}}{p_{\infty}}\right) F
$$

where the subscripts [.] $]_{t i}$ and $[.]_{t e}$ indicate total entry and exit conditions, respectively; $F$ is a "turbine attenuation factor", with $F=\Delta \mathcal{T}_{D} / \mathcal{T}_{\infty}$. Specifically, $\Delta \mathcal{T}_{D}$ is the total temperature drop across the full turbine stage at design conditions, i.e. at take-off thrust (or power). Hence, the combustor's noise response is related to the turbine conditions downstream. Alternative formulations exist for this attenuation factor ${ }^{190}$. A model for predicting the the spectral peaks was shown by Schuster \& Lieber ${ }^{191}$. This model follows SAE ARP $876^{172}$, but it has important differences, in that the directivity function is modified and depends on several spectral peaks (narrow bands). This model is presumably applicable to a range of combustors, from turbofan to turboprop and APU. The model proposed by Stone et al. ${ }^{188}$ includes a component level correlation which includes low-, middle- and high frequencies, supported by a database of spectral directivity relations. The results were supported by analysis of General Electric turbofan engines.

Turbine Noise Model. Turbine noise can be excessive on approach trajectories, therefore it merits consideration. The turbine noise model used in the FLIGHT code follows the approach of ANOPP 29 
with some differences; this model was validated with data by Kontos et al. ${ }^{30}$ In the first instance, we consider only the effects of the first HPT stage and the last LPT stage. This strategy is in line with assumptions made elsewhere on the basis of "engine experience" at General Electric ${ }^{30}$. As reported more recently ${ }^{88,192}$, accurate turbine noise models do not exist.

Several parameters of the HPT and the LPT are virtually unknown due to the lack of geometrical data; the important ones include the number of blades and the rotor diameter. Thus, some approximations are necessary. This is done by a statistical analysis on a small sample of engines. The turbine noise model requires the determination of the total inlet temperature and the static exit temperature. For an LPT having $n$ stages, we assume that the expansion of the gas through the turbine causes a uniform drop in temperature. The static exit temperature can be estimated from the conservation of total enthalpy, the continuity equation and an iterative procedure. The next procedure is to calculate the exit speed $V_{5}$ with a crucial approximation on the gas expansion. The core mass flow rate $\dot{m}_{c}$ is calculated from

$$
\dot{m}_{c}=\rho V_{5} A_{c}
$$

where $A_{c}$ is the cross-sectional area of the core flow at the exit of the LPT. We divide Eq. 16 by the corresponding equation at full thrust/power, static conditions, sea level, standard day (indicated by an asterisk):

$$
\frac{\dot{m}_{c}}{\dot{m}_{c}^{*}}=\left(\frac{\rho}{\rho^{*}}\right)\left(\frac{V_{5}}{V_{5}^{*}}\right)
$$

The left-hand-side of Eq. 17 is known from the engine simulation module at any given engine state. The reference speed $V_{5}^{*}$ is assumed to be sonic (for chocked flow) and can be calculated. The key assumption is that $\rho \simeq \rho^{*}$, which - although unlikely to be true - allows the rapid solution of Eq. 17. We approve this solution only in the context of undefined turbine parameters. An example of the effect of the number of rotor blades $n_{b}$ on the noise spectrum is shown in Figure 11, where an increase in blade count $n_{b}$ shifts the peak pressure level toward higher frequencies all other parameters being the same.

APU Noise. In general, this noise source is not modelled. This may be partly due to the fact that APU data are scarcely available, or because of various interference factors intervening in the propagation. APU noise is relevant when the aircraft is on the ground, and less important in 


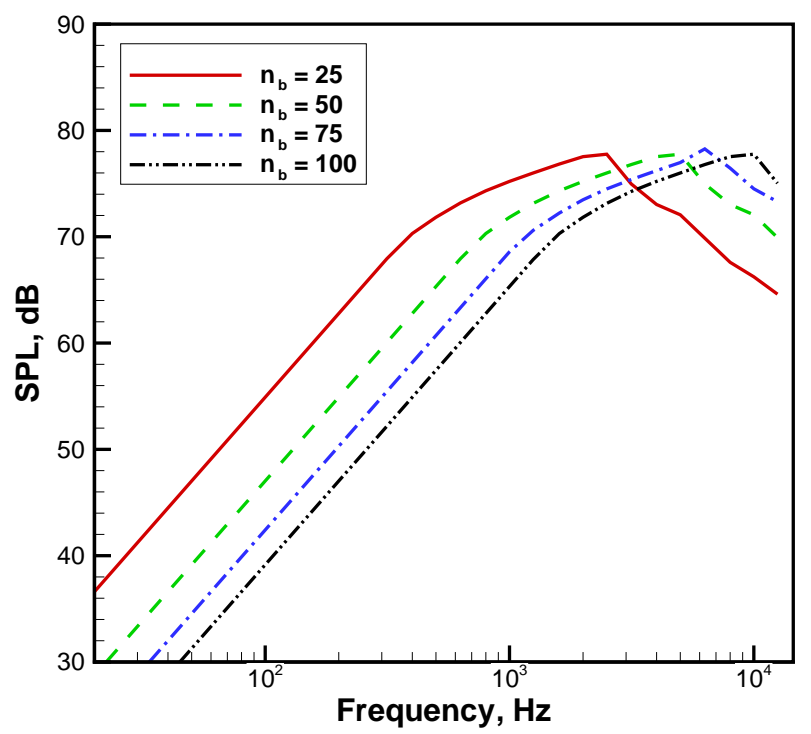

Figure 11: Effect of unspecified rotor blade count on the noise spectrum of an axial turbine.

flight, though it is unclear what its actual contribution is in such a case. Regulations on APU use on the ground are enforced by individual airports, particularly in Europe. The most stringent rules require that the environmental control system is started no more than 5 minutes before departure and be shut down no more than 5 minutes after parking at the gate. Its function is replaced by ground power units. The technical literature in this area is rather scarce. Health issues related to APU noise exposure are published by Tubbs ${ }^{193}$. Tam et al. ${ }^{194}$ published data and predictions for APU compressor and jet noise around a commercial aircraft; specific work on Boeing airplanes is available in Ref. ${ }^{195}$ As in the other noise sources, the SPL peaks at around 250 to $500 \mathrm{~Hz}$. A detailed analysis, covering extensive ground measurements of several airplanes, was published by Pott-Pollenske et al. ${ }^{196}$ An APU noise model has been implemented in the German noise simulation program SIMUL. The FLIGHT program has an APU noise model that includes the combustor and the jet/nozzle. As in the turbine case, statistical geometric and design data of APU are used.

\subsection{Propeller Noise}

This is another vast research area that has benefited from increasing efforts and more sophisticated models that operate at several levels. Again, we shall be concerned only with models that are suitable for comprehensive aircraft noise. Broadband noise has received considerable attention $^{197,198}$, due applications on all rotor systems: helicopters, propellers, fans, compressors, 
turbines. A review of problems related to noise metrics, measurement, prediction and certification was published by Heller ${ }^{1}$, whilst Magliozzi et al. ${ }^{199}$ focus on propeller prediction only.

The aerodynamic noise generated by the propeller is composed of a discrete frequency and a broadband component. The discrete component is due to the rotation of the blades and is sometimes called rotational noise. Two noise sources contribute to this discrete component: the "thickness noise", which results when a passing blade displaces a volume of air depending on its thickness, and the "loading noise", which is the acoustic disturbance generated by the aerodynamic loading. The thickness and loading noise are represented by a monopole and dipole distribution, respectively. Quadrupole noise induced by non-linear effects only arises when propeller blades rotate at high speeds ${ }^{200}$, typically $M>0.9$.

For our application, the thickness and loading noise for a subsonic propeller can be predicted using the frequency-domain computational approach developed by Hanson \& Parzych 201,202, which was derived on the exact formulation of the Goldstein acoustic analogy. Some practical details of this model, including non-axial flow effects, are also published by the ESDU ${ }^{203}$. Both noise contributions are computed at the blade passing frequency as well as at its higher harmonics. Unsteady flow effects are accounted for in the model when non co-axial, or angular, flow enters the propeller. The angular inflow produces an unsteady periodic effect. The broadband noise component is modelled in the FLIGHT program via a modification of the equations shown in Ref. ${ }^{199}$, using an estimation of the boundary layer properties from two-dimensional airfoil theory.

The first propeller models implemented in ANOPP are discussed by Zorumski \& Weir ${ }^{204}$, who describe the whole procedure, from geometry to aerodynamics and noise. The propeller was later upgraded ${ }^{205}$ (ANOPP-PAS) by using the formulation 1A by Farassat ${ }^{206}$ for discrete tonal noise, which is also used for helicopter rotor noise ${ }^{198}$.

The propeller models developed for the FLIGHT program include geometry, configuration, aerodynamics, performance (including trim), flight-mechanics coupling, and acoustics. The geometrical model is reconstructed from digital photography, measurements and published data. Figure 12 shows the FLIGHT model of the Dowty R408 propeller. The method of Hanson \& Parzych is used for the tonal components of the noise, because it has the additional advantage of splitting the aerodynamic loading from the acoustic loading. Thus, the propeller noise prediction is done with a multi-disciplinary code further discussed in $\S 3.1$. The model is not satisfactory when applied to prop-fans. Another issue that has not received sufficient effort in the open lit- 


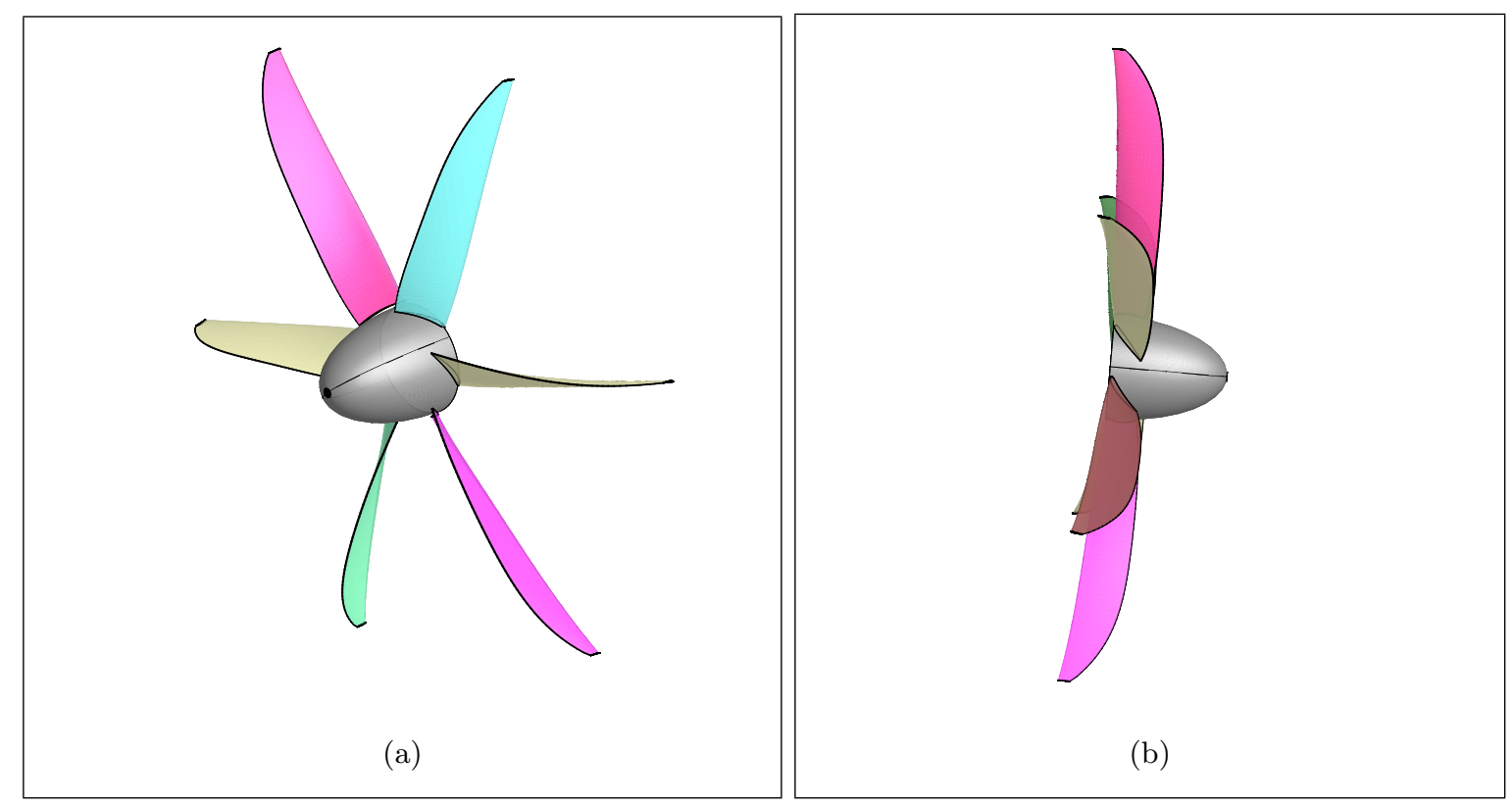

Figure 12: Geometrical model of the Dowty R408 six-bladed propeller.

erature (except for cabin interior noise) is the propeller synchrophasing, e.g. the noise effect of propellers rotating at slightly different speeds.

\subsection{Acoustic Liners}

Acoustic liners are installed in modern jet engines for noise suppression in the duct, especially suppression of fan-generated noise. Although the use of acoustic liners started in the early 1970s, the dissipation mechanism of sound still remains the subject of considerable research. Acoustic liners concepts for modern turbofan engines are reviewed by Bielak \& Premo ${ }^{207}$. The experimental work of Dittmar \& Elliott ${ }^{208}$ served to provide data on the effects of acoustic treatments at several fan operating conditions. Acoustic optimisation of the liners is also an established discipline, with some important contributions in recent years ${ }^{209,210}$. Properties of the acoustic liners themselves, for example the impedance, are part of the problem: the overall suppression effect depends on the acoustic impedance of the liners. Again, empirical and semi-empirical models exist ${ }^{211,212}$ that use basic parameters such as core cavity depth and diameter, face-sheet thickness, and perforation area. Important theoretical work is due to Melling ${ }^{213}$, who demonstrated that the perforated plates of the acoustic liners can have a linear or non-linear impedance, depending of the nature of the flow. Models exist also for acoustic liners in the combustor ${ }^{214}$ and turbine walls ${ }^{215}$.

In the early 1970s, Ko ${ }^{216}$ developed a theoretical method to predict the sound attenuation in an acoustically lined circular duct. Numerical solutions were obtained for sound attenuation 
in the presence of fluid flow for a given duct geometry, boundary layer thickness and acoustic lining configuration. The theoretical results obtained give the attenuation spectra of each mode that falls above the associated hard-wall cut-off frequencies for the inlet and exhaust conditions. These results also showed that the fundamental mode is not necessarily the least attenuated in a circular duct. Since the total attenuation spectrum is dependent upon the least attenuated mode, it inaccurate results could be obtained if only the fundamental mode in a lined duct is studied. A numerical solution of this model has been included in the FLIGHT program. A number of free parameters exist, such as the duct boundary layer (which can be switched off), the liners characteristics (length, depth) and hence the acoustic impedance quantities. Optimised duct liners can reduce the noise by $\sim 2 \mathrm{~dB}$ EPNL on both departure and arrival trajectories.

\subsection{Noise Shielding and Other Source Effects}

Noise shielding effects are not taken into account in basic component methods; the resulting noise level is due to the independent effect of each acoustic source. A number of important corrections have to be included in specific circumstances, e.g. when an acoustic source is shielded by another source or a sink. In the former case we have jet-by-jet shielding; in the latter case we have shielding by reflection and refraction from a solid surface of specified impedance (the fuselage) and is only considered when the source is out of the line of sight of the receiver.

Jet Noise Shielding. The idea behind jet shielding is that the resulting acoustic pressure at the receiver is affected by the acoustic shielding of a hot gas in the line of sight of the receiver. If $p_{1}$ and $p_{2}$ denote the acoustic pressure at a receiver in absence of noise shielding, and $p_{\text {shield }}$ is the acoustic pressure in the event of shielding, the difference in noise level is

$$
\Delta \mathrm{SPL}=10 \log _{10}\left(\frac{p_{\text {shield }}^{2}}{p_{1}^{2}+p_{2}^{2}}\right)
$$

This effect can be taken into account by using some existing analytical formulations, such as the jet-by-jet shielding model of Gerhold ${ }^{217}$. Simonich et al. ${ }^{218}$ carried out experiments on twin jet noise and provided a further refined mathematical model. ESDU ${ }^{219}$ provide a practical implementation, one not immune by errors. A numerical solution of these methods has been included in the FLIGHT program ${ }^{58}$.

Fuselage Shielding. The research in this area has focussed on novel configurations (blended wing bodies) and conventional configurations powered by advanced propellers. Nark et al. ${ }^{220}$ use a 
fast scattering method, whilst Agarwal et al. ${ }^{36,221,222}$ proposed boundary element methods and ray tracing methods. A boundary element method has also been used by Papamoschiou ${ }^{223}$, and implemented into ANOPP2 for the simulation of non-conventional airframes.

In the FLIGHT program we account only for the interference or shielding between a noise source and a cylindrical fuselage ${ }^{58}$. The interference effect of the fuselage is accounted for if the propeller or the engine is shielded from the line of sight of the receiver, such as in the case shown in Figure 13. Propellers and fans are reduced to a lumped mass fixed at their respective hub. In this instance we use a model for the scattering of a spherical wave from a point source by a long cylinder ${ }^{224}$, with or without an impedance boundary that simulates the ground.

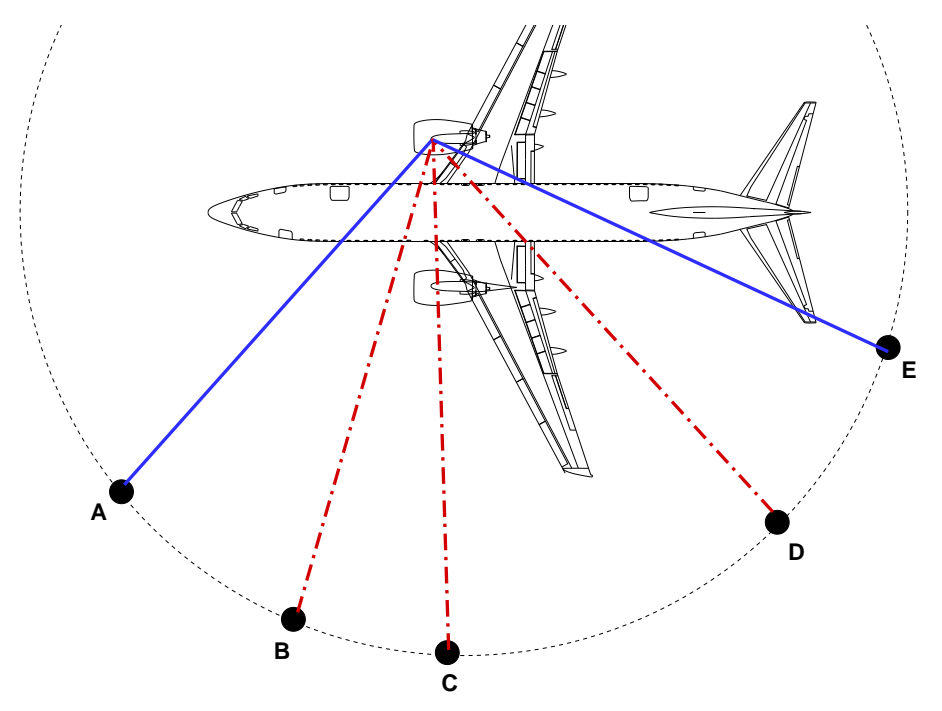

Figure 13: Fuselage shielding, top view. Shielding calculations are carried out for receiver positions $B, C, D$.

\subsection{Far-Field Noise Propagation}

Aircraft noise propagates over distances of the order of several $\mathrm{km}$. In their travel, the acoustic waves penetrate atmospheric layers which are subject to variable temperature, pressure, density and relative humidity. There exist standard methods for the calculation of atmospheric absorption through an homogeneous medium ${ }^{225,226}$. These methods produce absorption rates, generally given in $\mathrm{dB} / \mathrm{m}$. Appropriate integration methods exist to convert the absorption rates to a total absorption over a given distance.

The presence of wind shear and temperature gradients make things more difficult, therefore we treat this latter problem as a separate issue. In such a case, there is often a linear separation among the various effects, according to the following equation 


$$
L_{R}-L_{S}=\Delta L_{\text {spread }}+\Delta L_{\text {atm }}+\Delta L_{\text {wind }}+\Delta L_{g}
$$

where $L_{R}$ is the noise level at the receiver, $L_{S}$ is the near-field noise. The terms on the righthand side denote the spherical spreading, the atmospheric absorption (including the temperature gradients), the wind effects (including turbulence scattering), the ground effects and possibly non linear effects, which may occur over very long distances. The acoustic emission at the source at a time $t_{S}$ are received at the microphone at a time $t_{R}$, such that

$$
t_{R}=t_{S}+\frac{r}{\bar{a}}
$$

where $\bar{a}$ is the average speed of sound between the source and the receiver. The time delay can be several seconds. Therefore, it is necessary to have two clocks (on the airplane and at the measuring station), fully synchronised.

Studies in aircraft noise propagations started to appear in the technical literature in the 1950s. Theories exist for noise propagation in built-up and coastal areas. There is a full treatment of the outdoor propagation of noise in Attenborough et al. ${ }^{227}$, where additional references can be found. There exist standard models for the prediction of atmospheric sound absorption, including an ANSI standard ${ }^{228}$, an ISO standard ${ }^{225}$, a SAE standard ${ }^{229}$ and other models. Distance, frequency and humidity are critical parameters. At the highest frequencies, these models cut tens of $\mathrm{dB}$, and over long distances it is possible to hear only low-frequency noise; hence, the atmosphere operates like a low-pass filter. Therefore, it is important, in any aircraft noise prediction model, to be able to model low-frequency noise. Frequencies in $5-10 \mathrm{kHz}$ range are no less important, as they can be dominated by non-linear distortion effects ${ }^{230}$.

Ground Effect. Ground reflections can significantly affect the sound pressure received at standard microphone heights $(1.2 \mathrm{~m})$. A number of events takes place, including ground reflection and refraction. These effects are sometimes include a "lateral attenuation", a term that is not sufficiently clarified. Sound pressure level fluctuates by a degree which increases with larger incident angles and with higher frequencies. However, the real effect of large fluctuations at higher frequencies damps out in the broadband scales. The low to mid-frequency fluctuations must be captured accurately. Simple diffraction theory exists from a semi-infinite plate exists ${ }^{231}$ to deal with the shielding effect of screen-like surfaces. 
Theoretical studies on this problem are well established starting with the work of Rudnick ${ }^{232}$ and Ingard 233 in the early 1950s. Reviews of this matter have been published by Attenbor$\operatorname{ough}^{234,235}$. Other fundamental studies in this area include those of Embelton et al. ${ }^{236,237}$, whose methods have been implemented in a number of computer programs. A standard method has been published by SAE to predict such attenuation ${ }^{238}$ (with several limitations), and is implemented in INM $^{59}$. Ref. ${ }^{238}$ provides further references on this topic. However, Ref. ${ }^{239}$ is rather critical: "It is generally recognized by the technical community that the SAE-based lateral attenuation algorithm ... is the single-biggest acoustic weakness in the model ..."

Early contributions model the ground impedance used a single parameter: the specific flow resistance per unit thickness, based on the work of Delaney \& Bazley ${ }^{240}$. The model relies on curve fitting of various measurements of ground impedances. Attenborough ${ }^{241}$ showed that the single-parameter model is unreliable outside the range of the fitted data and introduced a more accurate model using two parameters: the effective flow resistivity, $\sigma_{e}$, and the rate of exponential decrease of porosity with depth, $\alpha$. A more recent ground impedance model using two parameters has been proposed in Ref. ${ }^{242}$ for user in environmental noise. Thus, a two-parameter model is used in FLIGHT, with various numerical modifications ${ }^{243,244}$ described in detail in Ref. ${ }^{58}$

Referring now to the other aircraft noise prediction models, the SAI program simplifies the ground effect further but substituting it with a $+3 \mathrm{~dB}$ correction to the received noise ${ }^{245}$. The ANOPP2 program uses the Gaussian beam approach ${ }^{246}$. The ground effect used by other programs, including PANAM and SIMUL (referred in §1.5), relies on semi-empirical data and models also implemented in the program $\mathrm{AzB}^{67}$. A practical use of the ground reflection model is shown by ESDU $^{247}$. Other semi-empirical methods exist to take-into account lateral attenuation ${ }^{248}$, though there is doubt of their validity.

Wind and Temperature Effects. Sound propagation in the presence of wind and/or temperature gradients are refracted, resulting in the sound received at a location being attenuated or enhanced. The degree of the frequency-dependent attenuation or enhancement depends on a number of factors, e.g. horizontal propagation distance, wind speed and direction angle relative to the sound propagation, wind and temperature variation with height, source and receiver elevation. The presence of wind and temperature variations in the atmospheric boundary layer produce a sound speed gradient. An increase of the sound speed from source to receiver would refract the sound downward and generally enhance the acoustic wave received. A model has been proposed by 
Zorumski ${ }^{249}$ to predict the effect of low-altitude propagation of a noise source. In the FLIGHT program the wind and temperature effects have been modelled following Rasmussen ${ }^{250} \mathrm{Alm}$ gren $^{251}$ and Pierce ${ }^{252}$, using a series of Hankel transforms of the acoustic pressure. The model has been extended to model long-distance propagation. Although this theoretical model is referred to as "exact", it relies on the assumption that the speed of sound gradient is linear, which is slightly incorrect. Problems of numerical implementations are not trivial and involve a number of other approximations. Figure 14 shows the results of the calculations achieved with FLIGHT and the comparison with experimental data for the specified distance, source-receiver height above the ground, flow resistivity, and rate of exponential decrease of porosity with ground depth $\left(\alpha_{p}\right)$.

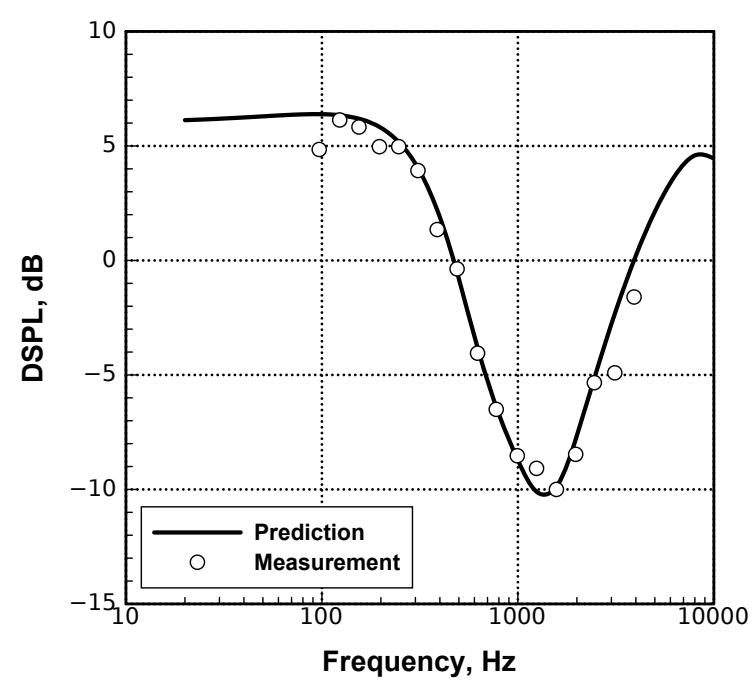

(a) $z_{R}=0.1 \mathrm{~m}, \sigma_{e}=16 \mathrm{kNsm}^{-4}$

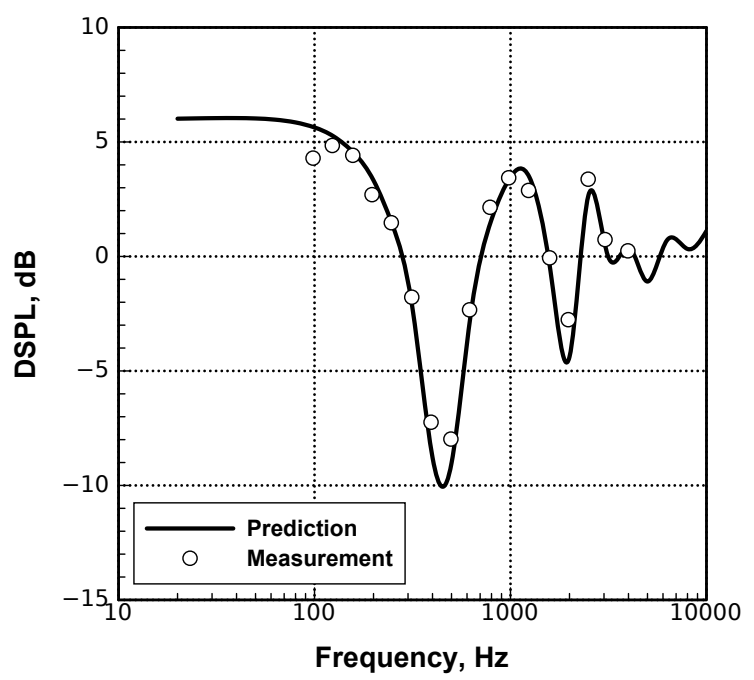

(b) $z_{R}=1 \mathrm{~m}, \sigma_{e}=13 \mathrm{kNsm}^{-4}$

Figure 14: Comparison of the SPL attenuation with experimental data ${ }^{250}$. Source-receiver distance $=10 \mathrm{~m}, z_{S}=$ $1 \mathrm{~m}, \alpha_{p}=70 \mathrm{~m}^{-1}$.

Alternatively, the ray tracing method of L'Espérance et al. ${ }^{253}$ can be used, although the latter method does not provide a solution in the shadow zones. A fast-field approach implemented by ESDU $^{254}$, based on an extension of the propagation to aircraft flight ${ }^{255}$ is not as fast as claimed. More recent work by Arntzen et al. ${ }^{256}$ dealt with noise propagation in a non-standard atmosphere. These authors used a form of the ray-tracing algorithm. Also notable are the modifications proposed by Raspet et al. ${ }^{257,258}$, who expressed the solution as a residue series and normal mode solution for an upward and downward refracting atmosphere, respectively. This formulation is unlikely to provide any computational advantage. Models based on ray tracing method exist for the prediction of long-range noise propagation of a cruising aircraft ${ }^{259}$. Another method that has 
become popular in some outdoor application problems include the ray tracing method $260,261,262$. Various sources of data exist for the verification and validation of the propagation methods, chiefly Ref. ${ }^{261,263}$.

\subsection{Engine Models}

A detailed and accurate aero-thermodynamic model is needed for the generation of flight trajectories (flight mechanics integration), as well as for predicting the noise of the main engine components. For this purpose, the appropriate support consists of a steady-state one-dimensional flow model of the engine. Various models exist. ANOPP2 and its previous versions use NASA's NEPP engine simulator ${ }^{147}$. DLR's program PANAM uses an undisclosed internal model. FLIGHT uses an interface with NLR's gas turbine program GSP ${ }^{264}$ to generate full engine envelopes. The object-oriented program is utilised to build a model of the engine via an iterative analysis of the mass flow rate and the fuel flow with a constraint on the net thrust (or shaft power) and a turbine temperature (Table 2), depending on the data available in the type certificate documents ${ }^{56}$.

Table 2: Aero-thermodynamic parameters used to simulate turbofan aircraft noise.

\begin{tabular}{ll}
\hline Parameter & Description \\
\hline$\dot{m}$ & Mass flow rate (total) \\
$T_{t 3}$ & Combustor inlet temperature \\
$p_{t 3}$ & HP Compressor pressure, exit \\
$T_{t 4}$ & Exit combustor temperature \\
$\dot{m}_{f}$ & Fuel flow rate \\
$T_{t 5}$ & Power turbine temperature \\
$F_{N}$ & Net thrust \\
TSFC & Specific fuel consumption \\
$T_{S 9}$ & Total static nozzle temperature \\
$p_{S 9}$ & Total static nozzle pressure \\
$M_{9}$ & Nozzle Mach number (core) \\
$T_{t 2.1}$ & Exit fan temperature (core side) \\
$T_{t 2.2}$ & Exit fan temperature (bypass side) \\
$N_{2} \%$ & High pressure rotor rpm \\
$\dot{m}_{c 2.5}$ & Core mass flow rate \\
$T_{t 2.5}$ & LP compressor exit temperature \\
$p_{t 2.5}$ & LP compressor exit pressure \\
$T_{t 4.5}$ & HP turbine total exit temperature \\
$T_{t 14}$ & Bypass flow temperature, exit \\
$p_{t 14}$ & Bypass flow total pressure, exit \\
\hline
\end{tabular}

Once the engine has been "designed", parametric runs are carried out in order to generate 
flight envelopes over the full range of air temperatures, Mach numbers, flight altitude and fuel flow. These flight envelopes are then interpolated with a high-order method to constrain them further to the limit turbine temperature and/or limit engine rpm $\left(N_{1} \%\right)$. Although more than 80 aero-thermodynamic parameters are currently used in the analysis, the parameters stored for the flight mechanics and acoustic calculations are limited to those listed in Table 2. We call $\boldsymbol{A}$ the sub-vector of these parameters. These sub-envelopes are integrated into the FLIGHT program via a direct or inverse mode. In the direct mode, a fuel flow $\dot{m}_{f}$ or a gas turbine speed $N_{1} \%$ is used to calculate the engine state $\mathcal{S}$, e.g. $\mathcal{S}(\boldsymbol{A})=f_{1}\left(\dot{m}_{f}\right)$, or $\mathcal{S}(\boldsymbol{A})=f_{1}\left(N_{1} \%\right)$. In the inverse mode, the independent parameter is either the net thrust $F_{N}$ (turbofan) or the shaft power $P_{\text {shaft }}$ (turboprop). Thus, the engine state is an interpolating function $\mathcal{S}(\boldsymbol{A})=f_{1}\left(F_{N}\right)$. The latter case occurs in those cases when the aircraft is trimmed to satisfy the flight mechanics equations.

The importance of the accuracy in the aero-thermodynamic model is emphasised by the fact that most noise sources depend on section temperatures, pressures, mass flows and Mach numbers.

An example of validation is shown in Figure 15, which displays FDR (Flight Data Recorder) data for the PW150A turboprop engine on departure, for sea level conditions, with the prediction of the FLIGHT program. Note that there is considerable difference between the left and right engines on the real aircraft. In the simulation method we consider the two engines as exactly the same (dashed line). A similar analysis is shown for the turbofan engine Rolls-Royce CF3410E7 (Embraer E195), Figure 16. In both cases, the engine models have been constructed out of information available in the public domain, before there was any knowledge of FDR data. The comparison was done at a later time, when FDR data were made available.

\section{Aircraft Noise Calculations}

It should be evident to the reader that a large variety of noise calculations can be carried out, each requiring a validation at several stages. Starting from the top level, the main interest is in the determination of noise maps (or noise footprints) of one or several airplanes. This type of analysis relies on a realistic flight trajectory. Therefore, the noise sub-models must account for Doppler effects, orientation with respect to a ground reference system (attitude, bank angle), orientation with respect the receiver (corrected emission angles) and other parameters. 


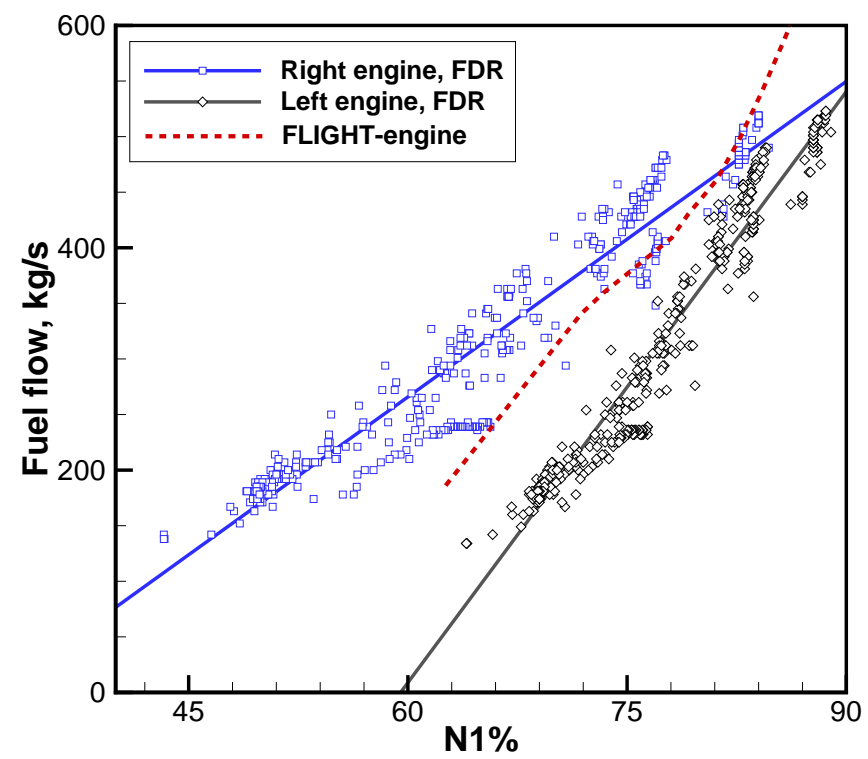

Figure 15: Flight performance of the PW150A turboprop engine at sea level; FDR data from the left and right engine compared with the prediction of the engine module of the FLIGHT program. The straight lines are linear regressions of the data points.

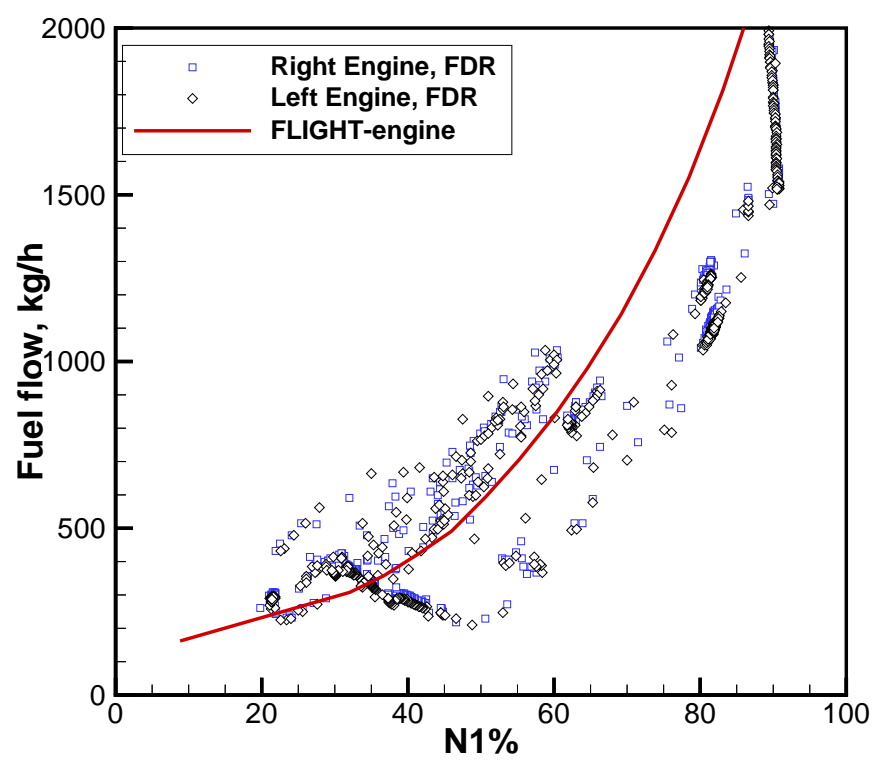

Figure 16: Flight performance of the CF34-10E7 turbofan engine at sea level; FDR data from the left and right engine compared with the prediction of the engine module of the FLIGHT program.

\subsection{Transfer Function for Aircraft Noise}

A general expression for the transfer function between the flight mechanics and the noise program is done through the vector 


$$
\boldsymbol{T}=f\left(I_{s f}, I_{l g} ; \boldsymbol{X}, \boldsymbol{V} ; \quad \psi, \theta ; \beta ; \quad N_{1} \%, \dot{m}_{f} ; \mathcal{H}, \mathcal{T}, V_{w}, \Psi_{w}\right)
$$

where $I_{s f}$ denotes the high-lift configuration (position and angle settings), $I_{l g}$ is an operator denoting the landing gear deployment/retraction; the vector $\boldsymbol{V}$ denotes the true air speed at position $\boldsymbol{X} ; \psi, \theta, \beta$ denote the heading, attitude and bank angle, respectively; $N_{1} \%$ and $\dot{m}_{f}$ denote the engine state (often only one of these parameters is required); the remaining parameters denote the state of the atmosphere at the position of the airplane (relative humidity, actual air temperature, wind speed and wind direction, respectively). The position sub-vector $\boldsymbol{X}$ is calculated either with respect to a reference system fixed on the airfield or from GPS coordinates (Global Positioning System), if real flight data are used. In the latter case, a transformation from GPS coordinates to an airfield reference system is done via the inverse geodetic distance $\operatorname{method}^{265}$.

The combination of the sub-vectors $\boldsymbol{X}$ and $\boldsymbol{V}$ denotes the flight trajectory. This is selfgenerated by the program if external FDR trajectories are not available. The program contains fully validated flight mechanics models ${ }^{58}$, without approximations or assumptions. ANOPP uses a flight mechanics code called FLOPS ${ }^{266,267}$, which has been widely used in a number of other applications.

Equation 21 contains parameters in four different categories: airplane state, airplane flight mechanics, engine state, atmospheric conditions. All the other parameters, including the external boundaries (ground topography) become part of the noise propagation problem, and thus are not included in Eq. 21. One of the important points to note in Eq. 21 is the availability of the correct engine parameters. The flight mechanics integration requires the net thrust, which is not readily available. There are indeed some indirect methods to estimate the thrust, but they depend on the correct estimate of the weight. The mass is absent from Eq. 21, because it is redundant. The additional information is split into three categories: aircraft information; airport information; microphone/receiver information.

The integration of a propeller noise model into a flight mechanics program that predicts aircraft noise from conventional trajectories is shown in the flowchart of Figure 17.

In this approach, the flight conditions are set by the parameters given by the transfer function Eq. 21. The fuel flow or the engine rpm at given at each time step, along with the other key parameters. Through the engine model, we calculate the relationship between the fuel flow and 


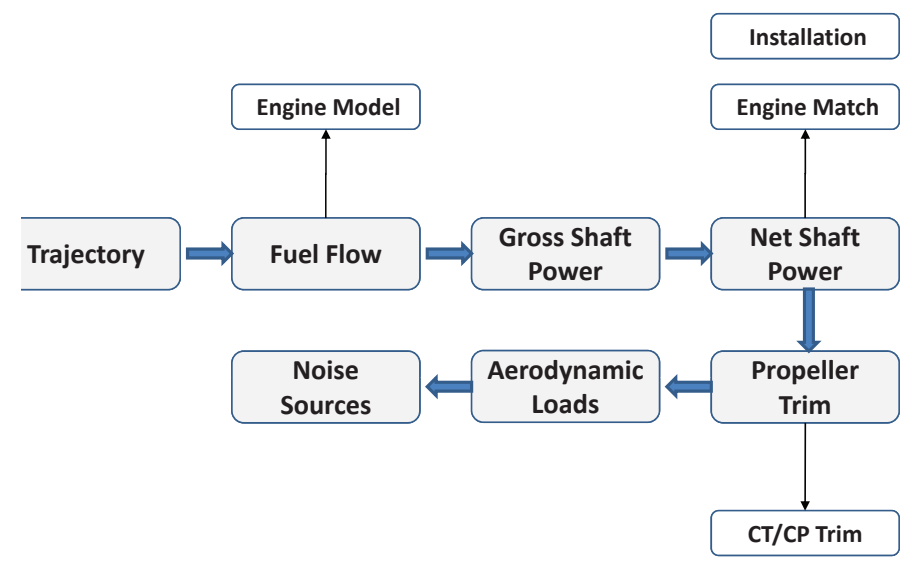

Figure 17: Flowchart showing the relationship between the flight mechanics and the corresponding propeller noise.

the gross shaft power of a single engine. This quantity is corrected for engine installation losses and for the effects of the residual jet thrust from the turboprop. Once the net shaft power is available, the propeller is trimmed to the required power coefficient $C_{P}$; the aerodynamic trim provides the aerodynamic loads on the blades, by using a strip theory with transonic corrections. The aerodynamic loads are decoupled from the acoustic sources, and can be used directly as the basis for calculation of the propeller noise. The aerodynamics is based on an generalised blade element method with transonic corrections. Thus, the propeller module consists of the following sub-programs ${ }^{57}$ :

- Blade, propeller, rotor, hub geometry.

- Aerodynamics, e.g. two-dimensional airfoil polars at low Mach numbers.

- Transonic aerodynamic model ${ }^{268}$ for prediction of aerodynamic loading $\left(C_{l}, C_{d}\right)$.

- Propeller performance, including combined momentum theory and blade elements.

- Propeller trim at all flight conditions.

- Propeller noise (tonal and broadband contributions).

An example of aerodynamic loading on the propeller is shown in Figure 18, for a case of yawed flight condition. 


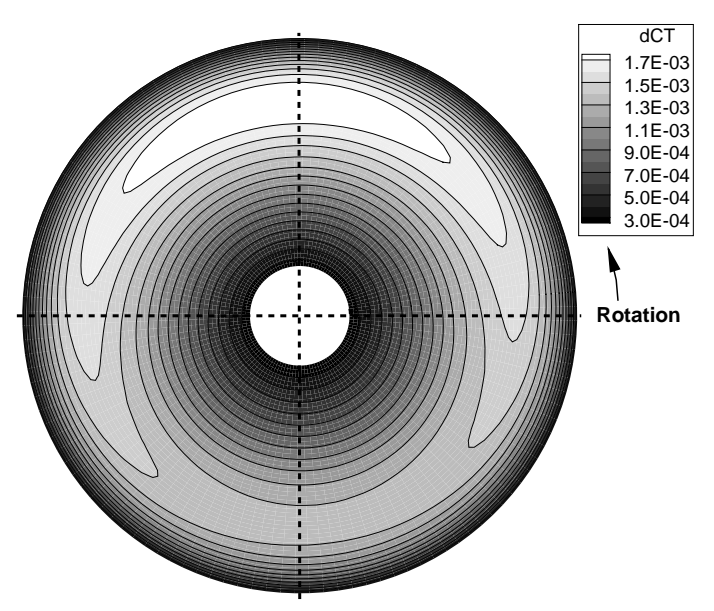

Figure 18: Propeller loading in non axial flight, yaw of 5 degrees, at trimmed conditions.

\subsection{Fly-over Trajectories}

A number of fly-over experiments has been carried out by various organisations in recent years, although there is still resistance in arranging for these exercises, for the data exchange and for the publication of the data themselves. There are two essential elements in the generation of experimental data:

1. Determination of the aircraft parameters (some of which are given in the transfer function

Eq. 21), possibly by post-processing of the FDR data.

2. Noise measurement on the ground with time synchronisation (FDR and microphone).

Among the examples available in the open literature, we name the fly-over experiments shown by Ref. ${ }^{114,269,270,271}$, with numerical comparisons shown by Bertsch et al. ${ }^{37}$ In a previous project fly-over results for an Airbus A319 and A340 were published (Pott-Pollenske et al. ${ }^{272,273}$ ). Heller ${ }^{1}$ published some data on propeller-airplane noise as function of the tip Mach number, although these data are limited to a single-value noise level. Some early fly-over measurements were published by Kipersztok \& Sengupta ${ }^{76}$ for the Boeing B747-100 with JT9D-7A engines to identify the sources of airframe noise, which were then predicted by using the Fink's method discussed earlier. Microphone arrays and beam-forming techniques have become a widespread technique for acoustic data acquisition and acoustic source location ${ }^{274,275,276}$.

The standard practice in fly-over measurements is to use microphones mounted horizontally on a $1.2 \mathrm{~m}$ high pole. However, the ground impedance causes a distortion of the measured fly-over 
noise; for this reason, the microphones are sometimes mounted flush with a hard surface on the ground to avoid the effects of acoustic reflection ${ }^{277}$. In any case, all fly-over data must clearly indicate how the measurements were taken and processed.

The measurements should include the atmospheric conditions, the integral noise metrics, the overall sound pressure levels, and if possible also the noise spectra. In addition, there is a need for correct aircraft parameters, such as position, speed, engine state, and configuration. Collection of such data requires at least the cooperation of airports, airline operators, airplane manufacturers, national aviation authorities and a host of other stakeholders, including at times the pilots unions. Data that have been taken over the past decade are proprietary (by the aircraft manufacturers or the national aviation authorities) on grounds of costs and "commercial sensitivity".

A comparison between climb-out trajectories is shown in Figure 19 for the Boeing B767-300. The data for INM and ANCON have been extrapolated from Ref. ${ }^{24}$ The ANCON data are referred to as a "mean" trajectory out of London, whilst the INM trajectory is referred to as "default". Interestingly, below 2,000 feet FLIGHT predicts a trajectory equivalent to ANCON. Real-life track dispersion is a major issue when attempting comparisons.

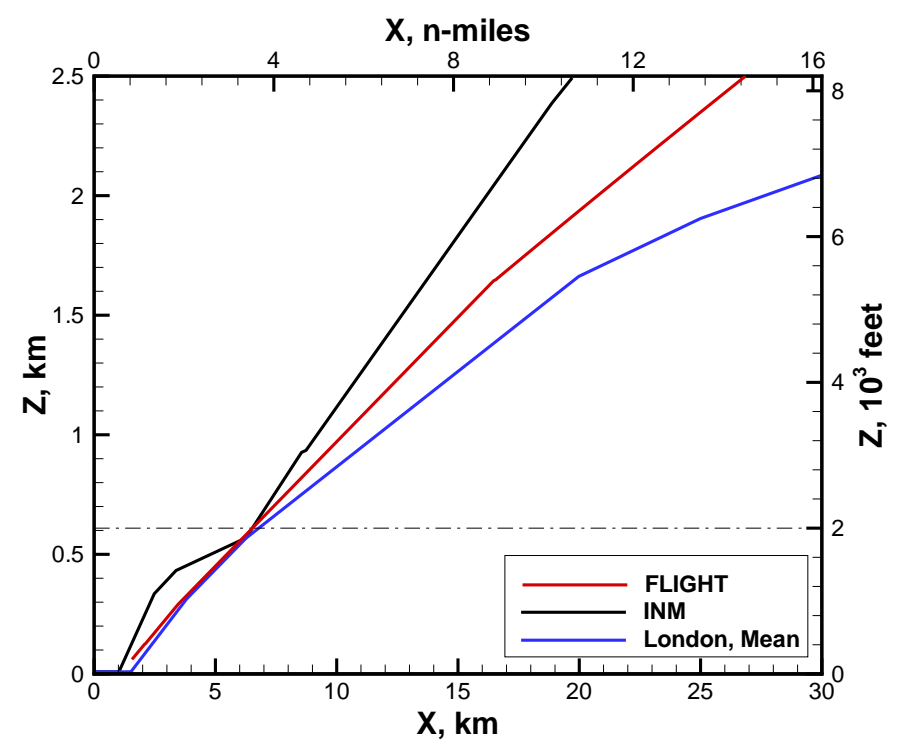

Figure 19: Simulations and measurements of climb-out trajectories for the Boeing B767-300 at London Heathrow.

The transfer function $\boldsymbol{T}$ in Eq. 21 is determined in two ways: 1.) by using the flight mechanics model; 2.) by using actual flight data extracted from the FDR. Ref. ${ }^{3}$ reports that:

FDR data provide the most detailed and accurate description of aircraft position (and 
attitude - angles of pitch, roll and yaw), aircraft speed, engine power setting and flight configuration (flaps, gear). They are the highest quality input data for use in any noise calculation engine.

Our research shows that uncertainties arise from several sources, including the fact that the GPS position of the aircraft is approximate, with errors of the order of two wing spans in the lateral direction and several metres in the vertical direction, depending on the FDR storage system. An example is shown in Figure 20, which displays the ground track of an Embraer E195 departing from Manchester airport. The square symbols denote community microphones used to monitor noise on the departure side. The dashed line is smoothed from the raw ground track.

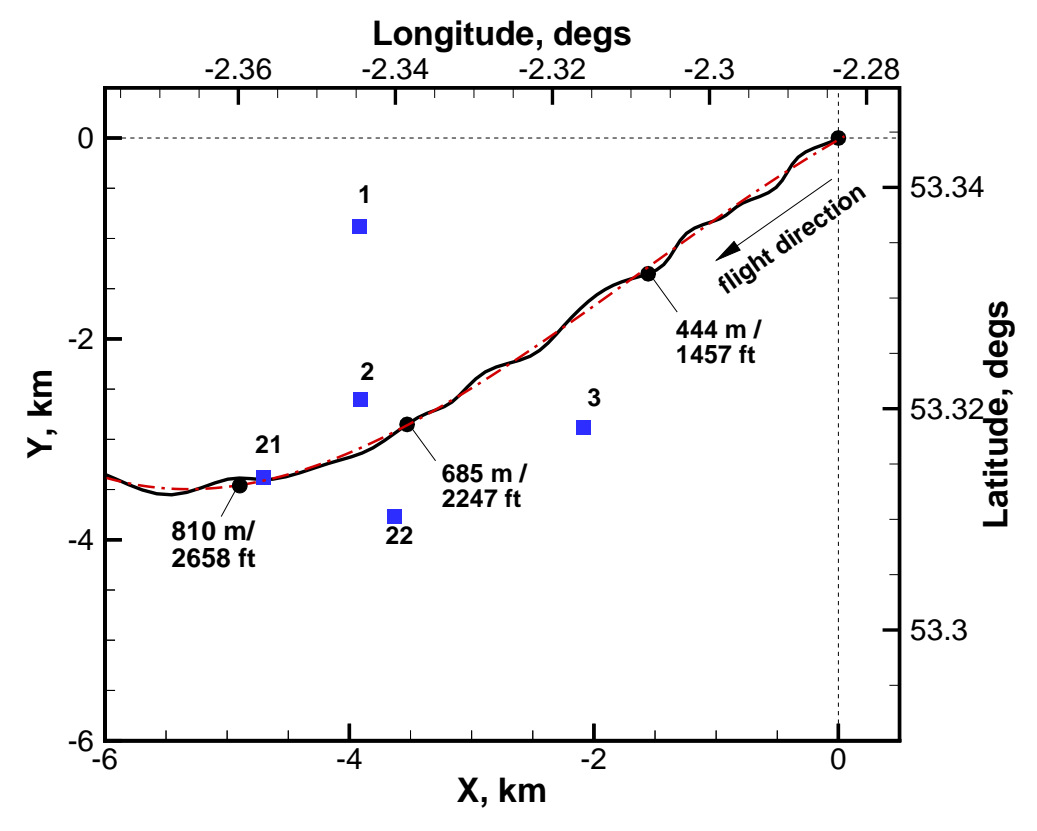

Figure 20: FDR track of an Embraer E195 departing from Manchester Airport; $x$-y coordinates not on scale. Numbered symbols denote community microphone positions.

Another example is shown in Figure 21, which displays the ground track recorded by the FDR for a Bombardier Dash8-Q400 landing at Manchester Airport. In this example, the FDR indicates that the airplane staggers around the average track by as much as $200 \mathrm{~m}$. With this level of inaccuracy on the flight trajectory, comparisons between measurements and simulations should be taken with caution.

Alternative methods used for the determination of some of the parameters in the transfer equation include radar data, which can be used to calculate the ground speed and the flight altitude with dubious accuracy. Flight track dispersion recorded at airports could be in part 


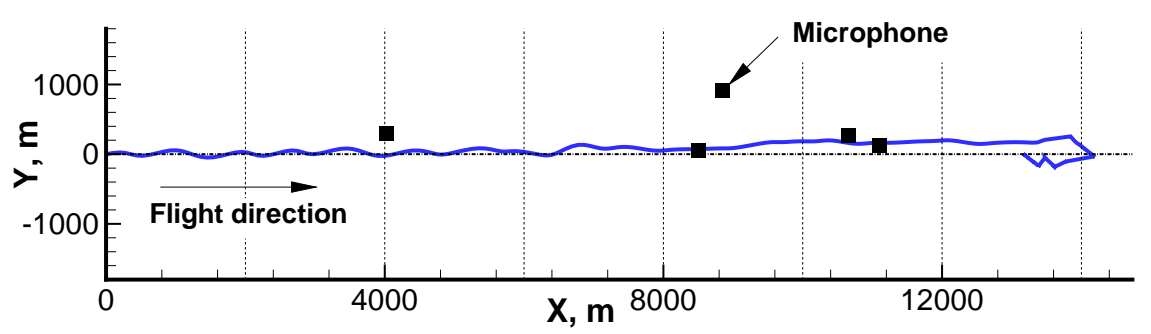

Figure 21: FDR track of a Bombardier Dash8-Q400 on approach and landing; $x-y$ coordinates not on scale; symbols denote microphone position.

attributed to this inaccuracy.

For reasons that are not entirely clear, many FDR parameters do not provide reasonable estimates of some parameters when the aircraft is on the ground, either on hold or rolling down the runway (for example, negative propeller torque). In these cases, the determination of the flight parameters by direct simulation is a better alternative. Figure 22 shows the behaviour of some key flight parameters for a Dash8-Q400 turboprop airplane, in particular the fact that the left and right engines have different fuel flow throughout most of the departure and arrival phases.

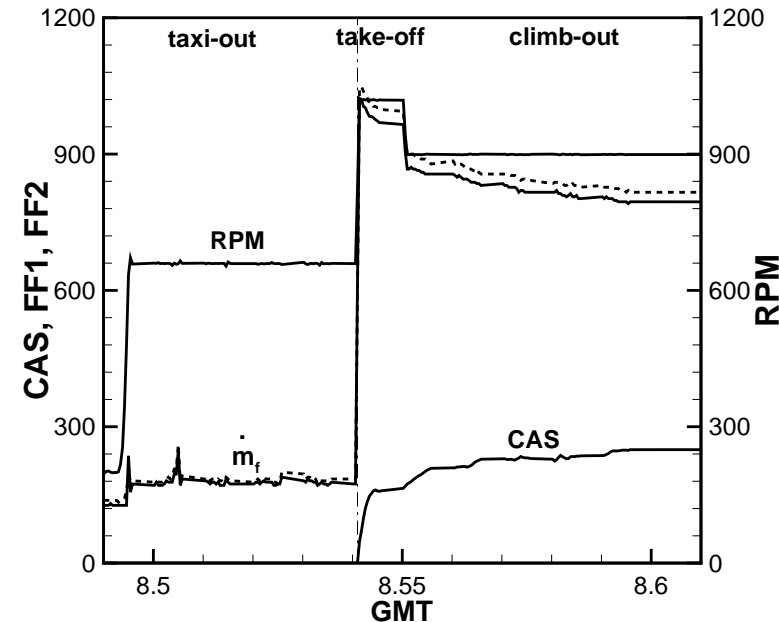

(a) Departure

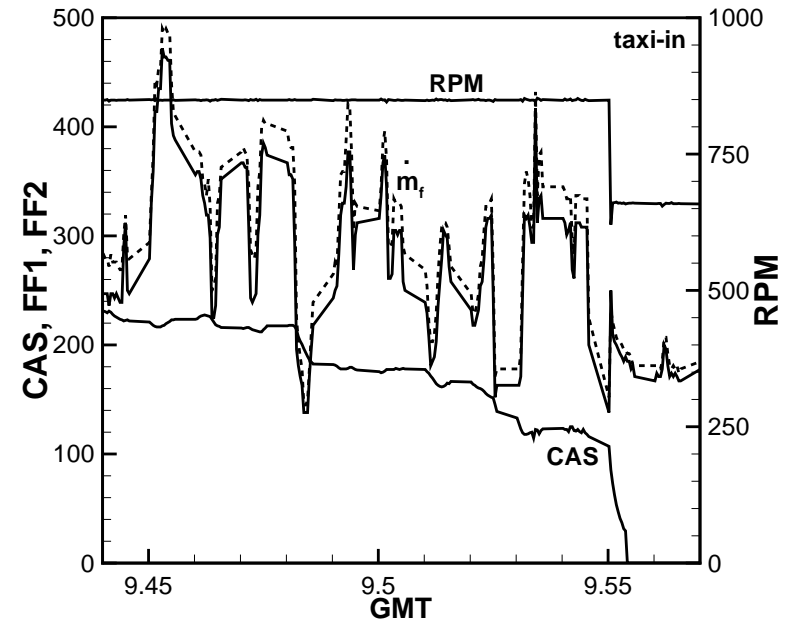

(b) Arrival

Figure 22: FDR recording of some parameters for a Bombardier Dash8-Q400; FF = fuel flow.

\subsection{Spectral Analysis}

Next, we show examples of spectral analysis. We compare the measured SPL in $1 / 3$ octave band frequencies with the predictions with the FLIGHT program. The airplane is the Bombardier Q400, powered by a PW-150A turboprop gas turbine engine and Dowty R408 propellers. 
Measurements were obtained with a Brüel \& Kjær 2250 SLM. The equipment was mounted on a tripod, with the microphone positioned at a height of $1.2 \mathrm{~m}$ above ground level, parallel to the ground, with the diaphragm of the microphone positioned approximately parallel to the flight path to minimise directivity effects. The measurements were taken manually. Measured values were logged with a time increment of $1 \mathrm{~s}$, using a $1 \mathrm{~s}$ integration time. For each time increment both broadband and $1 / 3$ octave band SPL values were stored.

Table 3: Measurement locations of fly-over flights of the Dash8 turboprop airplane.

\begin{tabular}{ccccl}
\hline Position & $\begin{array}{c}\text { Lat } \\
{[\mathrm{degs}]}\end{array}$ & $\begin{array}{c}\text { Long } \\
{[\mathrm{degs}]}\end{array}$ & $\begin{array}{c}\mathrm{z} \\
{[\mathrm{m}]}\end{array}$ & Comments \\
\hline D1 & 53.32696 & -2.32098 & 55 & End of runway 2; grassland surrounded by farms \\
L1 & 53.38180 & -2.21681 & 62 & Parkland, grassland; close to busy highway \\
L2 & 53.37219 & -2.23798 & 67 & As above \\
\hline
\end{tabular}

Measurements were taken at three separate locations (Table 3) over two days. Departure measurements were taken from the same location at the end of the runway $2(23 \mathrm{~L} / 05 \mathrm{R})$ landing/takeoff lights. During the takeoff measurements, aircraft were westbound, taking off from runway 1 (23R) on day 1 and from runway 2 (23L) on day 2. The landing measurements were taken at two separate locations, L1 and L2, taken on day 1 and day 2, respectively. For all landing measurements, the aircraft arrived from the east and landed on runway 1 (23R). The altitude of the microphone at each location is the altitude above mean sea level estimated from a ground level height obtained from Google Earth.

Figure 23 shows the contributions of some noise sources on departure and arrival trajectories, at the microphones specified in Table 3 , in $1 / 3$ octave band frequencies, at one point in the flight trajectory. The simulated overall noise levels are consistent with the measured data; they also highlight some important differences at low- to medium frequencies. The tonal components due to the propeller blade passing frequency is well predicted on departure, less so on arrival.

Figure 24 shows the comparison between measurements and predictions for a landing trajectory at microphone L1 at frequencies $250-8,000 \mathrm{~Hz}$. The background noise has a spectrum similar to the one shown in Figure 5, and has been added to the simulation. The background noise does not have any effect on the SPL peaks, which are onlly dependent on the propeller noise. The over- and under-prediction depends on the frequency. A combination of factors may be responsible for this discrepancy, not least the accuracy of the propeller geometry, Figure 12. 


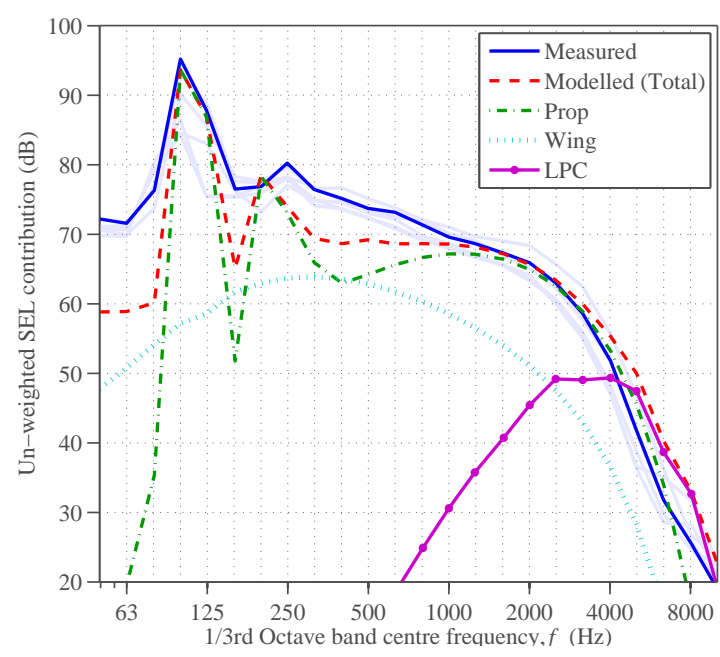

(a) Departure

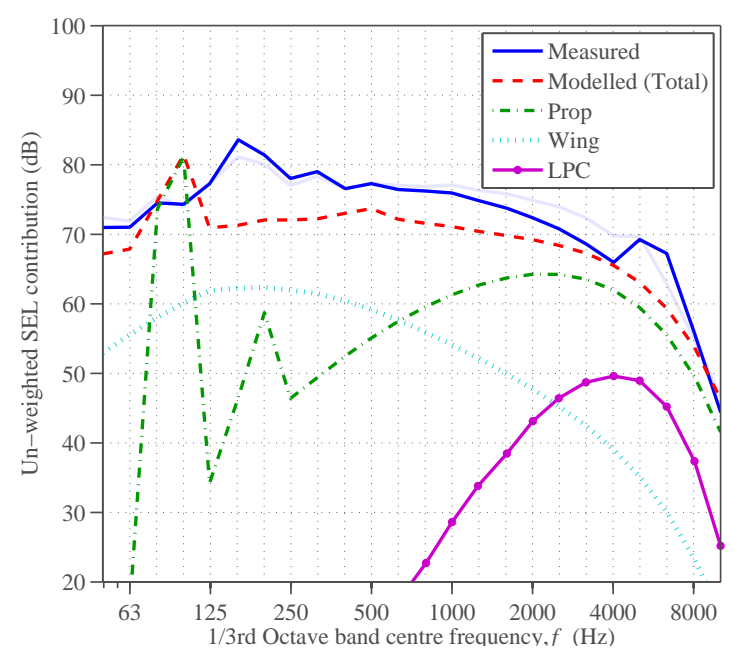

(b) Arrival

Figure 23: Comparison between simulated and measured noise levels on departure and arrival trajectories of the Bombardier Dash8-Q400, adapted from Ref. ${ }^{278}$. 


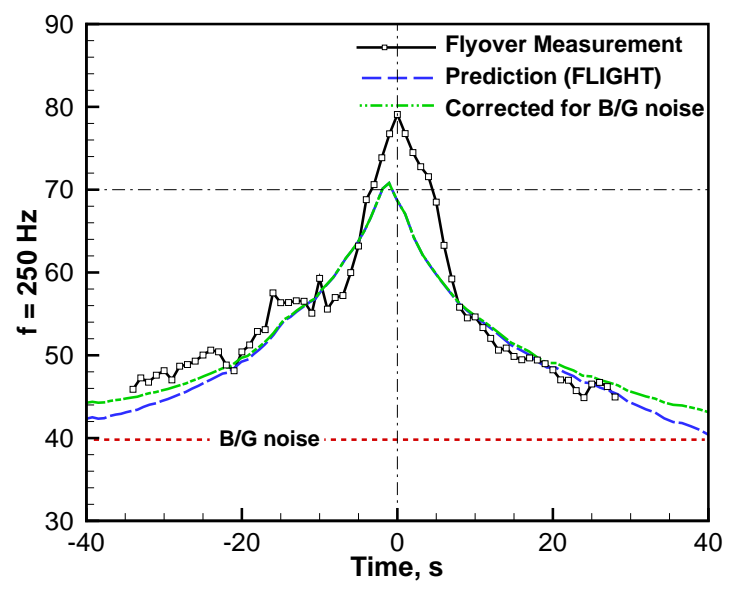

(a) $250 \mathrm{~Hz}$

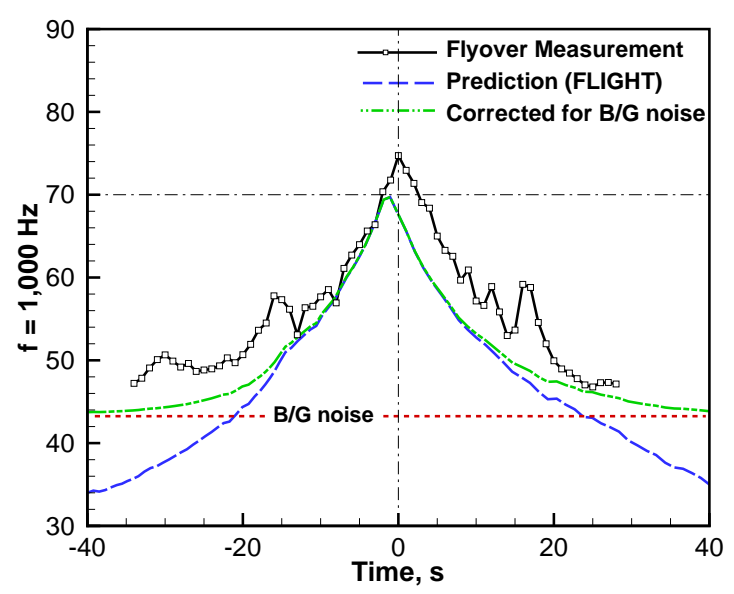

(c) $1,000 \mathrm{~Hz}$

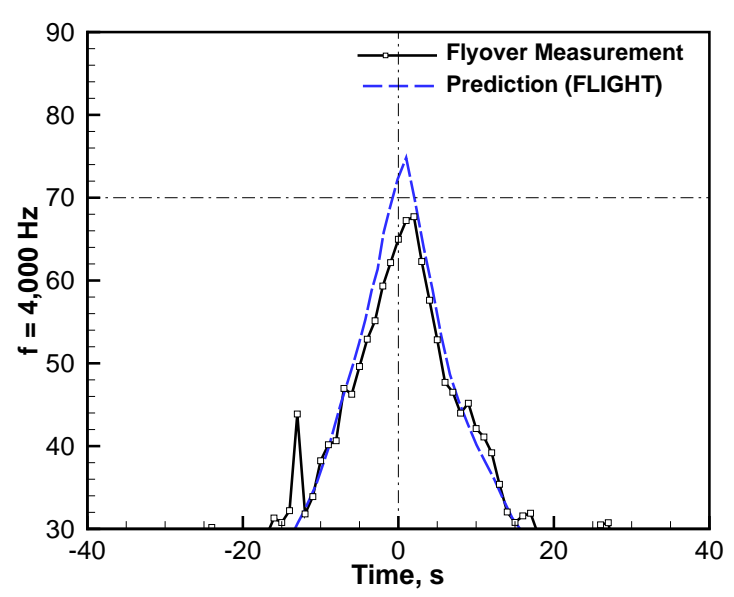

(e) $4,000 \mathrm{~Hz}$

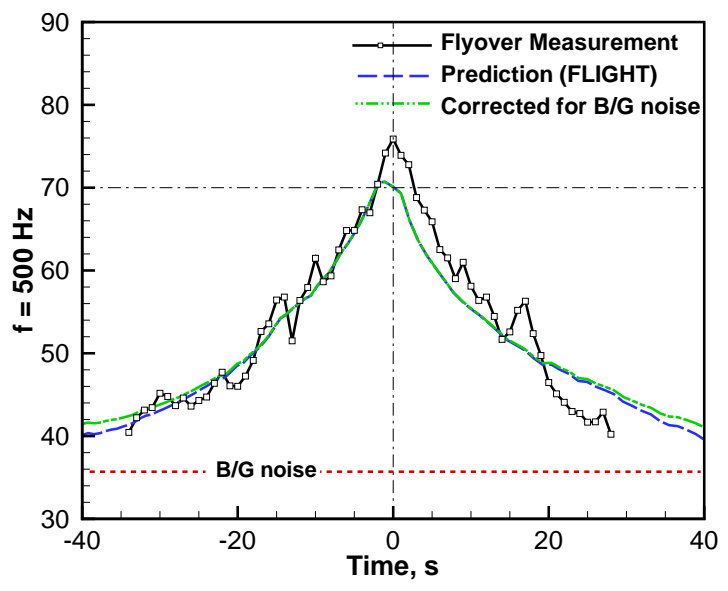

(b) $500 \mathrm{~Hz}$

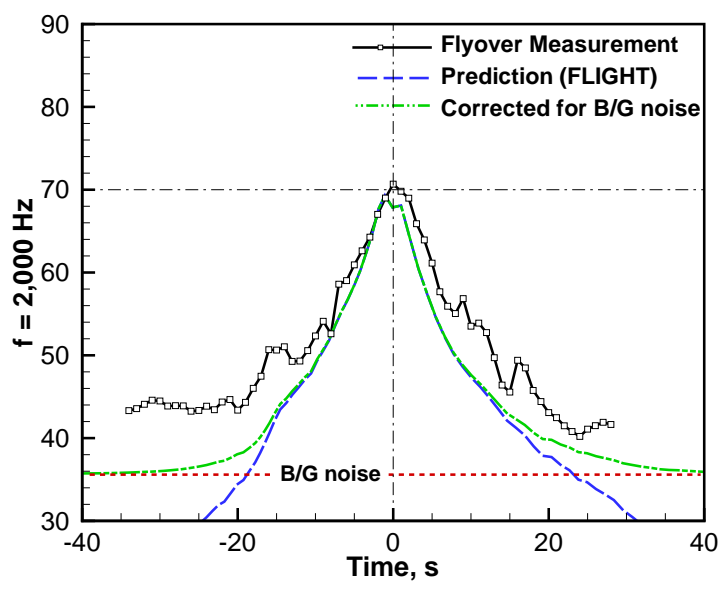

(d) $2,000 \mathrm{~Hz}$

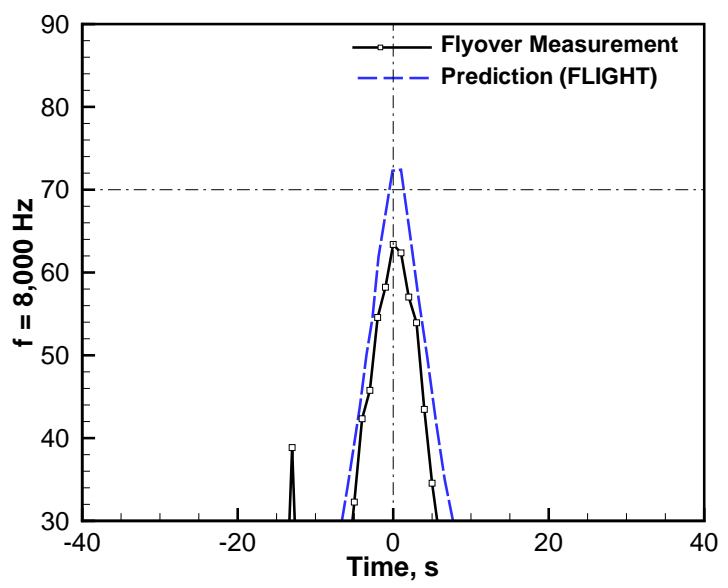

(f) $8,000 \mathrm{~Hz}$

Figure 24: Spectral analysis of the noise of a Dash8 turboprop airplane landing at Manchester airport. 


\subsection{Fly-over Trajectories}

A further comparison of fly-over noise is shown for the Airbus A319-100. Figure 25 shows the ground track of the arrival and departure trajectories (adapted from Ref. ${ }^{279}$ ). Selected microphones are shown on both the arrival and departure side. The original data sets were taken as part of a German national project on aircraft noise ${ }^{270,44}$. As in the previous cases, there is some uncertainty in the ground track, with the airplane apparently moving sideways by at least one wing span.

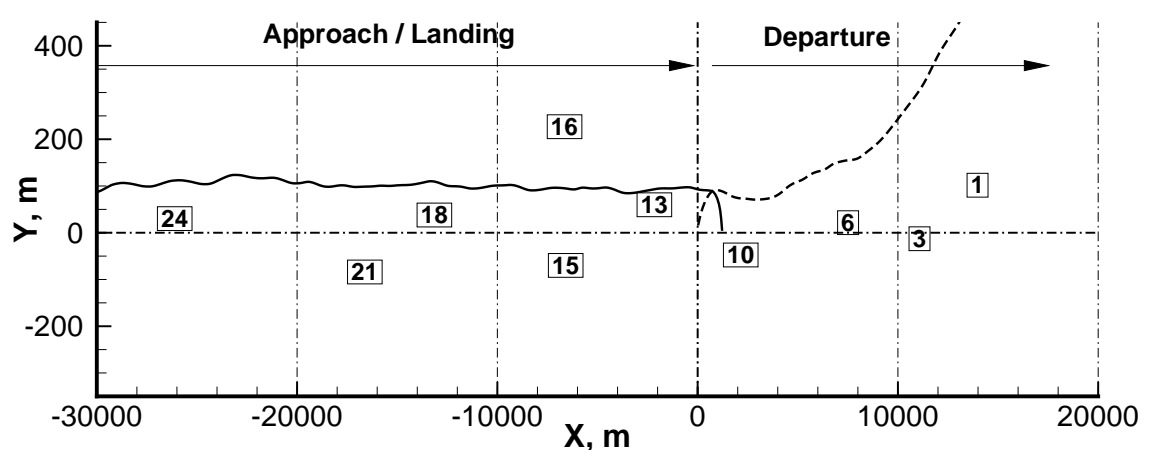

Figure 25: FDR track of an Airbus A319-100 arriving and departing ${ }^{270,279}$.

Figure 26 shows a comparison between the measured data and the predictions obtained with the FLIGHT code at selected microphones placed roughly under the flight path. Whilst the peak OASPL is generally well predicted, there are notable differences when the aircraft is several seconds away from the microphone. This is likely due to a noise propagation problem. 


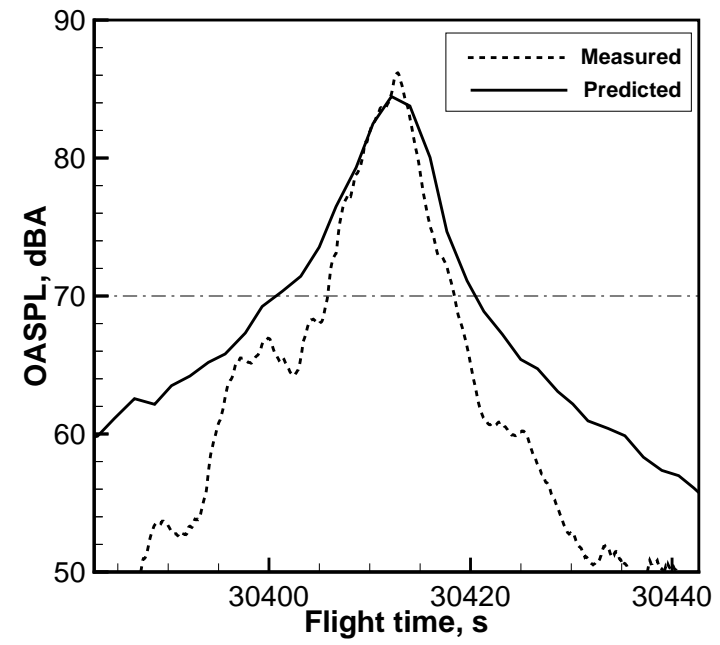

(a) Mic 13

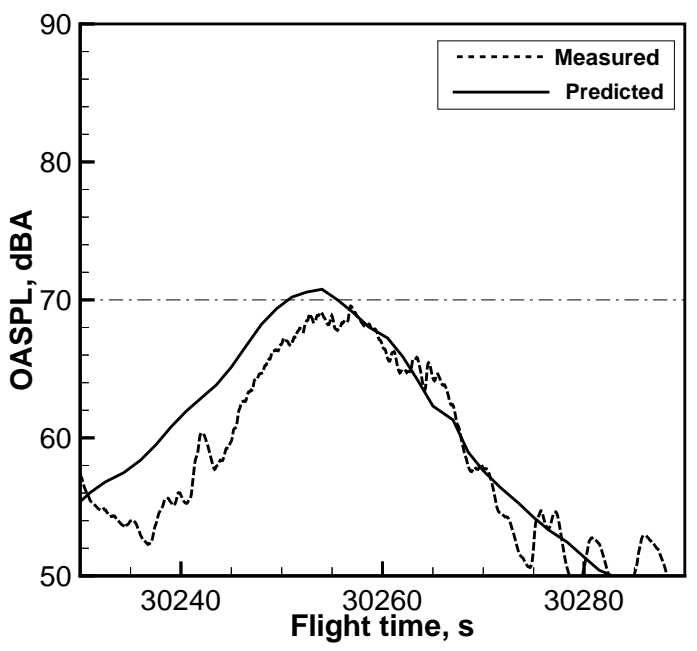

(c) Mic 18

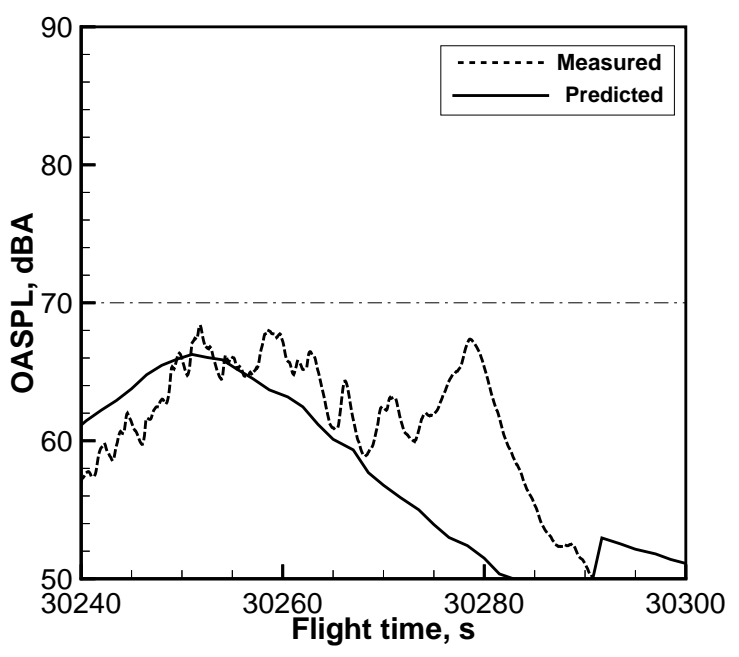

(e) Mic 17

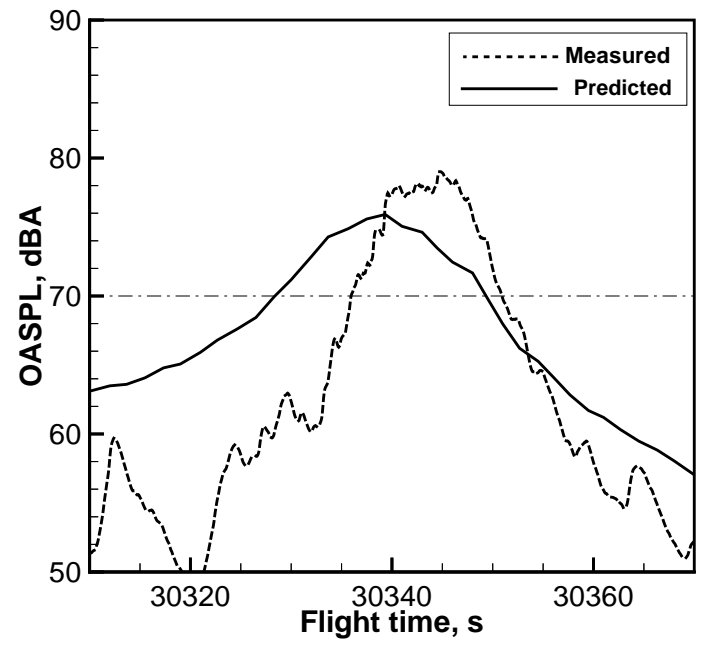

(b) Mic 15

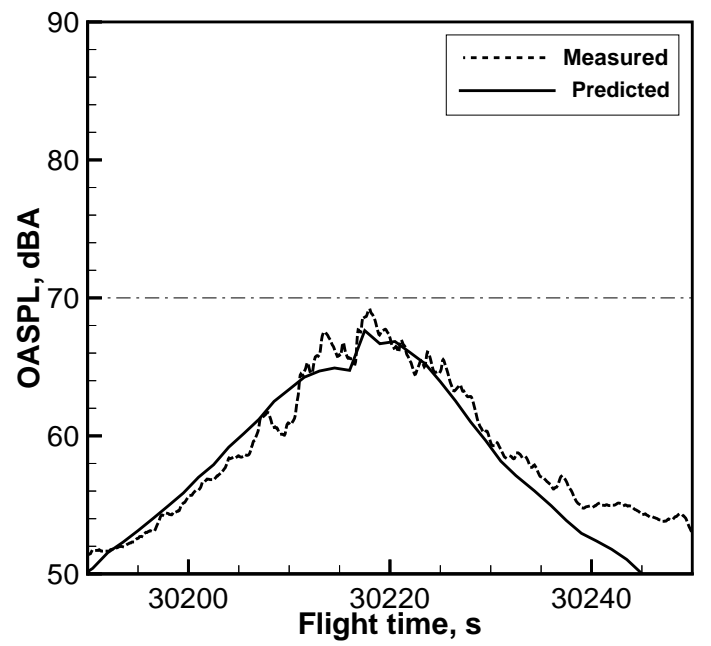

(d) Mic 21

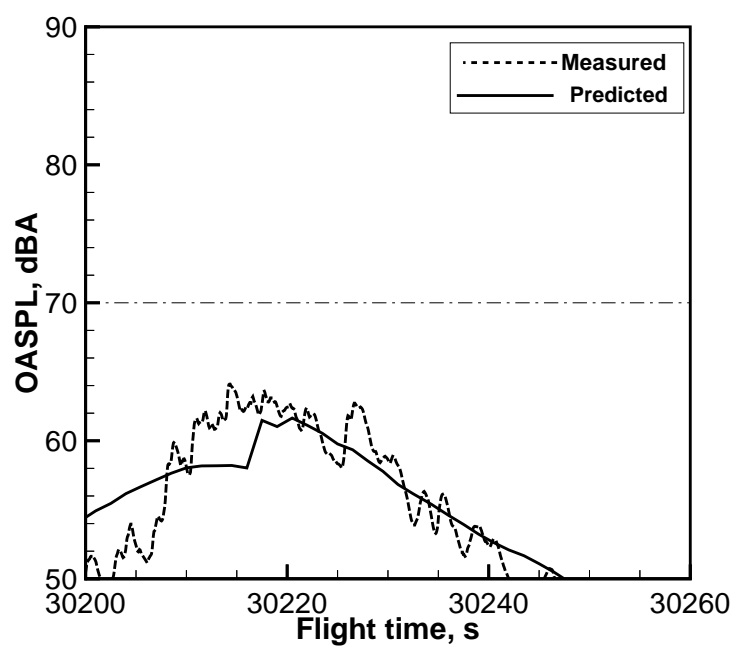

(f) Mic 20

Figure 26: Comparison between measured and predicted sound pressure level for a landing trajectory; sideline microphones. 


\subsection{Noise Directivities}

Aircraft noise is not limited to airborne vehicles. Ground noise has been a source of concern for some time, and regulations are in place for the use of the APU and other systems. A key contribution in this area is represented by Pott-Pollenske et al. ${ }^{196}$ Aircraft manufacturers provide data with engine noise directivity measured with the aircraft on the ground, at idle or take-off throttle setting.

Figure 27 shows a comparison between the directivity calculate by the FLIGHT program and reference data extracted from the airplane airport planning manual. The circle containing the microphones has a radius of $60 \mathrm{~m}$ centred at a reference point on the symmetry place forward of the wing emergency exit doors; the microphones are placed at a hight of $1.2 \mathrm{~m}$ above the ground at The conditions, as specified by Airbus*, include: engine speed $N_{1}=87 \%$, with both engines running; APU off; environmental conditioning system off; negligible wind speed; temperature $\mathcal{T}=22{ }^{\circ} \mathrm{C} ; p_{\text {air }}=1,016 \mathrm{hPa}$. We have assumed dry tarmac for the ground model. The main discrepancy appears at emission angles between 45 and 70 degrees on either side of the symmetry. Noise shielding is not properly modelled at these points (see also Figure 13).

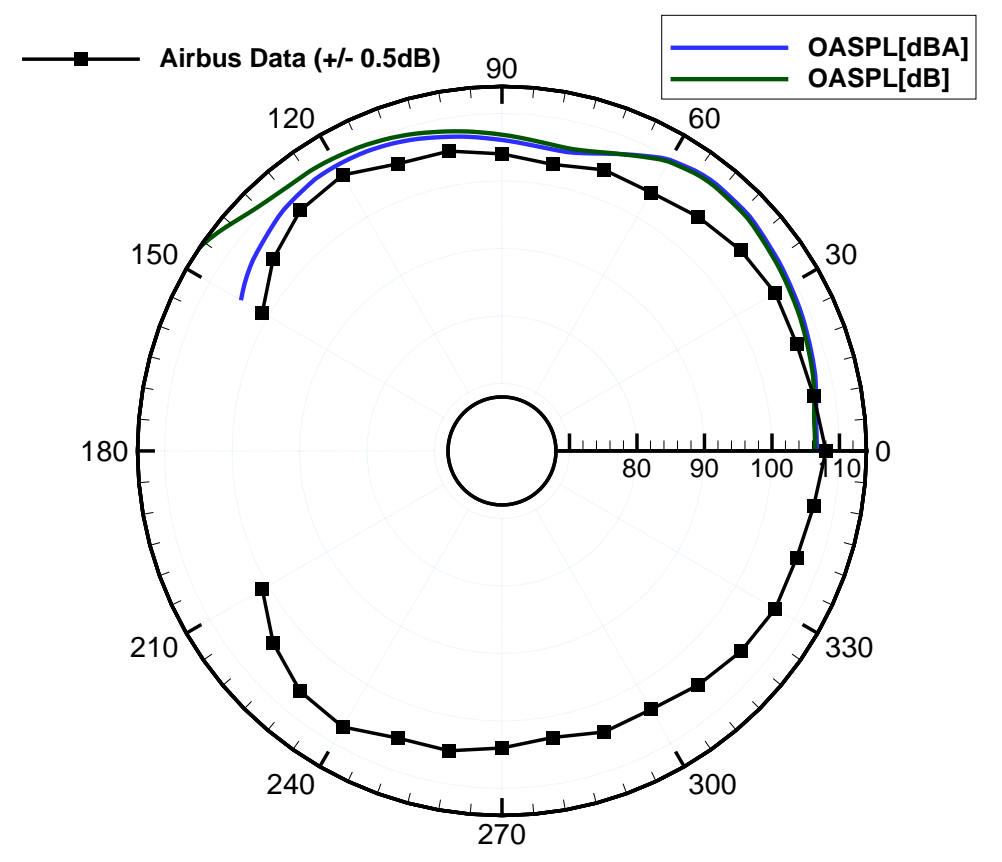

Figure 27: Comparison between computed and reference engine directivity for an Airbus A319-100 on the ground. Reference data from Airbus.

\footnotetext{
*Airbus: A319 Aircraft Characteristics, page 6-2-1, Airbus S.a.S, Blagnac Cedex, France, June 2012.
} 


\subsection{Noise Footprints}

Noise footprints are a series of contours traced on the ground and corresponding to one or more noise isolevel. These footprints are essential in the determination of the actual noise annoyance over longer periods of time, and involve stake-holders at several levels, including those involved in flight planning, airport management and expansion, noise zoning, local communities ${ }^{3,62}$. Data for airports such as London Heathrow are particularly critical for regulatory reasons. It is estimated that the number of people within the same noise contour levels has decreased from about 2 million in the 1970 s to about 250,000 at the present time*. This is no consolation for those still affected; people want to know if they are within or outside a certain contour level; night-time contours are more critical, as aircraft noise is far less tolerable, as discussed. Footprints are published by aircraft manufacturers for specific airplanes, not all of which in a scientific format. A standard has seemingly not emerged; often these footprints lack grid scales, noise levels and even noise metrics. Therefore, comparisons with simulated data of a single aircraft are difficult at best. The noise maps produced on a regular basis by airports and aviation organisations are an exception, as they clearly specify the noise metrics $\left(L_{e q}, L_{d e n}, L_{d a y}\right)$ over topographic maps.

The determination of such isolevels requires first a decision as to which noise metric is appropriate. One such metric is the "equivalent noise level", $L_{A e q T}$. Since this metric corresponds to multiple aircraft movements, the curves are statistically regressed over a fixed period of time. For an accurate contour level, a high number of microphones is required, something which is not possible in most instances. Therefore, there is the problem of refining and extrapolating contours in certain areas. Various numerical algorithms exist for this purpose. Both $\mathrm{INM}^{59}$ and $\mathrm{ANCON}^{64}$ provide such contours for cases as complicated as multiple runways in different directions. The noise contours obtained for the equivalent noise level can be extended to several other metrics, such as EPNL, SEL, $L_{A_{\max }}$, SPL $\max$.

Best resolutions for noise contours are about $150 \mathrm{~m}$. To calculate a full carpet, about 4,000 microphones would be required. This is clearly impossible in practice, and extremely demanding from a computational point of view. This limitation is overcome by using a moderately coarse grid; the resolution is then improved by recursive refinement. This is straightforward if the grid is block-structured. The noise metric is interpolated by using cubic splines.

\footnotetext{
*Information available from the London Heathrow website.
} 
To illustrate the features of these footprints, Figure 28 shows the computed contours due to multiple aircraft movements. The noise metric in this case is instantaneous the OASPL, which can be tracked in the time domain to provide varying noise levels.

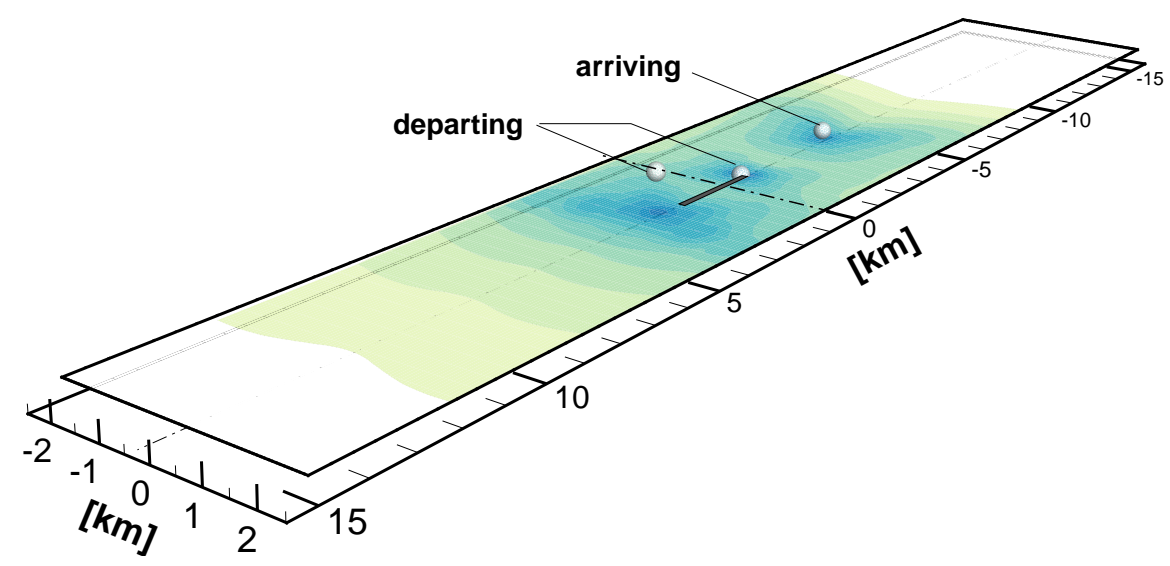

Figure 28: Multiple movements (arrival/departures) of a Boeing B737-800.

Figure 29 shows the predicted effects of atmospheric winds on the noise footprint of a Boeing B787-800 on arrival/landing.

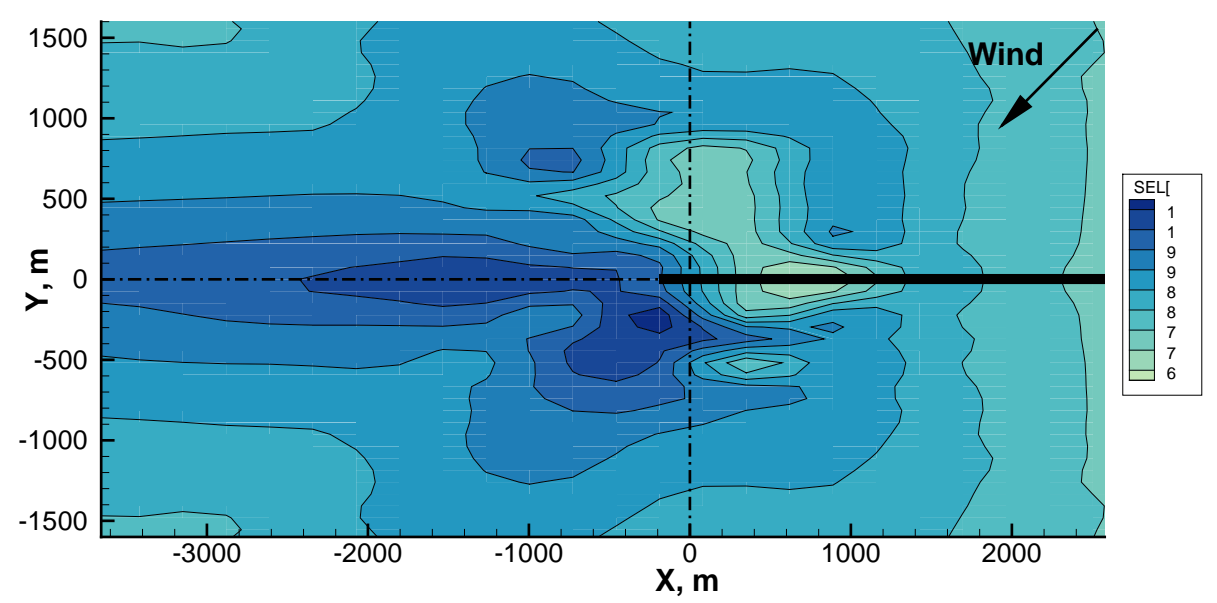

Figure 29: Noise contours on a landing trajectory of a Boeing B787-800 model with a 45-degree wind.

\subsection{The Need for Validation Standards}

Validation exercises in the field of computational aero-acoustics are plentiful. By contrast, validation of numerical methods for aircraft noise are mediocre, and lacking scientific rigour in most cases. There are two fundamental reasons for this. First, is the lack of reliable data, 
interpreted as noise measurements at an airfield (fly-over). Second, the numerical methods used in aircraft noise, as we have seen, are often lacking a scientific basis on their own, and suffer from lack of details of the aircraft system. Ref. ${ }^{3}$ reports some goals for validation and in particular some "Performance Criteria" aimed at reliability, consistency, accuracy and other criteria, none of which can currently be fully guaranteed with any scientific method.

Figure 30 shows the process required for the validation and verification of an aircraft noise model. The comprehensive model is several layers deep; thus, a scientific validation process is required.

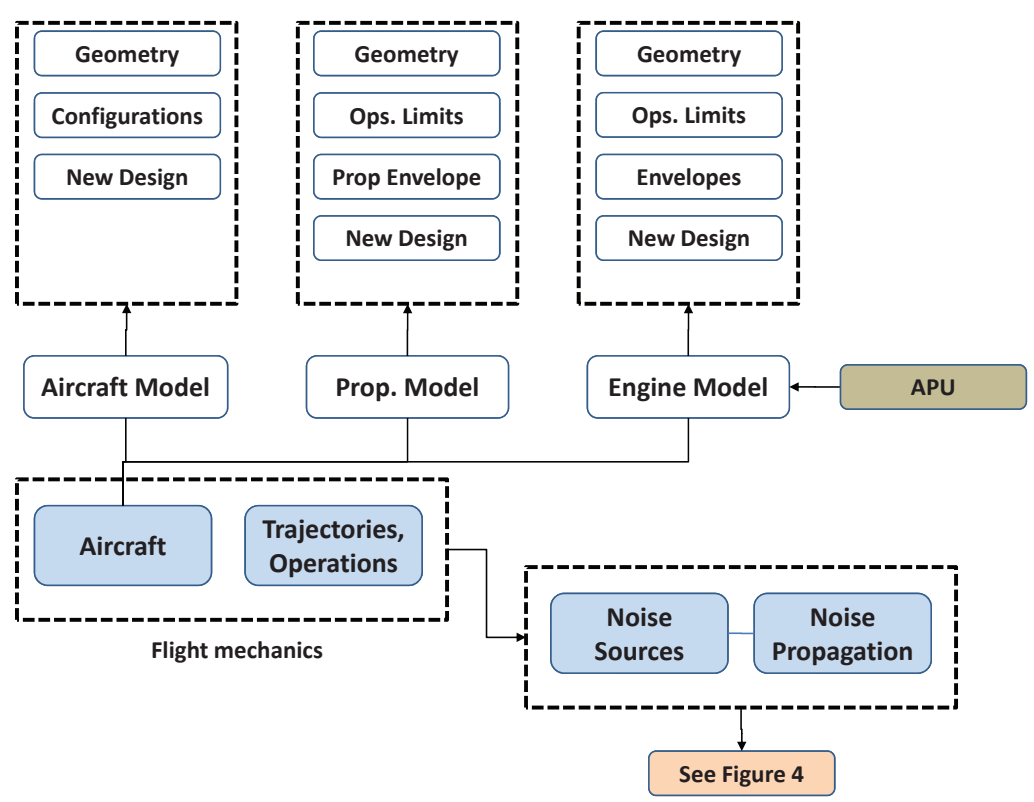

Figure 30: Flowchart of validation process for aircraft noise model.

The process starts with the development of an airplane model, which includes the full geometry, the mass properties, the set of configuration changes (flap and slat positions), and eventually a set of alternative designs. Likewise, the engine-propulsion model consists of engine limitations, configuration details and a full set of flight envelopes. These sub-models must be integrated into a flight mechanics framework and independently validated. In other words, the airframe-engine integration should be able to generate realistic flight trajectories in most conditions.

If the engine is powered by a propeller, then there is a need for a development of a propeller model, including detailed geometry (Figure 12), operating limitations and flight envelopes. The propeller is trimmed at the requested operation point in the flight mechanics module. 
Once these verifications are done, testing of the noise model can begin. At the basic level, validation and verification is done on each single component, whenever data exist; if reference data do exist, they are generally limited to few operation points; therefore, extrapolation to new flight conditions is required. For such extension the data are non-existent. At the top level, all the noise sources operate on the aircraft system and generate rather complex acoustic pressures over the full spectrum of frequencies. One of the key aspects of this validation process is that any discrepancy with reliable reference data cannot be solely attributed to shortcomings of the noise models. In all but a few cases, the interest is on noise received at ground locations.

With regards to the "Engine Model" in Figure 30, there is no rational validation process for a modern turbofan engine, and less so for a turboprop engine. The data available from the manufacturer are too sparse to be considered reliable. Additional data are available from the ICAO Data Bank ${ }^{\ddagger}$, although these are currently limited to turbofan only. At the very least, data required include the following: mass flow rate, fuel flow rate, overall pressure ratio, gas turbine temperature at the design condition $M=0, z=0$, standard day. Other data can be inferred.

\subsection{Systems Analysis}

One the key aspects in the determination of aircraft noise, with either experimental or numerical methods, centers around handling uncertainties in a multidisciplinary system ${ }^{280}$. With reference to numerical methods only, the approach used by FLIGHT in these circumstances is a statistical analysis. A similar method has been used with ANOPP ${ }^{281}$. Guidelines for verification and validation have been published in recent years on the back of rapid progress in the application of computational fluid dynamics (CFD) to increasingly complex problems ${ }^{282}$. These guidelines apply to the matter discussed in this paper. The relevant technical literature provides the following definitions:

- Verification: this is the process by which a physical-mathematical model has been correctly translated into a computer program. This process includes the so-called debugging process, which has long been recognised as non trivial.

- Validation: this is the process aimed at demonstrating that the output of the computer program compares favourably with a set of reliable experimental data. Since these data are

\footnotetext{
${ }^{\ddagger}$ ICAO Engine Emissions Data Bank, periodically updated; available from the ICAO and other Internet sites. Key word: "ICAO emissions databank".
} 
most likely to be limited to a small set of operational conditions, with uncertainty of their own, the use of the computer program to cases beyond the matrix of the experimental data cannot be fully validated.

During the validation process we have to deal with a series of uncertainties and unknown quantities. Both can contribute to poor results, independently of the sophistication of the numerical methods. A formal approach to the understanding and handling of uncertainties in multidisciplinary aircraft system was proposed in Ref. ${ }^{280}$ In brief, the uncertainties in the aircraft noise system can be classified as follows:

1. Geometrical configuration of aircraft components; specifically, dimensions, positions and settings of the key components used in the airframe noise models. For example, in the case of high-lift systems, we need accurate position, angles, span, chord, others).

2. Geometrical configuration of engine components, including most rotor blades diameters and chords, rotor-stator clearances.

3. Geometrical configuration of propellers (for turboprop aircraft), including chord distribution, blade sections, sweep angles (see Figure 12).

4. Aero-thermodynamic parameters of the engines at the specified flight condition as a result of the engine model being a surrogate of the actual engine (see sub-parameters $N_{1} \%$ and $\dot{m}_{f}$ in Eq. 21; list in Table 2).

5. Flight trajectory: aircraft position, air speed, pitch attitude (sub-vectors $\boldsymbol{X}, \boldsymbol{V}$ in Eq. 21), as a result of the inaccuracy in GPS data and other FDR digital data (Figure 20).

6. Atmospheric and external conditions: atmospheric data (parameters in Eq. 21), ground properties (for ground reflection), due to stochastic variability even on a short time scale.

All these uncertainties (known unknowns) are taken into account. We use the basic methods of statistics to define the mean computed result $\bar{R}_{c}$, the standard deviation $\sigma$ and other quantities.

System or sensitivity analysis is used to identify the various sources of noise at different flight conditions. Acoustic signals are expressed in log-scale metrics; as such, these metrics are less sensitive to changes in the energy content of received noise - a doubling of acoustic energy increases the SPL by $3 \mathrm{~dB}$, or about $3-5 \%$ of typical maximum SPL at airport certification points. Thus, the overall sound level of multiple sources would likely be determined by the most dominant ones only, diluting the impact of the remaining sources. 
Generalising from Eq. 1, assume an overall sound level $L$, where $L$ is the sum of $n$ noise levels $L_{i}$ (all at the same frequency):

$$
L=10 \log _{10}\left(\sum_{i=1}^{n} 10^{L_{i}}\right)
$$

The sensitivity due to perturbations $d L_{i}$ on the sound levels $L_{i}$ of $n$ contributing components can be written as

$$
L+d L=10 \log _{10}\left(\sum_{i}^{n} 10^{\left(L_{i}+d L_{i}\right) / 10}\right)
$$

It is possible to show from Eq. 23 that the effect of an individual component towards the overall perturbation $d L$ is negligible, unless the perturbed component is within $10 \mathrm{~dB}$ from the maximum contribution.

Sensitivity analysis is performed here to determine such components and to quantify the extent of which the remaining components contribute to the overall EPNL. To illustrate this effect, Figure 31 shows the effects of some design, operational and external parameters on the predicted noise metrics of a Boeing B737-800 during a conventional approach, with a glide slope of 3 degrees; the microphone is at the standard ICAO/FAR reference point (Figure 3). The different categories of parameters are indicated on top of the graph. By far, the largest effect is due to temperature differences cross the fan (parameter number 1); this result underscores the importance of a reliable engine model, as long as the noise model depends on temperature changes and mass flow rates across the fan. Also important are uncertainties in the aircraft position (in this case $\pm 5 \mathrm{~m}$ on the ground track, $\pm 2 \mathrm{~m}$ on the altitude) and true air speed $( \pm 2 \mathrm{~m} / \mathrm{s})$.

Table 4: System sensitivity analysis on noise metrics for a Boeing 737-800 on approach. Data are: average, mean, standard deviation, variance. See also data in Figure 31.

\begin{tabular}{lrrcc}
\hline Metrics & Ave & Adev & $\sigma$ & Var \\
\hline EPNL & 94.73 & 0.23083 & 0.62138 & 0.38611 \\
SEL & 89.24 & 0.17046 & 0.56839 & 0.32307 \\
LAeqT & 65.06 & 0.18363 & 0.56598 & 0.32033 \\
PNLTM & 101.81 & 0.31412 & 0.70154 & 0.49216 \\
L $_{A_{\max }}$ & 86.04 & 0.33800 & 0.74016 & 0.54783 \\
max SPL & 87.69 & 0.31403 & 0.65686 & 0.43147 \\
\hline
\end{tabular}

For the Q400 airplane model on approach (Figure 24), we plot in Figure 32 the bar chart in terms of EPNL contributions, along with the estimated uncertainty on the main contributions. 


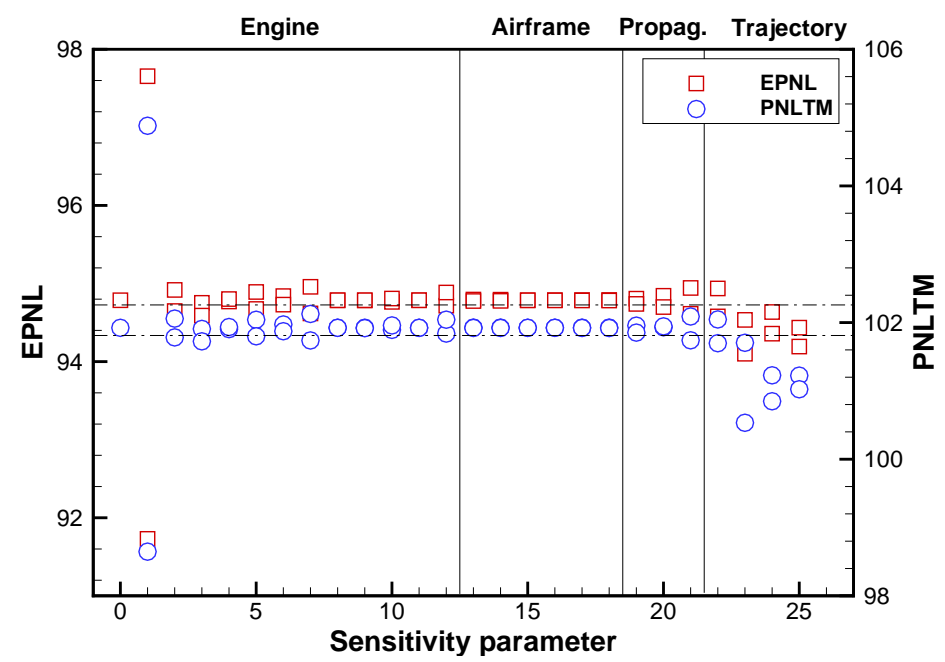

Figure 31: System sensitivity analysis on noise metrics for a Boeing 737-800 on approach.

The results indicate that in this instance the contribution of the propellers is critical.

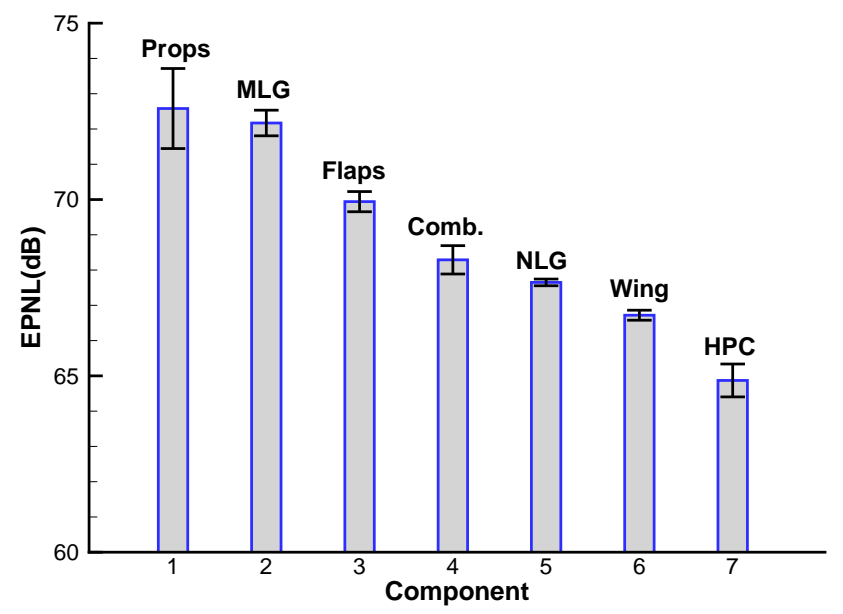

Figure 32: Bar chart of noise contributions at landing for the Q400 turboprop airplane.

A more rational approach to sensitivity analysis using the design of experiments ${ }^{283}$ has not yet been attempted. However, several investigations carried out from the mix of uncertain parameters have convinced us that system complexity seldom works, as it often reduces validity. Combinations of simple parameters in a reduced model often fare better, although one is naturally inclined to discard the latter in favour of the former. The sensitivity and associated noise component analyses show that the noise from an aircraft, as measured at a take-off or landing event, is contributed by a small number of dominant components. 


\subsection{Code-to-Code Comparisons}

The comparison between aircraft prediction methods is still at its infancy. This is due to lack of validation standards and the limited availability of comprehensive models. A code-tocode comparison between FLIGHT the German PANAM code was shown in Ref. ${ }^{279}$ This exercise highlighted issues of disagreement at several levels, due to a combination of reasons, not least because of different engine models, different ground reflection model, and different shielding models.

To support the need for this type of validation, a comparison between FLIGHT and ANOPP2 is shown in Figure 33 for an approach trajectory of the Boeing B737-800 with CFM56-7B27 turbofan engines. As in the case of ANOPP2, all the data for the aircraft and the engine are extracted from documents in the open domain, following the procedures described in Ref. ${ }^{58}$ The flight time is calculated differently, therefore there are two different scales; the time frame is the same. Two results are shown for the ANOPP2 case, interpolated from Ref. ${ }^{32}$ : one with ANOPP2 airframe models and the other with Boeing airframe models. There is little difference in maximum PNLT, although in the present case oscillations in the SPL and PNLT occur due to ground reflection. The comparison of EPNL is good: $95.73 \mathrm{~dB}$ (FLIGHT, see data on Table 4), with a standard deviation $\sigma=0.62 \mathrm{~dB}$. For the reference case, we have $95.55 \mathrm{~dB}$ (ANOPP2), $95.89 \mathrm{~dB}$ for ANOPP2/Boeing. The differences between these predictions are $<0.5 \mathrm{~dB}$. The details of each model and several assumptions cannot be assessed, therefore we cannot examine the discrepancy in any further detail.

\section{Perspectives in Noise Reduction}

Further substantial noise reduction is required on all areas of technology if aviation can be allowed to expand. In this section we discuss a number of state-of-the-art problems that need a step-change in knowledge to make this noise reduction possible. We discuss the possibilities offered by airframe shielding of propulsive noise and the physical limits to aircraft noise.

To begin with, we must assess what technology goals can be realistically achieved. For example, a virtual elimination of noise complaints can be achieved if the noise is limited to the airport property. However, it is essential to agree on the noise metric to consider. There are also indications that the number of noise complaints voiced depend on the relative wealth of those concerned. 


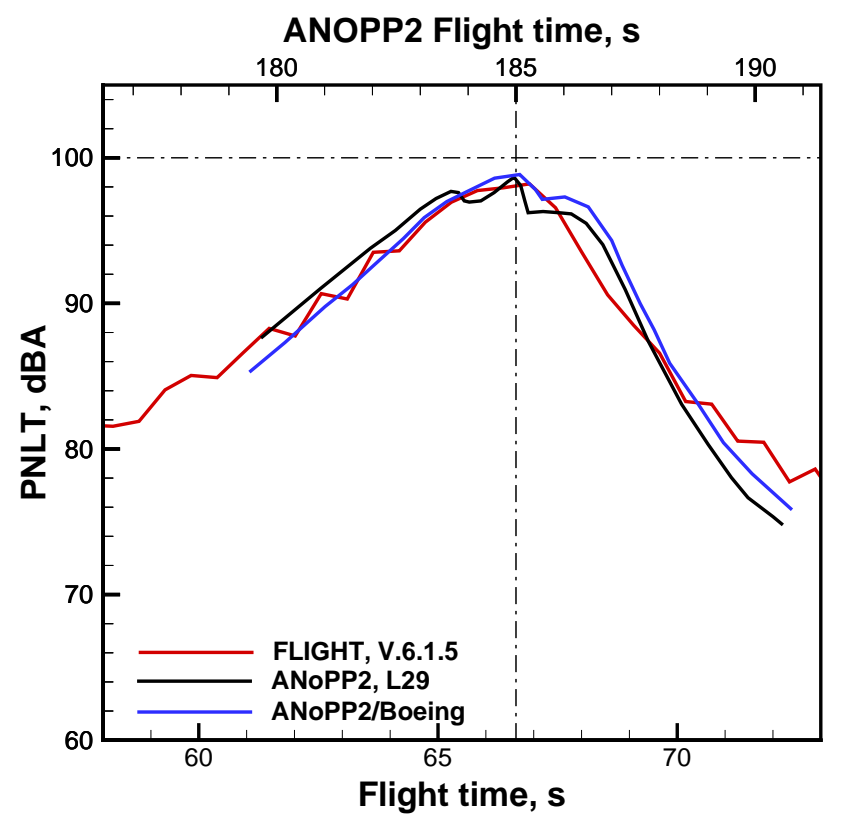

Figure 33: Simulated landing trajectory of the Boeing B737-800 aircraft model. Comparison of predictions for PNLT predictions between FLIGHT and ANOPP2 $2^{32}$.

\subsection{Noise Trajectory Optimisation}

The options around trajectories optimisation depends on constraints at several levels, including avoidance of built-up areas (if possible), of topographical details (land and water distribution, hills), safety requirements and air traffic control requirements. In this context, the integration between flight mechanics, engine performance and acoustic sources is required. Since aircraft noise certification is essential to maintain the aircraft in service, the first line of investigation focusses on the standard ICAO measuring stations on approach and on the departure, Figure 3. On approach there is limited flexibility, since the minimum aircraft-receiver distance is $\sim 120 \mathrm{~m}$ with a conventional trajectory with a glide slope of three-degrees. The effects of distance on noise propagation are also limited, with exception for those cases where extreme atmospheric conditions intervene. On departure, instead, there is some degree of flexibility, which is the result of a relative large aircraft-receiver distance (several hundred metres), and turning away from the ground receivers.

Low-Noise Trajectories. Several standard or quasi standard procedures already exist to limit noise emissions on departure. These procedures are described as Noise Abatement Departure 
Procedures (NADP). Without going into details, which can be found in the technical literature*, these procedures consist of a sequence of steps with regards with thrust settings, climb angles, speed level, accelerations and aircraft configurations (flap retraction). Two procedures exist, called NADP1 and NADP2, and several variations thereof.

Other standard low-noise departure trajectories include the ICAO-A procedure. In this case, the aircraft accelerates from take-off speed $V_{2}$ to a speed $V_{2}+20 \mathrm{kt}$; at 1,500 feet $(457 \mathrm{~m})$ above ground level (AGL) there is a reduction in thrust, and the aircraft climbs further to 3,000 feet $(914 \mathrm{~m})$ AGL at constant air speed; beyond this point the aircraft accelerates. On the approach side, in recent years there has been interest in continuous descent approach (CDA). This is a procedure where the aircraft descends continuously to minimize landing time, engine emissions and community noise. The CDA is a flight path in which the aircraft joins the final ILS (Instrument Landing System) glide path at an appropriate altitude for the distance from the runway. The point at which the ILS glide slope is joined can be higher than the conventional flight path. An example of this maneuver is given by Amsterdam Schipol ${ }^{284}$, where it has been shown a noise reduction due to lower fan speed.

Flight trials have been carried out at a number of airports around the world, but this practice is not yet widespread, as it is aimed first at increasing traffic capacity. Noise abatement with this procedure is not well-defined, as estimates range from $-2 \mathrm{~dB}$ EPNL to $-5 \mathrm{~dB}$ EPNL. Finally, there are procedures aimed at flight track dispersion and noise-preferred runways (so called spatial management), to limit the DNL and other annoyance metrics. On the ground, there is restriction on using reverse thrust, which in any case is not allowed for certification purposes; furthermore, there is restriction on APU use and other forms of ground management. All these procedures are aimed at getting the most benefits with existing technology and rely on operational practices at each individual airfield.

The work of Visser \& Wjinen ${ }^{285,286}$ deals with the optimisation of departure and arrival procedures from a heavily constrained airfield. The noise model used was INM and included a geographic information system as the basis for a dynamic trajectory optimisation model. Prats et $a l .{ }^{287}$ used INM $^{59}$ as a noise prediction tool; their optimisation technique was based an optimum control problem whose cost function is the deviation of noise annoyance on a specified region

\footnotetext{
${ }^{*}$ See proceedings of the Committee on Aviation Environmental Protection (CAEP), annual meeting proceedings, in particular Doc. 8983, CAEP6, Appendix J, Montreal, Feb. 2006.
} 
around an airport. Prior to that work, Clarke ${ }^{288}$ developed a tool for aircraft guidance and navigation (NOISIM), which again uses ANOPP as the supporting noise simulation. Ref. ${ }^{289}$ used a cost function that includes both noise (SEL, L $\left.A_{\max }\right)$ and emissions $\left(N O_{x}, C O, H C\right)$, and thus generated complex trajectories around an airport. The noise simulation was done using the method described in Ref. ${ }^{62}$.

Landing. In principle, there are two strategies that can be used to reduce community noise on the approach side: 1.) steep trajectory; 2.) touch-down displacement. The latter option would require permission and a critical analysis of increased flight safety risks.

Koenig \& Macke ${ }^{290}$ used an Airbus flight simulator, along with the best-practice noise simulation method SIMUL to determine optimal flight paths for minimum noise on approach and landing. These trajectories included low-drag-low-power, continuous descent, steep final descent and other procedures (not all feasible), which would lead to a maximum noise reduction of $-10 \mathrm{dBA}$.

Steep descents have been trialled with several aircraft and various airports around the world, and have now become practice at very few locations (for example, London City, with an approach of 5.5 degrees; Lugano, with an approach of about 6.5 degrees), with only a few aircraft types (Dornier Do 228, BAe RJ146, A318, Embraer E190). Ref. ${ }^{291}$ contends that the maximum Aweighted peak sound pressures can be reduced by as much as $6.5 \mathrm{~dB}$ by using a continuous descent approach. These procedures are still severely limited by air traffic control, flight safety and intrinsic performance limitations ${ }^{292}$.

There are other strategies that have been proposed, such as delay in landing gear deployment and a better management of the flap/slat operation. However, like in many other aspects of engineering, there are side-effects that need addressing. One such effect is the dissipation of the total energy, which is partly done by the drag caused by exposed landing gear. If energy is not dissipated by increased aerodynamic drag with conventional methods, there arises a need for additional braking systems, which themselves could add weight and noise. An alternative was proposed in Ref. ${ }^{293}$, which consists an an engine air brake. Thus, there is a need for "silent drag" devices that do not add weight to the airframe. The trade-offs between these aspects and the relationships between glide slopes, aerodynamic performance and energy balance are discussed in Ref. $^{292}$

The shift in the trajectory $(\mathrm{T})$ would imply that touch down is shifted by a distance $\Delta x$ 
downstream. This is only possible if there is enough runway length to bring the aircraft to a halt. In any case, this procedure is not contemplated in the current certification procedures. It is proposed for the SAI aircraft by Hileman et al. ${ }^{245}$ Spiral trajectories have been proposed by Bertsch et al. ${ }^{294}$, which require the aircraft to approach the airport at a relatively high altitude before performing a spiral descent along a helical flight path. Flight tests have been run with an experimental test bed at DLR and highlighted a number of shortcomings, including increased fuel consumption and flight time. Numerical optimisation has been attempted for over a decade. One typical cost function is based on sleep disturbance ${ }^{295}$ and uses a form of community annoyance ${ }^{5}$.

Optimization Examples. One of the most effective approaches to noise reduction rely on trajectory optimisation. The problem of trajectory optimisation is well established in flight mechanics, with various constraints at the start and/or at the end (initial value and boundary value problems, respectively). Various methods have been proposed, including heuristic and gradient-based methods. One of the issues that has been made clear by recent research $285,295,296,297$, is that the minimum-noise trajectories are generally not compatible with other environmental emissions. For example, it is possible that a minimum noise metrics can be achieved at the cost of increasing the flight time, and hence the fuel consumption and the exhaust emissions. Therefore, any future effort in this area will inevitable be multi-disciplinary, and must seek a compromise among conflicting requirements. Restricting the discussion to noise alone, a typical cost $J$ function is:

$$
J[t, \boldsymbol{X}(t), \boldsymbol{V}(t)]=10 \log _{10}\left(\sum_{i} 10^{L_{\operatorname{Amax}_{i}} / 10}\right)
$$

Alternative cost functions have been proposed that use Pareto optimality ${ }^{297,298}$. In particular, Ref. ${ }^{297}$ provides optimality conditions that include both noise and emissions, by defining a cost function directly related to the direct operating costs of the aircraft.

Following the verification and validation procedures discussed in this account, we are in a position to address the problem of optimal control procedures that lead to minimum noise levels at selected microphone locations. Some parametrisation is necessary, one that is at least partially compatible with the relevant regulations. This is done with the approach and landing trajectory shown in Figure 34. In this case, we have chosen four free parameters, as listed in Table 5. This is a severely constrained trajectory, in spite of the four free parameters. There can be multiple microphones for multi-objective optimisation. 


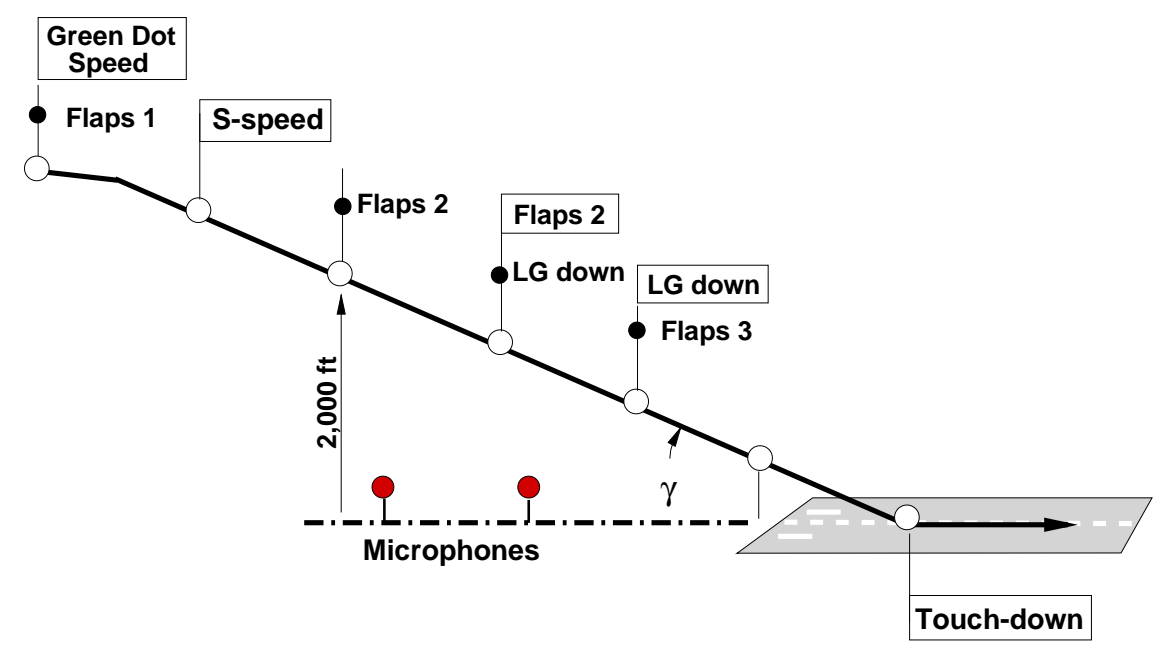

Figure 34: Typical approach and landing procedure of a commercial aircraft.

Table 5: Free flight parameters for approach/landing trajectory optimisation; see Figure 34.

\begin{tabular}{cll}
\hline Symbol & Limits & Description \\
\hline$\Delta \gamma$ & $0.0-1.5 \mathrm{deg}$ & change in glide slope of approach trajectory \\
$\Delta t_{s f}$ & $0.0-10.0 \mathrm{~s}$ & time delay for slat/flap deployment and/or switch, Figure 34 \\
$\Delta t_{l g}$ & $3.0-15.0 \mathrm{~s}$ & time delay for landing gear deployment after Flap2 has been set \\
$\Delta V$ & $-5-20 \mathrm{kt}$ & correction to approach speed during a final approach, Figure 34 \\
\hline
\end{tabular}

In this instance, the numerical optimisation has been carried out with a particle swarming optimisation, which is a heuristic model used in several other branches of science and engineering ${ }^{2}$.

A multi-objective optimisation result is shown in Figure 35 for the Airbus A320-211, where we have considered two microphones under the flight track: the first microphone is placed at the standard ICAO/FAR location (see also Fig. 3); the second one is 2 n-miles upstream. The optimised parameters are: $\Delta \gamma=1.40$ degrees; $\Delta t_{s f}=0.83 \mathrm{~s} ; \Delta t_{l g}=10.97 \mathrm{~s} ; \Delta V=12.0 \mathrm{kt}$.

The noise metrics summarised on Table 6 indicate that it is possible to cut about $2 \operatorname{EPNL}(\mathrm{dB})$. Various other tests have been conducted, which indicate that these are not the absolute optima, because the result of the heuristic search depends on the initial choice of the free parameters.

A similar trajectory parametrisation for fly-over trajectory, Fig. 36. The sequence of events is clearly indicated in the figure. Point B is conventionally set at 800 feet (244 m) AGL. At that point there is a small thrust cut-back and the aircraft starts climbing at constant CAS (KCAS1, in $\mathrm{kt}$ ) until it reaches 3,000 feet $(914 \mathrm{~m})$, point C. Here it performs a level acceleration to point

\footnotetext{
${ }^{2}$ Free-ware code in various programming languages is available across the Internet.
} 


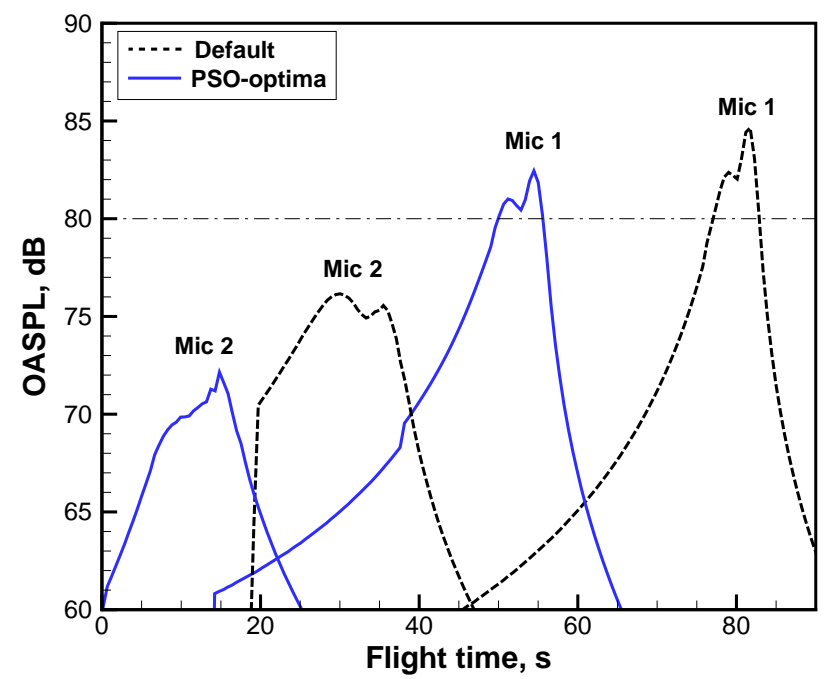

Figure 35: Optimisation of approach/landing trajectory for minimum noise at two receivers.

Table 6: Results of optimised approach trajectory.

\section{Mic $1 \quad$ Mic 2}

\begin{tabular}{ccccc} 
& Default & Optima & Default & Optima \\
\hline EPNL & 94.34 & 92.20 & 86.04 & 82.18 \\
SEL & 89.79 & 88.34 & 83.75 & 79.72 \\
LAeqT & 70.58 & 69.97 & 63.28 & 60.03 \\
\hline
\end{tabular}

D, where it has reached a target CAS for a third climb segment at CAS2 (KCAS2, in kt).

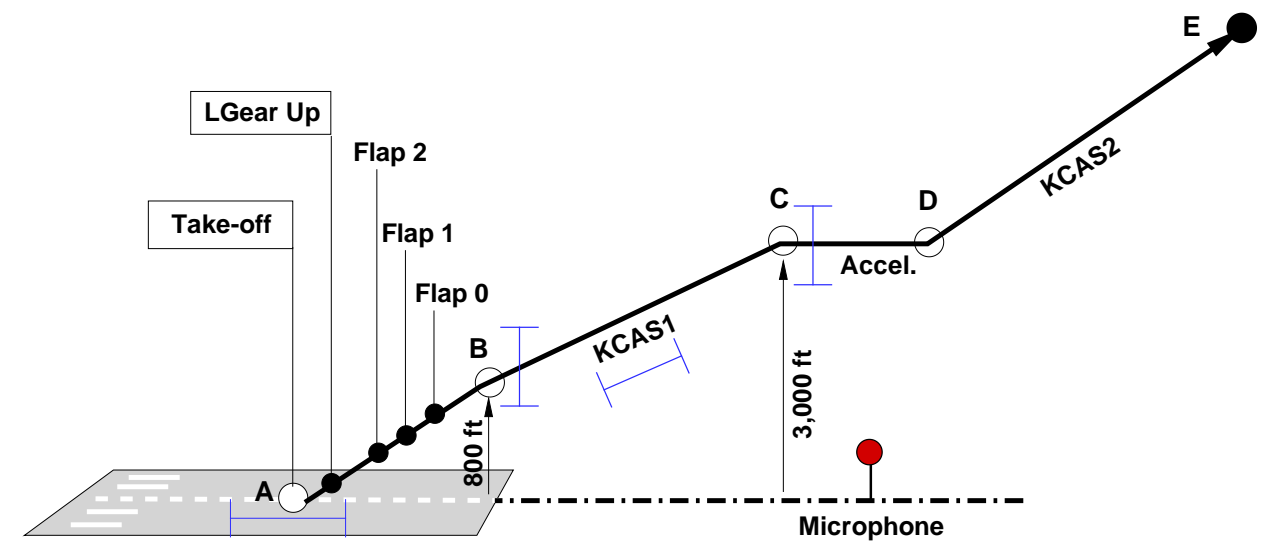

Figure 36: Take-off and climb-out nomenclature and flight path.

Tmhe take-off and climb-out have been parametrised, so that we can study the effect of the main parameters (thrust, speed, climb rate) on the noise perceived at a conventional microphone 
below the airplane (6,500 $\mathrm{m}$ from the brake-release point). The deployment and retraction of the lifting surfaces has not been parametrised because they have little effect on take-off noise. The free parameters listed in Table 7.

Table 7: Free parameters in fly-over (departure) trajectory optimisation; see Figure 36.

\begin{tabular}{lcccl}
\hline Parameter & Min & Max & Units & Description \\
\hline$d_{e}$ & 0.8 & 1.0 & - & Engine derating \\
$\Delta \gamma$ & 0.0 & 2.0 & $\mathrm{deg}$ & change in flight path angle \\
$\Delta z_{800}$ & 0.0 & 100 & $\mathrm{~m}$ & change in altitude with respect to 800 feet \\
$\Delta z_{4000}$ & 0.0 & 100 & $\mathrm{~m}$ & change in altitude with respect to 4,000 feet \\
$\Delta v_{c}$ & 0.0 & 10 & $\mathrm{~m} / \mathrm{s}$ & change in climb rate, $1^{\text {st }}$ segment \\
$\Delta F_{N}$ & 0.8 & 1.0 & - & thrust cut-back \\
\hline
\end{tabular}

The optimised departure trajectory is given by the noise metrics shown on Table 8; the corresponding free parameters are: $\Delta \gamma=1.44 \mathrm{degs}, d_{e}=0.935 ; d z_{800}=84.5 \mathrm{~m} ; d z_{4000}=37.5 \mathrm{~m}$; $\Delta v_{c}=6.84 \mathrm{~m} / \mathrm{s}, \Delta F_{N}=0.904$.

Table 8: Results of optimised departure trajectory.

\begin{tabular}{ccc}
\hline & Default & Optima \\
\hline EPNL & 96.63 & 92.87 \\
SEL & 93.38 & 91.12 \\
LAeqT & 70.10 & 69.81 \\
\hline
\end{tabular}

We conclude that although the trajectories are severely constrained, there is scope for noise minimisation by using a reduced-order analysis, which can eventually be coupled with cost functions involving fuel consumption, flight time and environmental emissions.

\section{Conclusions}

Aircraft noise is a buoyant area of research, dominated by needs at several levels Considerable advances have been made in recent years in a number of related fields. In this paper we have pointed out several problems that are still open to a solution. The key points of our findings are as follows:

- Noise due to aircraft operations is a more complex problem than noise created by other means of transport and human activities. This penalty is reflected by the large number of noise metrics devised, many of them in place as a regulatory measure. These metrics 
refer to instantaneous events, single trajectories and cumulative effects due to traffic over a typical day. It was emphasised how we have evolved to dislike aircraft noise more than causes of ground noise, perhaps because we have not evolved by fearing threats from the sky. A field of research has been developed as a result (psycho-acoustics).

- In response to technological needs at several levels, the number of aircraft simulation models has been rapidly expanding in recent years, with efforts devoted either to best-practice methods or to semi-scientific methods making use of some degree of empiricism. A large amount of experimental evidence has been gathered from wind tunnel and fly-over tests, including parametric effects that currently are not included in the prediction methods.

- Whilst best-practice methods have gained acceptance by industry, airports and national aviation regulators, scientific noise prediction methods remain so far confined to conceptual studies and are considered of inferior reliability, in spite of recognised shortcomings of the best-practice methods, which are now synonymous of "standard". How do we bridge this gap?

- There is a need to identify the noise sources; to identify when these sources are relevant, and which are the operational and design parameters that must be modelled. Not everything is important, not at the same time. A robust sensitivity analysis is required. We need to expand the design of the experiments and surrogate models for the validation. How accurate should our prediction be? — What is the meaning of "high fidelity"?

- At the level of noise source modelling there is a need to advance most sub-models from a rudimental state, still dominated by empiricism. Although empiricism has served us well over many years, we are at a stage where there is increased momentum in the research capabilities. Major constraints remain in terms of developing methods that are reasonably accurate, whilst being physically rational and computationally affordable. Ideally, these methods are based on computational aero-acoustics. However, we also recognise that some physics-based models have been proposed and successfully validated in a number of areas, including propeller noise and short-distance noise propagation. Better models for compressor noise are needed.

- With very few exceptions, the effects of geometrical details cannot be modelled with the 
methods described in this paper. Since progress in this area is likely to come from design fine-tuning, small adjustments have to be modelled. At present, only computational aeroacoustics can address these problems. From the point of view of comprehensive noise models, reduction of complexity is essential, though not to the point of being unable to discriminate between important parameters; the fan and the duct are a case in point.

- At the level of computational burden, this can no longer be considered an issue. It is possible to increase the burden by two orders of magnitude and still obtain solutions in a reasonable amount of time. However, the use of field methods for isolated components will remain confined to detailed analysis, design and optimisation.

- Noise minimisation alone will not be sufficient to satisfy all the concurrent requirements and constraints on modern aircraft operations. Therefore, there is a need for comprehensive models that expand from noise alone to a full environmental impact, including exhaust emissions, fuel consumption, flight time. In fact, noise-optimum solutions are often incompatible with fuel-time optimum solutions.

- Comparisons between measured fly-over noise data and noise predictions are not yet mature; comparisons shown in this paper, as well as in the literature cited, indicate that major gaps still exist, some of which must be attributed to internal and external uncertainties. These gaps cannot be identified when dealing with conceptual aircraft design. Validation and verification of isolated components at a selected conditions is necessary but not sufficient.

- Code-to-code comparisons aiming at improving scientific noise predictions have not yet been developed. An agreement is needed to establish the accuracy required for important applications such as certification, community annoyance and noise footprints. With regards to the latter item, no reliable comparison has been shown to date; unresolved issues remain at the level of noise propagation over complex ground topography and over long distances; nevertheless, the accuracy of the best-practice tools described in this paper is taken for granted. This is particularly serious if policy decisions are derived from such tools. Some research on "noise mapping" is available, though not fully documented.

- At the level of cooperation among stake-holders, there is a need of expanding the availability of experimental data, which should include key engine parameters (required for engine noise 
validation models), airframe parameters (particularly in the high-lift applications) as well as good-quality fly-over measurements. FDR data would be very useful for partial validation. This field of research is currently dominated by commercial interests.

- From the design point of view, we could benefit from systems capable of creating silent drag. Drag is required to dissipate the energy on approach and landing, but not at the expense of noise. Aside from fairing of landing gears, research in this area is modest.

A number of noise calculations done with the FLIGHT program have been shown. This calculations indicate the range of problems that can be tackled and the accuracy issues.

For reference, trajectory calculations of a turbofan airplane take $<45$ seconds on a current workstation in absence of winds, and $\sim 10$ minutes the presence of shear winds. Turboprop calculations are slower ( $\sim 3$ minutes, without winds), due to the propeller and flight mechanics trim. For footprint calculations, these numbers have to be multiplied by the number of grid points (we use $\sim 600$ grid points or more). Most of the effort is derived from the propagation modules. The trajectory optimisation requires several hours of computing time.

\section{Acknowledgments}

The Author wishes to acknowledge the contribution of his research group: Richard Hughes (noise measurements; acoustic liners), Zulfaa Mohammed-Kassim (noise propagation; engine and airframe noise), Jian Jiang (noise shielding), Xiaofang Wang (trajectory optimisation) for their contributions to the developments of the computer program FLIGHT. This work has been partly funded by the EU CleanSky Systems for Green Operations (SGO), Grant Agreements 255750 and 277580 , as well as private syndicates.

[1] Heller HH. Propeller aircraft noise legislation - A comprehensive review. Progress in Aerospace Sciences, 23(4), pp. 239-342, 1986. doi:10.1016/0376-0421(86)90009-6.

[2] Smith MTJ. Aircraft Noise. Cambridge University Press, 2004.

[3] ECAC. Report on standard method of computing noise contours around civil airports. Vol. 1: Applications guide. Technical Report Doc. 29, European Civil Aviation Conference, Dec. 2005.

[4] Schultz TJ. Synthesis of social surveys on noise annoyance. J. Acoust. Soc. Am., 64(2), pp. 377-405, 1978. doi:10.1121/1.382013. 
[5] Fidell S, Barber DS, and Schultz TJ. Using a dosage-effect relationship for the prevalence of annoyance due to general transportation noise. J. Acoust. Soc. Am., 89(1), pp. 221-233, 1991. doi:10.1121/1.400504.

[6] Fidell S and Silvati L. Parsimonious alternative to regression analysis in characterizing prevalence rates of aircraft noise analysis issues. Noise Control Eng. J., 52(1), pp. 56-68, Jan. 2004.

[7] Casalino D, Nölting S, Fares E, Van de Ven T, Pérot F, and Brés GA. Towards numerical aircraft noise certification: Analysis of a full-scale landing gear in fly-over configuration. In 18th AIAA/CEAS Aeroacoustics Conf., AIAA 2012-2235. Colorado Springs, May 2012.

[8] Quantities and Procedures for Description and Measurement of Environmental Sound Part 6: Methods for Estimation of Awakenings Associated with Outdoor Noise Events Heard in Homes, 2008. ANSI S.10.9-2008/6.

[9] Passchier-Vermeer W, Vos H, Steenbekkers JHM, van der Ploeg FD, and GroothuisOudshoorn K. Sleep disturbance and aircraft noise exposure. Technical Report 2002.027, TNO Prevention \& Health, Leiden, NL, Jun. 2002.

[10] Basner M, Samel A, and Isermann U. Aircraft noise effects on sleep: Application of the results of a large polysomnographic field study. J. Acoust. Soc. Am., 119(5), pp. 2772-2784, May 2006. doi:101121/1.2184247.

[11] Haines MM, Stanfeld SA, Brentnall S, Head J, Berry B, Jiggins M, and Hygge S. The West London schools study: The effects of noise exposure on child health. Psychological Medicine, 31(8), pp. 1385-1396, Nov. 2001. doi:10.1017/S003329170100469X.

[12] Haines MM, Stansfeld SA, Job RFS, Berglund B, and Head J. Chronic aircraft noise exposure, stress responses, mental health and cognitive performance in school children. Psychological Medicine, 31:265-277, Jan. 2001.

[13] Anon. Acoustical Terminology, American National Standard. Technical Report S1.1-1994, ANSI, Jun. 1994.

[14] Schultz TJ. Community Noise Ratings. Applied Science Publishers, 2nd edition, 1982. ISBN 0853341370. 
[15] Anon. Acoustics - Unattended monitoring of aircraft sound in the vicinity of airports. BS Standards Publications, 2009. BS ISO 20906:2009.

[16] Monkman D and McMahon J. London Heathrow airport: Strategic noise maps 2006. Technical Report ERCD-0706, ERCD, Civil Aviation Authority, 2007.

[17] Anon. Specification for octave-band and fractional octave-band analog and digital-filters. Technical Report S1.11-2004, ANSI, Jun. 2004.

[18] Michel U. Correlation of aircraft certification noise levels EPNL with controlling physical parameters. In 19th AIAA/CEAS Aeroacoustics Conf., AIAA 2013-2014. Berlin, May 2013.

[19] Lim C, Kim J, Hong J, and Lee S. Effect of background noise levels on community annoyance from aircraft noise. J. Acoust. Soc. Am., 123(2), pp. 766-771, Feb 2008. doi: $10.1121 / 1.2821985$.

[20] Anon. Acoustics-Description: Measurement and Assessment of Environmental Sound Part 1: Basic Quantities and Assessment Procedures. 1996-1:2003. ISO, Genève, Switzerland, 2003.

[21] Berglund B, Hassmen P, and Soames JRF. Sources and effects of low-frequency noise. $J$. Acoust. Soc. Am., 99(5), pp. 2985-3002, 1996. doi:10.1121/1.414863.

[22] Mace RA. Ownership of Airspace, volume 17. Univ. Cincinnati Law Rev., 1948. p. 344.

[23] Lee J, Beaton D, Edmonds L, and Patel J. Noise exposure contours for Heathrow Airport, 2009. Technical Report ERCD-1001, ERCD, Civil Aviation Authority, Mar. 2010.

[24] Jopson I, Rhodes D, and Havelock P. Aircraft noise - How accurate do we need to be? Technical Report ERCD-1102, ERCD, Civil Aviation Authority, Mar. 2003. (Unofficial report).

[25] Feitelson EJ, Hurd RE, and Mudge RR. The impact of airport noise on the willingness to pay for residences. Transp. Res. D, 1(1), pp. 1-14, 1996. doi: 10.1016/S1361-9209(96)00004-1.

[26] Raney JP. Development of a new computer system for aircraft noise prediction. J. Sound E Vibration, 75:536, 1975. 
[27] Clark BJ. Computer program to predict aircraft noise levels. Technical Report TP-1913, NASA, 1981.

[28] Zorumski WE. Aircraft noise prediction program (ANOPP) theoretical manual - Part 1. Technical Report TM 83199, NASA, Feb. 1982.

[29] Zorumski WE. Aircraft noise prediction program (ANOPP) theoretical manual - Part 2. Technical Report TM-83199, NASA, Feb. 1982.

[30] Kontos K, Janardan B, and Gliebe P. Improved NASA-ANOPP noise prediction computer code for advanced subsonic propulsion systems - Volume 1. Technical Report CR-195480, NASA, Aug. 1996.

[31] Hough JW and Weir DS. Aircraft noise prediction program (ANOPP) fan noise prediction for small engines. Technical Report CR-198300, NASA, 1996.

[32] Lopes LV and Burley CL. Design of the next generation aircraft noise prediction program: ANOPP2. In 17th AIAA/CEAS Aeroacoustics Conf., AIAA 2011-2854, Portland, Jun. 2011.

[33] Stone JR, Krejsa EA, and Clark BJ. Philosophy and evolution of a semi-empirical model for jet noise prediction. In 42nd AIAA Aerospace Sciences Meeting, AIAA 2004-0361. Reno, NV, Jan. 2004.

[34] Diedrich A, Hileman J, Tan D, Willcox K, and Spakovszky Z. Multidisciplinary design and optimization of the silent aircraft. In 44th AIAA Aerospace Sciences Meeting and Exhibit, AIAA 2006-1323, Jan. 2006.

[35] Hileman J, Spakovszky Z, Drela M, and Sargeant M. Airframe design for silent aircraft. In AIAA Aerospace Sciences Meeting, AIAA 2007-0453, Reno, NV, Jan 2007.

[36] Agarwal A, Dowling AP, Shin HC, and Graham W. A ray tracing approach to calculate acoustic shielding by the silent aircraft airframe. In 12th AIAA/CEAS Aeroacoustics Conf., AIAA 2006-2618, May 2006.

[37] Bertsch L, Dobrzynski W, and Guerin S. Tool development for low-noise aircraft design. J. Aircraft, 47(2), pp. 694-699, 2010. 
[38] Bertsch L. Noise Prediction within Conceptual Aircraft Design. PhD thesis, Institute of Aerodynamics and Flow Technology, DLR, Braunschweig, 2013.

[39] Liersch C and Hepperle M. A unified approach for multidisciplinary preliminary aircraft design. In CEAS European Air and Space Conf., Oct. 2009.

[40] Isermann U, Matschat K, and Müller EA. Prediction of aircraft noise around airports by a simulation procedure. In InterNoise, pages 717-722. Cambridge, MA, 1986.

[41] DLR. Leiser flugverkehr II - Abschussbericht. Technical report, DLR, Göttingen, Dec. 2007. (in German; available for download from ww.dlr.de).

[42] Bertsch L and Isermann U. Noise prediction toolbox used by the DLR aircraft noise working group. In Internoise, Paper 0206, Innsbruck, Sept. 2013.

[43] Henke R. Validation of wing technologies on an Airbus A340 flying testbed: First flight test results from the European program AWIATOR. In 24th Congress of the ICAS, Yokohama, Japan, Paper ICAS-2004-4.4, volume 1, 2004.

[44] Dobrzynski W, Pott-Pollenske M, Buchholz H, Isermann U, König R, Heimann D, Jans W, Brandes KH, Scheid U, Saueressing G, and Köhler I. Messkampagne zur Verifizierung lärmoptimierte Flugverfahren. Technical report, DLR, Braunschweig, Germany, Jun. 2007.

[45] Niese W. Lärmoptimierte An- und Abflugverfahren LanAb. zusammenfassender schlussbericht des forschungsprojecks gefordert von Bundesministerium Wirtschaft und Technologie. Technical report, DLR, Nov. 2007.

[46] Olson ED and Mavris DN. Aircraft conceptual design and risk analysis using physics-based noise prediction. In 12th AIAA/CEAS Aeroacoustics Conf., AIAA 2006-2619, Cambridge, MA, May 2006.

[47] Airbus. Getting to grips with aircraft noise. Technical report, Flight Operations Support Dept., Blagnac, France, Dec. 2003.

[48] Shahadi PA. Military aircraft noise. J. Aircraft, 12(8), pp. 653-657, 1975. 
[49] Neilsen T, Gee K, and James M. Spectral characterization in the near and mid-field of military jet aircraft noise. In 19th AIAA/CEAS Aeroacoustics Conf., AIAA 2013-2191. Berlin, 2013.

[50] Plotkin KJ. The role of aircraft noise simulation models. In Int. Congress on Noise Control Eng. (InterNoise). Den Hag, NL, Aug. 2001.

[51] Moulton CL. Air force procedure for predicting noise around airbases: Noise exposure model (NOISEMAP). Technical Report AL-TR-1992-059, 1992.

[52] ESDU. Aircraft Noise Prediction. Data Item 09009. ESDU International, London, Nov. 2011.

[53] Filippone A. Comprehensive analysis of transport aircraft flight performance. Progress Aero. Sciences, 43(3), pp. 192-236, April 2007. doi:10.1016/j.paerosci.2007.10.005.

[54] Filippone A. Analysis of carbon-dioxide emissions from transport aircraft. J. Aircraft, 45(1), pp. 183-195, Jan. 2008. doi:10.2514/1.31422.

[55] Filippone A. On the benefits of lower Mach number aircraft cruise. Aeronautical J., 111(1122), pp. 531-542, Aug. 2007.

[56] Filippone A. Theoretical framework for the simulation of transport aircraft flight. J. Aircraft, 47(5), pp. 1669-1696, Sept 2010.

[57] Filippone A. Multi-disciplinary simulation of propeller-turboprop aircraft flight. Aeronautical J., 116(1184), pp. 985-1014, Oct 2012.

[58] Filippone A. Advanced Aircraft Flight Performance. Cambridge Univ. Press, 2012.

[59] Boeker ER, Dinges E, He B, Fleming G, Roof CJ, Gerbi PJ, Rapoza AS, and Hemann J. Integrated noise model (INM) Version 7.0. Technical Report FAA-AEE-08-01, Federal Aviation Administration, Jan. 2008.

[60] SAE A21 Committee. Procedure for the calculation of aircraft noise in the vicinity of airports. Technical Report SAE-AIR-1845, Society of Automotive Engineers, Warrendale, PA, Mar. 1986. 
[61] Anon. Recommended method for computing noise contours around airports. Technical Report Circular 205-AN/1/125, ICAO, 1987 (revised 2001).

[62] ECAC. Report on standard method of computing noise contours around civil airports. Vol. 2: Technical guide. Technical Report Doc. 29, European Civil Aviation Conference, Dec. 2005 .

[63] Ollerhead JB. The CAA aircraft noise contour model ANCON version 1. Technical Report R\&D 9120, ERCD Dept., Civil Aviation Authority (CAA), Nov. 1992.

[64] Ollerhead JB, Rhodes DP, Viinikainen MS, Monkman DJ, and Woodley AC. The UK civil aircraft noise contour model ANCON: Improvements in Version 2. Technical Report R\&D 9842, ERCD Dept., Civil Aviation Authority (CAA), Jun. 1999.

[65] Pietrzko S and Bütikofer R. FLULA — Swiss aircraft noise prediction program. In Acoustics 2002, Ann. Conf. Australian Acoust. Soc., pages 92-99, Adelaide, Australia, Nov. 2002.

[66] Schäffer B, Bütikofer R, and Isermann U. Aircraft noise: Accounting for changes in air traffic with time of day. J. Acoust. Soc. Am., 129(1), pp. 185-199, Jan 2011. doi: 10.1121/1.3518729.

[67] Isermann U. Anleitung zur Berechtung von Lärmschutzbereichen (AzB). Technical report, DLR, May 2007. (in German).

[68] Brunet M, Chaboud T, and Huynh N et al. Environmental evaluation of air transport systems through physical modeling and simulation. In 9th AIAA/ATIO Conf., AIAA 20096936, Hilton Head, SC, Sept. 2009.

[69] Aubry S, Chaboud T, Dupeyrat M, Elie A, Huynh N, Lefebvre T, and Riviere T. Evaluating the local environmental impact of air traffic with air transport systems evaluation infrastructure: Outputs and validation walkthrough. Proc. IMechE, Part G: J. Aero. Eng., 226:1192-1201, 2012. doi:10.1177/0954410011419413.

[70] Malbéqui P, Rozenberg Y, and Bulté J. Aircraft noise prediction in the IESTA program. In European Conf. for Aerospace Sciences, EUCASS. Versailles, July 2009. 
[71] Bertsch L, Guérin S, Looye G, and Pott-Pollenske M. The parametric aircraft noise analysis module - Status overview and recent applications. In 17th AIAA/CEAS Aeroacoustics Conf., AIAA 2011-2855, Portland, Oregon, Jun. 2011.

[72] Alexandre A, Barde J-Ph, and Pearce DW. The practical determination of a charge for noise pollution. J. Transport Econ. E Policy, 14(2), pp. 205-220, May 1980.

[73] Girvin R. Aircraft noise-abatement and mitigation strategies. J. Air Transp. Management, 15(1), pp. 14-22, 2009.

[74] Hubbard HH, editor. Aeroacoustics of Flight Vehicles: Theory and Practice: Noise Sources, volume 1 of TR 90-3052. 1991.

[75] Block PJW. Assessment of airframe noise. J. Aircraft, 16(12), pp. 834-841, Dec. 1979.

[76] Kipersztok O and Sengupta G. Flight test of the 747-JT9D for airframe noise. J. Aircraft, 19(12), pp. 1061-1069, 1982.

[77] Horne WC, Burnside NJ, Soderman PT, Jaeger SM, Reinero BR, James KD, and Arledge TK. Aeroacoustic study of a $26 \%$ scale semispan model of a Boeing 777 in the NASA Ames 40- by 80-foot wind tunnel. Technical Report TP 2004-212802, NASA, Oct. 2004.

[78] Horner W, James K, Arledge T, Soderman P, Burnside N, Jaeger S, and Gordon C. Measurements of a $26 \%$ scale 777 airframe noise in the NASA Ames 40 by 80 foot wind tunnel. In 11th AIAA/CEAS Aeroacoustics Conf., AIAA-2005-2810. Monterey, CA, May 2005.

[79] Crighton DG. Model equations of nonlinear acoustics. Ann. Rev. Fluid Mech., 11:11-33, 1979.

[80] Farassat F and Casper JH. Towards an airframe noise prediction methodology: Survey of current approaches. In 44th AIAA Aerospace Sciences Meeting, AIAA 2006-0210, Reno, NV, Jan. 2006.

[81] Fink MR. Noise component method for airframe noise. J. Aircraft, 16(10), pp. 659-665, 1979.

[82] Fink MR and Schlinke RH. Airframe noise component interaction studies. J. Aircraft, 17(2), pp. 99-105, 1980. 
[83] Crighton DG. Aeroacoustics of Flight Vehicles: Theory and Practice, volume RP 1258, WRDC TR-90-3052, chapter Airframe Noise. NASA, 1991.

[84] Rackl RG, Miller G, Guo Y, and Yamamoto K. Airframe noise studies - review and future direction. Technical Report CR-2005-213767, NASA, Jun. 2005.

[85] Casalino D, Diozzi F, Sannino R, and Paonessa A. Aircraft noise reduction technologies: A bibliographic review. Aero Sci. E Techn., 12(1), pp. 1-17, Jan. 2008. doi:10.1016/j.ast.2007.10.004.

[86] Dobrzynski W, Ewert R, Pott-Pollenske M, Herr M, and Delfs J. Research at DLR towards airframe noise prediction and reduction. J. Aero. Sci. Tech., 12(1), pp. 80-90, Mar. 2008. doi:10.1016/j.ast.2007.10.014.

[87] Dobrzynski W. Almost 40 years of airframe noise research: What did we achieve? J. Aircraft, 47(2), pp. 353-367, Mar. 2010. doi:10.2514/1.44457.

[88] ESDU. An Introduction to Aircraft Noise. Data Item 02020. ESDU International, London, Dec. 2002.

[89] ESDU. Airframe Noise Prediction. Data Item 90023. ESDU International, London, June 2003.

[90] Amiet RK. Noise due to turbulent flow past a trailing edge. J. Sound $\mathscr{E}$ Vibration, 47(3), pp. 387-393, 1976.

[91] Rossignol KS. Development of an empirical prediction model for flap side-edge noise. In 16th AIAA/CEAS Aeroacoustics Conf, AIAA 2010-3836. Stockholm, May 2010.

[92] Rossignol KS. Flow field measurements to characterize flap side-edge noise generation. In 19th AIAA/CEAS Aeroacoustics Conf., AIAA 2013-2061. Berlin, May 2013.

[93] Brooks TF and Humphreys WM. Flap-edge aeroacoustic measurements and predictions. J. Sound E Vibration, 261(1), pp. 31-74, Jan. 2003. doi:10.1016/S0022-460X(02)00939-2.

[94] Hayes JA, Horne WC, , and Jaeger SM Soderman PT. Measurement of Reynolds number effect on airframe noise in the 12-foot pressure wind tunnel. In 15th Aerodynamic Decelerator Systems Conf., AIAA 1999-1959. Jun. 1999. 
[95] Guo YP and Joshi MC. Aircraft characteristics of aircraft hight lift systems. AIAA J., 41(7), pp. 1247-1256, July 2003. doi:10.2514/2.2093.

[96] Ura H, Yokokawa Y, Inamura T, and Yamamoto K. Investigation of airframe noise from high lift configuration model. In 46th AIAA Aerospace Sciences Meeting, AIAA 2008-0019. Reno, NV, Jan. 2008.

[97] Dobrzynski W, Gehlhar B, and Buchholz H. Model and full scale high-lift wing wind tunnel experiments dedicated to airframe noise reduction. Aero. Sci. \& Techn., 5(1), pp. 27 - 33, 2001.

[98] Howe MS. A review of the theory of trailing edge noise. J. Sound E Vibration, 61(3), pp. 437-466, Dec. 1978. doi: 10.16/0022-460x(82)90391-7.

[99] Howe MS. On the generation of side-edge flap noise. J. Sound $\mathcal{E}$ Vibration, 80(4), pp. 555-573, Feb. 1982. doi: 10.16/0022-460x(82)90498-9.

[100] Hardin JC. Noise radiation from the side edges of flaps. AIAA J., 18(5), May 1980.

[101] Sen R. Vortex-oscillation model of airfoil side-edge noise. AIAA J., 35(3), pp. 441-449, Mar. 1997. doi:10.2514/2.149.

[102] Rossignol KS. Empirical prediction of flap tip noise. In 17th AIAA/CEAS Aeroacoustics Conf, AIAA 2011-2733. Portland, OR, Jun. 2011.

[103] Guo YP, Yamamoto KJ, and Stoker RW. Component-based empirical model for high-lift system noise prediction. J. Aircraft, 40(5), pp. 914-922, Sept. 2003.

[104] Sen R, Hardy B, Yamamoto K, Guo YP, and Miller G. Airframe noise sub-component definition and model. Technical Report CR-2004-213255, NASA, Sept. 2004.

[105] Guo YP. Aircraft flap side edge noise modeling and prediction. In 17th AIAA/CEAS Aeroacoustics Conf., AIAA 2011-2731. Portland, OR, Jun. 2010.

[106] Guo YP. Flap side edge noise modeling and prediction. J. Sound E Vibration, 332(5), pp. 3846-3868, Aug 2013. doi: 10.1016/j.jsv.2013.02.029. 
[107] Revel JD, Kuntz HL, Balena FJ, Horne C, Storm BL, and Dougherty RP. Trailing-edge flap noise reduction by porous acoustic treatment. In 3rd AIAA/CEAS Aeroacoustics Conf., AIAA 1997-1646. May 1997.

[108] Guo YP. On noise reduction by flap side edge fences. J. Sound \& Vibration, 277(1), pp. 369-390, Oct. 2004.

[109] Choudhari M and Khorrami M. Slat cove unsteadiness: Effect of 3D flow features. In AIAA Aerospace Sciences Meeting, AIAA 2006-0211. Reno, NV, Jan. 2006.

[110] Khorrami MR and Lockhard DP. Effects of geometric details on a slat noise generation and propagation. In 12th AIAA/CEAS Aeroacoustic Conf., AIAA 2006-2664. Cambridge, MA, May 2006.

[111] Dobrzynski W and Pott-Pollenske M. Slat noise source studies for farfield noise prediction. In 7th AIAA/CEAS Aeroacoustics Conf., AIAA 2001-2158, Maastricht, NL, May 2001.

[112] Mendoza JM, Brooks TF, and Humphreys WM. Aeroacoustic measurements of a wing/slat model. In 8th AIAA/CEAS Aeroacoustics Conf., AIAA 2002-2604. Brenckenridge, CO, May 2002.

[113] Fleury V and Malbéqui P. Slat noise assessment from an A340 flyover acoustic measurements with a microphone phased array. In 4th Beamforming Conf. Berlin, 2012.

[114] Pott-Pollenske M, Dobrzynski W, Buchholz H, Guerin S, Sauressig G, and Finke U. Airframe noise characteristics from flyover measurements and predictions. In 12th AIAA/CEAS Aeroacoustics Conf., AIAA 2006-2567, Cambridge, May 2006.

[115] Guo YP. Slat noise modeling and prediction. J. Sound \& Vibration, 331(15), pp. 3567-3586, 2013. doi: $10.1016 /$ j.jsv.2012.03.016.

[116] Casalino D. CFD/CAA analysis of the LAGOON landing gear configuration. In 19th AIAA/CEAS Aeroacoustics Conf., AIAA 2013-2256. Berlin, May 2013.

[117] Humphreys WM and Brooks TF. Noise spectra and directivity for a scale-model landing gear. In $13^{\text {th }}$ AIAA/CEAS Aeroacoustics Conf., AIAA 2007-3458, Rome, Italy, May 2007. 
[118] Zawodny NS, Liu F, Yardibi T, Cattafesta L, Khorrami MR, and Neuhart DH. A comparative study of a 1/4-scale Gulfstream G550 aircraft nose gear model. In 15th AIAA/CEAS Aeroacoustic Conf., AIAA 2009-3153. May 2009.

[119] Zawodny NS, Dussault D, Ukeiley L, Liu F, and Cattafesta L. Characterization of noise generation on a canonical nose landing gear sub-system. In 19th AIAA/CEAS Aeroacoustics Conf., AIAA 2013-2116. Berlin, May 2013.

[120] Smith M, Chow L, and Molin N. The influence of aerodynamic interactions between components on landing gear noise. In 19th AIAA/CEAS Aeroacoustics Conf., AIAA 2013-2118, Berlin, May 2013.

[121] Dobrzynski W, Schoning B, Choi CL, Wood C, Smith M, and Seror C. Design and testing of low noise landing gears. In 11th AIAA/CEAS Aeroacoustics Conf., AIAA 2005-3008. AIAA, Monterey, CA, 2005.

[122] Dobrzynski W and Buchholz H. Full-scale noise testing on Airbus landing gears in the German Dutch wind tunnel. In 3rd AIAA/CEAS Aeroacoustics Conf., AIAA 1997-1597. AIAA, Atlanta, GA, 1997.

[123] Guo YP, Yamamoto KJ, and Stoker RW. Experimental study on aircraft landing gear noise. J. Aircraft, 43(2), pp. 306-317, Mar. 2006. doi: 10.2514/1.11085.

[124] Ravetta P, Burdisso R, and Ng W. Wind tunnel aeroacoustic measurement of a 26\%-scale 777 main landing gear. In 10th AIAA/CEAS Aeroacoustics Conf., AIAA 2004-2885. AIAA, Manchester, UK, 2004.

[125] Dedoussi I, Hynes T, and Siller H. Investigating landing gear noise using fly-over data: The case of Boeing 747-400. In 19th AIAA/CEAS Aeroacoustics Conf., AIAA 2013-2115. Berlin, May 2013.

[126] Michel U and Qiao W. Directivity of landing-gear noise based on flyover measurements. In 13th AIAA/CEAS Aeroacoustics Conf., AIAA 1999-1956, Monterey, CA, May 1999.

[127] Oerlemans S and Pott-Pollenske M. An experimental study of gear wake and flap interaction. In 10th AIAA/CEAS Aeroacoustics Conf., AIAA 2004-2886. 2004. 
[128] Molin N, Piet JF, Chow L, Smith M, Dobrzynski W, and Seror C. Prediction of low noise aircraft landing gears and comparison with test results. In 12th AIAA/CEAS Aeroacoustics Conf., AIAA 2006-2623, Cambridge, MA, May 2006.

[129] Smith MG and Chow LC. Prediction method for aerodynamic noise from aircraft landing gear. In 4th AIAA/CEAS Aeroacoustics Conf., AIAA 1998-2228. Jun. 1998. doi:10.2514/6.1998-2228.

[130] Guo YP. Empirical prediction of aircraft landing gear noise. Technical Report CR-2005213780, NASA, 2005.

[131] Guo YP. A statistical model for landing gear noise prediction. J. Sound E V Vibration, 282:61-87, 2005. doi:10.1016/j.jsv.2004.02.021.

[132] Guo YP. A component-based model for aircraft landing gear noise prediction. J. Sound $\&$ Vibration, 312:801-820, 2008.

[133] Burley C, Brooks TF, Humphreys WM, and Rawls JW. ANOPP landing gear noise prediction comparisons to model-scale data. In 13th AIAA/CEAS Aeroacostics Conf., AIAA 2007-3459. Rome, Italy, May 2007.

[134] Heller HH and Dobrzynski WM. Sound radiation from aircraft wheel-well/landing gear configurations. J. Aircraft, 14(8), pp. 768-774, 1977.

[135] Lopes LV, Brentner KS, Morris PJ, Lilley GM, and Lockhard DP. Complex landing gear noise prediction using as simple toolkit. In AIAA Aerospace Sciences Meeting, AIAA 20051202, Reno, NV, Jan. 2005.

[136] Lopes LV. Prediction of landing gear noise reduction and comparison to measurements. In 16th AIAA/CEAS Aeroacoustics Conf., AIAA 2010-3970, Stockholm, Jun. 2010.

[137] Smith M, Chow L, Molin N, Piet N, and Carrilho J. Landing gear noise with installation effects. In 13th AIAA/CEAS Aeroacoustics Conf., AIAA 2007-3472, Rome, May 2007.

[138] Smith M, Carrilho J, Molin N, Piet JF, and Chow L. Modelling landing gear noise with installation effects. In 13th AIAA/CEAS Aeroacoustics Conf., AIAA 2007-3472, Rome, Italy, May 2007. 
[139] Marsden O, Bailly C, Bogey C, and Jondeau E. Investigation of flow features and acoustic radiation of a round cavity. J. Sound \& Vibration, 331(15), pp. 3521-3543, July 2012. doi:10.1061/j.jsv.2012.03.017.

[140] Czech M, Crouch J, Stoker R, Strelets M, and Garbaruk A. Cavity noise generation from circular and rectangular vent holes. In 12th AIAA/CEAS Aeroacoustics Conf., AIAA 20062508, Cambridge, MA, May 2006.

[141] Ravetta P, Burdisso R, and Ng W. Noise control of landing gears using elastic membranebased fairings. In 13th AIAA/CEAS Conf., AIAA 2007-3466. Rome, Italy, May 2007.

[142] Liu Y and Dowling A. Assessment of the contribution of surface roughness to airframe noise. AIAA J., 45(4), pp. 855-869, Apr. 2007. doi:10.2514/1.25217.

[143] Lilley GM. A study of the silent flight of the owl. In 4th AIAA/CEAS Aeroacoustics Conf., AIAA 1998-2340, Jun. 1998. doi:10.2514/6.1998-2340.

[144] Lilley GM. The prediction of airframe noise and comparison with experiment. J. Sound $\mathcal{F}$ Vibration, 239(4), pp. 849-859, Jan. 2001. doi:10.1006/jsvi/2000.3219.

[145] Lockard DP and Lilley GM. The airframe noise reduction challenge. Technical Report TM-213013, NASA, 2004.

[146] Sarradj E, Fritzsche C, and Geyer T. Silent owl flight: Bird flyover noise measurements. AIAA J., 49(4), pp. 769-779, Apr. 2011. doi: 10.2514/1.J050703.

[147] Klann JL and Snyder CE. NEPP programmers manual. volume 1: Technical description. Technical Report TM-106595, NASA, 1994.

[148] Visser O, Kogenhop O, and Oostveen M. A generic approach for gas turbine adaptive modeling. ASME J. Enginering for Gas Turbine ES Power, 128(1), pp. 13-19, Jan 2006.

[149] Envia E. Fan noise reduction: An overview. In 39th AIAA Aerospace Sciences Meeting, AIAA 2001-0661, Reno, NV, Jan. 2001.

[150] Envia E and Nallasamy M. Design selection and analysis of a swept and leaned stator concept. J. Sound \& Vibration, 228(9), pp. 793-836, Dec. 1999. doi:10.1006/jsvi.1999.2441. 
[151] Ganz UW, Joppa PD, Patten TJ, and Scharpf DF. Boeing 18-inch fan rig broadband test. Technical Report CR-1998-208704, NASA, 1998.

[152] Heidmann MF. Interim prediction method for fan and compressor noise source. Technical Report TM X-71763, NASA, 1979.

[153] ESDU. Prediction of Noise Generated by Fans and Compressors in Turbojet and Turbofan Engines Combustor Noise from Gas Turbine Engines. Data Item 05001. ESDU International, London, June 2003.

[154] Dunn MH, Tweed J, and Farassat F. The application of a boundary integral equation method to the prediction of ducted fan engine noise. J. Sound E Vibration, 227(5), pp. 1019-1048, 1999. doi:10.1006/jsvi.1999.2394.

[155] Nark DM, Envia E, and Burley CL. Fan noise prediction with applications to aircraft noise system assessment. In 15th AIAA/CEAS Aeroacoustics Conf., AIAA 2009-3291. Miami, FL, May 2009. 10.2514/6.2009-3291.

[156] Ventres CA, Theobald MS, and Mark WD. Turbofan noise generation. Volume 1: Analysis. Technical Report CR-167952, NASA, Jul. 1982.

[157] Meyer HD and Envia E. Aeroacoustic analysis of turbofan noise generation. Technical Report 4715, NASA, Mar. 1996.

[158] McAlpine A and Fisher MJ. On the prediction of "buzz-saw" noise in aero engine inlet ducts. J. Sound $\&$ Vibration, 248(1), pp. 123-149, Nov. 2001. doi:10.1006/jsvi.2001.3770.

[159] McAlpine A, Fisher MJ, and Tester BJ. "buzz-saw" noise: A comparison of measurement with prediction. J. Sound ES Vibration, 290(3-5), pp. 1202-1233, 2006.

[160] Lighthill MJ. On sound generated aerodynamically - Part II. Proc. Royal Soc. London, Sect. A, 222:1-32, 1954.

[161] Ribner HS. Perspectives on jet noise. AIAA J., 19(12), pp. 1513-1526, Dec. 1981.

[162] Huff DL and Envia E. Jet Engine Noise Generation, Prediction and Control, chapter Handbook of Noise and Vibration Control, 89, pages 1096-1108. John Wiley \& Sons, 2007. 
[163] Viswanathan K. Quality of jet noise data - Iissues, implications and needs. In 40th AIAA Aerospace Sciences Meeting, AIAA 2002-0365. Reno, NV, Jan. 2002.

[164] Balsa TF and Gliebe PR. Aerodynamics and noise of coaxial jets. AIAA J., 15(11), pp. 1550-1558, Nov. 1977.

[165] Fisher MJ, Preston GA, and Bryce WD. A modelling of the noise from coaxial jets. Part 1: With unheated primary flow. J. Sound ES Vibration, 209(3), pp. 385-403, Jan. 1998. doi:10.1006/jsvi.1997.1217.

[166] Fisher MJ, Preston GA, and Mead WD. A modelling of the noise from coaxial jets. Part 2: With heated primary flow. J. Sound ES Vibration, 209(3), pp. 405-417, Jan. 1998. doi:10.1006/jsvi.1997.1218.

[167] ESDU. Computer-based Estimation Procedure for Coaxial Jet Noise. Data Item 01004. ESDU International, London, May 2001.

[168] Stone JR, Groesbeck DE, and Zola CL. Conventional profile coaxial jet noise prediction. AIAA J., 21(3), pp. 336-342, Mar. 1983. doi:10.2514/3.8077.

[169] Stone JR, Krejsa EA, Clark BJ, and Berton JJ. Jet noise modeling for suppressed and unsuppressed aircraft in simulated flight. Technical Report TM-2009-215524, NASA, Mar. 2009 .

[170] Stone JR, Krejsa EA, and Clark BJ. Enhanced core noise modeling for turbofan engines. Technical Report CR-2011-217026, NASA, Jun. 2011.

[171] Stone JR, Krejsa EA, and Clark BJ. Jet noise modeling for coannular nozzles including the effects of chevrons. Technical Report CR-2003-212522, NASA, Sept. 2003.

[172] Anon. Gas Turbine Jet Exhaust Noise Prediction. SAE, 1994. ARP 876, Revision D.

[173] Bridges J, Khavaran A, and Hunter C. Assessment of current jet noise prediction capabilities. In 14th AIAA/CEAS Aeroacoustics Conf., AIAA 2008-2933. Vancouver, BC, May 2008 .

[174] Rask O, Kastner J, and Gutmark E. Understanding how chevrons modify noise in a supersonic jet with flight effects. AIAA J., 49(8), pp. 1569-1576, Aug. 2011. 
[175] Bridges J and Brown CA. Parametric testing of chevrons on single flow hot jets. In 10th AIAA/CEAS Conf., AIAA 2004-2824, Manchester, UK, Sept. 2004.

[176] Henderson B, Kinzie K, Whitmire J, and Abeysinghe A. The impact of fluidic chevrons on jet noise. In 11th AIAA/CEAS Conf., AIAA 2005-2888, Monterey, CA, May 2005.

[177] Henderson B and Bridges J. An MDOE investigation of chevrons for supersonic jet noise reduction. In 16th AIAA/CEAS Aeroacoustics Conf., AIAA 2010-3926, Stockholm, Jun. 2010.

[178] Low JKC. Ultra-high bypass ratio jet noise. Technical Report CR-195394, NASA, Oct. 1994.

[179] Viswanathan K, Czech MJ, and Lee IC. Toward prediction of dual stream jet noise: Database generation. AIAA J., 49(12), pp. 2695-2711, Dec. 2011. doi:10.2514/1.J051124.

[180] Gutierrez O. Results from cascade thrust reverser noise and suppression experiments. In Archive Set 107, Meeting Paper Archive. AIAA, Jan. 1963. doi:10.2514/6.1974-46.

[181] Rice C. Restricting use of reverse thrust as an emissions reduction strategy. Transportation Research Board: J. Transp. Res. Board, 1788:124-131, 2007. doi:10.3141/1788-16.

[182] Matta RK, Sandusky GT, and Doyle VL. GE core engine noise investigation - Low emission engines. Technical Report FAA-RD-74, FAA, Feb. 1977.

[183] Mendoza J, Nance D, and Ahuja K. Source separation from multiple microphone measurements in the far field of a full scale aero engine. In 14th AIAA/CEAS Acoustics Conf., AIAA 2008-2809. May 2008.

[184] Hultgren L. Core noise - NASA fundamental aeronautics subsonic fixed wing program. Acoustics Technical Working Group, Oct. 2010. NASA Glenn Research Center.

[185] Miles JH. Core noise diagnostics and turbofan engine noise using correlation and coherence functions. J. Propulsion ES Power, 26(2), pp. 303-316, Mar. 2010. doi:10.2514/1.42980.

[186] Mahan JR and Karchmer A. Combustion and core noise. Technical Report RP 1258, Vol. 1, pp. 483-517, NASA, 1991. 
[187] Hultgren LS. A comparison of combustor-noise models. In 18th AIAA/CEAS Aeroacoustics Conf., AIAA 2012-2087. Colorado Springs, CO, Jun. 2012.

[188] Stone JR, Krejsa EA, and Clark BJ. Enhanced core noise modeling for turbofan engines. Technical Report CR-2011-217026, NASA, Jun. 2011.

[189] ESDU. Prediction of Combustor Noise from Gas Turbine Engines. Data Item 05001. ESDU International, London, Feb. 2005.

[190] Hultgren L. Full-scale turbofan-engine turbine-transfer function determination using three internal sensors. In 17th AIAA/CEAS Aeroacoustics Conf., AIAA 2011-2912. Portland, OR, Jun. 2011.

[191] Schuster B and Lieber L. Narrowband model for gas turbine engine combustion noise prediction. In 12th AIAA/CEAS Aeroacoustics Conf., AIAA 2006-2677. Cambridge, MA, May 2006.

[192] ESDU. Prediction of Turbine Noise from Aero Engines. Data Item 12001. ESDU International, London, Mar. 2012.

[193] Tubbs RL. Case studies noise exposure to airline ramp employees. Appl. Occ. E Env. Hygiene, 15(9), pp. 657-663, 2000. doi:10.1080/1047322005011.

[194] Tam C, Pastouchenko N, Mendoza J, and Brown D. Combustion noise of auxiliary power units. In 11th AIAA/CEAS Aeroacoustics Conf., AIAA 2005-2829, Monterey, CA, May 2005.

[195] Kwan JSW and Yang SJE. Auxiliary power unit noise of Boeing B737 and B747 aircraft. NASA STI/Recon Technical Report A, 95:88468-+, 1992.

[196] Pott-Pollenske M, Dobrzynski W, Buchholtz H, and Almoneit D. Characteristics of noise from aircraft ground operations. In 13th AIAA/CEAS Aeroacoustics Conf., AIAA 20073560. May 2007.

[197] Schlinker RH and Amiet RK. Helicopter rotor trailing edge noise. Technical Report CR3470, NASA, 1981. 
[198] Farassat F. Linear acoustic formulas for calculation of rotating blade noise. AIAA J., 19(9), pp. 1122-1130, Sept. 1981. doi:10.2514/3.60051.

[199] Magliozzi B, Hanson DB, and Amiet RK. Propeller and propfan noise. In Hubbard HH, editor, Aeroacoustics of Flight Vehicles: Theory and Practice, RP 1258. NASA, Aug. 1991.

[200] Hanson DB and Fink MR. The importance of quadrupole sources in prediction of transonic tip speed propeller noise. J. Sound \& Vibration, 62(1), pp. 19-38, Jan. 1979. doi:10.1016/0022-460X(79)90554-6.

[201] Hanson DB. Near-field frequency-domain theory for propeller noise. AIAA J., 23(4), pp. 499-504, Apr. 1985. doi: 10.2514/3.8943.

[202] Hanson DB and Parzych DJ. Theory for noise of propellers in angular inflow with parametric studies and experimental verification. Technical Report CR-4499, NASA, Mar. 1993.

[203] ESDU. Prediction of Near-field and Far-field Harmonic Noise from Subsonic Propellers with Non-axial Inflow. Data Item 95029. ESDU International, London, 1996.

[204] Zorumski WE and Weir DS. Aircraft noise prediction program theoretical manual: Propeller aerodynamics and noise (part 3). Technical Report TM-83199, NASA, Feb. 1986.

[205] Kelly J and Nguyen C. Influence of shaft angle of attack on sound radiation by subsonic propellers. J. Aircraft, 34(4), pp. 539-544, July 1997. doi: 10.2514/2.2206.

[206] Farassat F and Succi GP. A review of propeller discrete frequency noise prediction technology with emphasis on two current methods for time domain calculations. J. Sound $\mathcal{F}$ Vibration, 71(3), pp. 399-419, Aug. 1980.

[207] Bielak GW, Premo JW, and Hersch AS. Advanced turbofan duct liner concepts. Technical Report CR-1999-209002, NASA, Feb. 1999.

[208] Dittmar JH and Elliot DM. Some acoustic results from the Pratt and Whitney advanced ducted propulsor — Fan 1. Technical Report TM 1999-209049, NASA, Mar. 1999.

[209] Gerhold CH, Jones MG, Brown M, and Nark D. Advanced computational and experimental techniques for nacelle liner performance evaluation. In 15th AIAA/CEAS Aeroacoustics Conf., AIAA 2009-3168. Miami, FL, May 2009. doi:10.2514/6.2009-3168. 
[210] Law TR and Dowling AP. Optimization of traditional and blown liners for a silent aircraft. In 12th AIAA/CEAS Aeroacoustic Conf., AIAA 2006-2525. Cambridge, MA, May 2006.

[211] ESDU. Normal incidence absorption coefficients and acoustic impedances of single layer perforated sheet liners. Data Item 74004. ESDU International, London, Nov. 1976.

[212] Jones MG, Parrott TL, and Watson WW. Uncertainty and sensitivity analysis of a twoparameter impedance prediction model. In 14th AIAA/CEAS Aeroacoustics Conf., AIAA 2008-2928. May 2008. doi:10.2514/6.2008-3013.

[213] Melling TH. The acoustic impendance of perforates at medium and high sound pressure levels. J. Sound \& Vibration, 29(1), pp. 1-65, 1973. doi: 10.1016/S0022-460X(73)80125-7.

[214] Zhao D, Morgans A, and Dowling A. Tuned passive control of acoustic damping of perforated liners. AIAA J., 49(4), Apr. 2011. doi:10.2514/1.J050613.

[215] Chien E, Ruiz M, Yu J, Morin B, Cicon D, Schweiger P, and Nark D. Comparison of predicted and measured attenuation of turbine noise from a static engine test. In 13th AIAA/CEAS Aeroacoustics Conf., AIAA 2007-3533. May 2007.

[216] Ko SH. Sound attenuation in acoustically lined circular ducts in the presence of uniform flow and shear flow. J. Sound ES Vibration, 22(2), pp. 193-210, 1972.

[217] Gerhold CH. Analytical model of jet shielding. AIAA J., 21(5), pp. 694-698, May 1983. doi: $10.2514 / 3.8135$.

[218] Simonich JC, Amiet RK, and Schlinker RH. Jet shielding of jet noise. Technical Report CR-3966, NASA, 1986. Experimental and theoretical study of jet noise reduction achieved by shielding one jet exhaust with a second, closely spaced and identical jet...

[219] ESDU. Jet-by-Jet Shielding of Noise. Data Item 88023. ESDU International, London, March 1992.

[220] Nark D, Burley C, Tinetti A, and Rawls J. Initial integration of noise prediction tools for acoustic scattering effects. In 14th AIAA/CEAS Aeroacoustics Conf., AIAA 2008-2996. Vancouver, BC, May 2008. 
[221] Agrawal A and Dowling A. The calculation of acoustic shielding of engine noise by the silent aircraft airframe. In 11th AIAA/CEAS Aeroacoustics Conf., AIAA 2005-2996, Monterey, CA, May 2005.

[222] Agarwal A and Dowling AP. Low-frequency acoustic shielding by the silent aircraft airframe. AIAA J., 45(2), pp. 358-365, Feb. 2007. doi:10.2514/1.19351.

[223] Papamoschou D. Prediction of jet noise shielding. In 48th AIAA Aerospace Science Meeting, AIAA 2010-0653, Orlando, FL, Jan. 2010.

[224] Lui WK and Li KM. The scattering of sound by a long cylinder above an impedance boundary. J. Acoust. Soc. Am., 127(2), pp. 664-674, 2010.

[225] Anon. Attenuation of sound during propagation outdoors - Part I: Calculation of the absorption of sound by the atmosphere. Technical Report ISO-9613-1, ISO, Genève, Switzerland, 1993.

[226] Anon. Attenuation of sound during propagation outdoors - Part II: General method of calculation. Technical Report ISO-9613-2, ISO, Genève, Switzerland, 1996.

[227] Attenborough K, Ming Li K, and Horoshenkov K. Predicting Outdoor Sound. Taylor \& Francis, 2007.

[228] Anon. Method for the calculation of the absorption of sound by the atmosphere. Technical Report S1.26-1978, ANSI, Jun. 1978.

[229] Anon. Standard values of atmospheric absorption at a function of temperature and humidity. Technical Report ARP-866A, SAE, 1975.

[230] Morfey CL and Howell GP. Nonlinear propagation of aircraft noise in the atmosphere. AIAA J., 19(8), pp. 986-992, Aug. 1981. doi:10.2514/3.51026.

[231] Maekawa Z. Noise reduction by screens. Appl. Acoustics, 1(3), pp. 157-173, Jul. 1968. doi:10.1016/0003-682X(68)90020-0.

[232] R. Rudnik, S. Melber, A. Ronzheimer, and O. Brodersen. Three-dimensional Navier-Stokes simulations for transport aircraft high-lift configurations. J. Aircraft, 38(5), pp. 895-903, 2001. 
[233] Ingard U. On the reflection of a spherical sound wave from an infinite plane. J. Acoust. Soc. Am., 23(3), pp. 329-335, 1951. doi:10.1121/1.1906767.

[234] Attenborough K. Review of ground effects on outdoor sound propagation from continuous broadband sources. Appl. Acoustics, 24(4), pp. 289-319, Jan. 1988. doi:10.1016/0003682X(88)90086-2.

[235] Attenborough K. Sound propagation close to the ground. Ann. Rev. Fluid Mech., 34(1), pp. 51-82, Jan. 2002. doi:10.1146/annurev.fluid.34.081701.143541.

[236] Embleton TFW, Piercy JE, and Olson N. Outdoor sound propagation over ground of finite impedance. J. Acoust. Soc. Am., 59(2), pp. 267-277, 1976. doi:10.1121/1.380882.

[237] Embleton TFW, Piercy JE, and Daigle GA. Effective flow resistivity of ground surfaces determined by acoustical measurements. J. Acoust. Soc. Am., 74(4), pp. 1239-1244, 1983. doi:10.1121/1.390029.

[238] Anon. Method for Predicting Lateral Attenuation of Airplane Noise. SAE, July 2012. AIR 5662, Revision D.

[239] Fleming G, Burstein J, Rapoza A, Senzig D, and Gulding J. Ground effects in FAA's integrated noise model. Noise Control Eng. J, 48(1), pp. 16-24, Jan 2000. doi:10.3397/1.2827979.

[240] Delaney M and Bazley E. Acoustical properties of fibrous absorbent materials. Appl. Acoustics, 3:105-116, 1970.

[241] Attenborough K. Ground parameter information for propagation modeling. J. Acoust. Soc. Am., 92(1), pp. 418-427, Jan. 1992. doi:10.1121/1.404251.

[242] Taraldsen G and Jonasson H. Aspects of ground effect modeling. J. Acoust. Soc. Am., 129(1), pp. 47-53, Jan. 2011. doi:10.1121/1.3500694.

[243] Attenborough K. Propagation of sound above a porous half-space. J. Acoust. Soc. Am., 68(1), pp. 1493, Jan. 1980. doi:10.1121/1.384074.

[244] Chessel CI. Propagation of noise along a finite impedance boundary. J. Acoust. Soc. Am., 62(4), pp. 825-834, Apr. 1977. 
[245] Hileman JI, Reynolds TG, de la Rosa Blanco E, Law T, and Thomas S. Development of approach procedures for silent aircraft. In 45th AIAA Aerospace Sciences Meeting, AIAA 2007-0451, Reno, NV, Jan. 2007.

[246] Gabillet Y, Schroeder H, Daigle GA, and L'Esperance A. Application of the Gaussian beam approach to sound propagation in three atmosphere: Theory and experiments. J. Acoust. Soc. Am., 93(6), pp. 3105-3116, 1993. doi:10.1121/1.405722.

[247] ESDU. The Correction of Measured Noise Spectra for the Effects of Ground Reflection. Data Item 94035. ESDU International, London, Dec. 1994.

[248] ESDU. An Introduction to Aircraft Noise Lateral Attenuation. Data Item 81035. ESDU International, London, Nov. 1981.

[249] Zorumski WE and Illshire WL. Downwind sound propagation in an atmospheric boundary layer. AIAA J., 27(5), pp. 515-523, May 1989. doi: 10.2514/3.10141.

[250] Rasmussen KB. Outdoor sound propagation under the influence of wind and temperature gradients. J. Sound \& Vibration, 104(2), pp. 321-335, Jan. 1986. doi:10.1016/0022460X(86)90271-3.

[251] Almgren M. Simulation by using a curved ground scale model of outdoor sound propagation under the influence of a constant sound speed gradient. J. Sound $\&$ Vibration, 118(2), pp. 353-370, Oct. 1987. doi:10.1016/0022-460X(87)90531-1.

[252] Pierce AD. Acoustics: An Introduction to Its Physical Principles and Applications. Acoust. Soc. America, 1989.

[253] L'Espérance A, Herzog P, Daigle, and G Nicolas J. Heuristic model for outdoor sound propagation based on an extension of the geometrical ray theory in the case of a linear sound speed profile. Applied Acoustics, 37(2), pp. 111-139, Feb. 1992. doi:10.1016/0003$682 \mathrm{X}(92) 90022-\mathrm{K}$.

[254] ESDU. Prediction of Sound Attenuation in a Refracting Turbulent Atmosphere with a Fast Field Program. Data item 04011. ESDU International, London, May 2004. 
[255] Lee SW, Richards WF, Bong N, and Raspet R. Impedance formulation of the fast field program for acoustic wave propagation in a layered medium. J. Acous. Soc. Am., 79(3), pp. 628-634, 1986. doi:10.1121/1.393452.

[256] Arntzen M, Rizzi SA, Visser HG, and Simons DG. A framework for simulation of aircraft flyover noise through a non-standard atmosphere. In 18th AIAA/CEAS Aeroacoustics Conf., AIAA 2012-2079. Colorado Springs, CO, Jun. 2012.

[257] Raspet R, Baird G, and Wu W. Normal mode solution for low-frequency sound propagation in a downward refracting atmosphere above a complex impedance plane. J. Acoust. Soc. Am., 91(3), pp. 1341-1351, 1992. doi:10.1121/1.402463.

[258] Raspet R and Baird G. The relationship between upward refraction above a complex impedance plane and the spherical wave evaluation for a homogeneous atmosphere. $J$. Acoust. Soc. Am., 89(1), pp. 107-114, 1991. doi:10.1121/1.397588.

[259] Yamamoto KJ and Donelson MJ. Long distance propagation model and its application to aircraft en route noise prediction. AIAA J., 32(1), pp. 207-209, Jan. 1994.

[260] Lamancusa JS and Darous PA. Ray tracing in a moving medium with two-dimensional sound-speed variation and application to sound propagation over terrain discontinuities. $J$. Acoust. Soc. Am., 93(4), pp. 1716-1726, 1993. doi:10.1121/1.406737.

[261] Attenborough K et al. Benchmark cases for outdoor sound propagation models. J. Acoust. Soc. Am, 97(1), pp. 173-191, 1995. doi:10.1121/412302.

[262] Li MK, Taherzadeh S, and Attenborough K. An improved ray-tracing algorithm for predicting sound propagation outdoors. J. Acoust. Soc. Am., 104(4), pp. 2077-2083, 1998. doi:10.1121/1.423721.

[263] Salomons ES. Computational Atmospheric Acoustics. Kluwer Academic Publishers, 2001.

[264] Visser WJP and Broomhead MJ. GSP: A generic object-oriented gas turbine simulation environment. In ASME Gas Turbine Conference, ASME 2000-GT-0002, Munich, Germany, 2000. Program available from www.gspteam.com.

[265] Vincenty M. Direct and inverse solutions of geodesics on the ellipsoid with application of nested equations. Technical Report XXIII, No. 176, Survey Review, 1975. 
[266] McCullers LA. Aircraft configuration optimization including optimized flight profiles. In Experiences in Multidisciplinary Analysis and Optimization, NASA CP-2327, pages 394412. NASA Langley, Jan 1984.

[267] McCullers LA. FLOPS User's Guide. Version 6.11. NASA Langley Research Center, Hampton, VA, 2004. (Various updates available).

[268] Filippone A. Rapid estimation of airfoil aerodynamics for helicopter rotor calculations. $J$. Aircraft, 45(4), pp. 1468-1472, July 2008.

[269] Siller H and Michel U. Buzz-saw noise spectra and directivity from flyover tests. In 12th AIAA/CEAS Aeroacoustics Conf., AIAA 2002-2562. Cambridge, MA, May 2002. doi:10.2514/6.2006-2464.

[270] Guerin S, Michel U, and Siller H. Airbus A319 database from dedicated flyover measurements to investigate noise abatement procedures. In 11th AIAA/CEAS Aeroacoustics Conf., AIAA 2005-2981. Monterey, CA, May 2005.

[271] Siller H, Michel U, Zwiener C, and Saueressig G. Reduction of approach noise of the MD-11. In 12th AIAA/CEAS Aeroacoustics Conf., AIAA 2006-2464. Cambridge, MA, May 2006. doi:10.2514/6.2006-2464.

[272] Pott-Pollenske M, Dobrzynski W, Buchholtz H, Bukhard G, and Walle F. Validation of a semiempirical airframe noise prediction method through dedicated A319 flyover noise measurements. In 8th AIAA/CEAS Aeroacoustics Conf., AIAA 2002-2470. May 2002.

[273] Chow LC, Mau K, and Remy H. Landing gears and high-lift devices airframe noise research. In 8th AIAA/CEAS Aeroacoustics Conf., AIAA 2002-2408. Breckenridge, CO, Jun. 2002.

[274] Piet JF, Michel U, and Böhning P. Localization of the acoustic sources of the A340 with a large phases microphone array during flight tests. In 8th AIAA/CEAS Aeroacoustics Conf., AIAA 2002-2506. May 2002.

[275] Sijtsma P and Stoker RW. Determination of absolute contributions of aircraft noise components using fly-over array measurements. In 10th AIAA/CEAS Aeroacoustics Conf., AIAA 2004-2058. Manchester, UK, May 2004. 
[276] Siller H, Drescher M, Saueressig G, and Lange R. Fly-over source localisation on a Boeing 747-400. In Beamforming Conf. Berlin, Feb. 2010.

[277] Shivashankara B and Stubbs GW. Ground plane microphone for measurement of aircraft flyover noise. J. Aircraft, 24(11), pp. 751-758, Nov. 1987. doi:10.2514/3.45517.

[278] Hughes R and Filippone A. Fly-over measurements and simulation for a turboprop aircraft. In InterNoise. Innsbruck, Sept. 2013.

[279] Filippone A and Bertsch L. Validation strategies for comprehensive aircraft noise prediction methods. In 12th AIAA/ATIO Conf. Indianapolis, IN, Sept. 2012.

[280] DeLaurentis DA and Mavris DN. Uncertainty modeling and management in multidisciplinary analysis and synthesis. In 38th AIAA Aerospace Sciences Meeting, AIAA 2000-0422, Reno, NV, Jan. 2000. doi:10.2514/6.2000-422.

[281] Dahl M. A process for assessing NASA's capability in aircraft noise prediction technology. In 14th AIAA/CEAS Aeroacoustics Conf., AIAA 2008-2813. Vancouver, BC, May 2008.

[282] Oberkampf WL and Trucano TG. Verification and validation in computational fluid dynamics. Progress Aero. Sciences, 38(3), pp. 209-272, Apr. 2002. doi:10.1016/S03760421(02)00005-2.

[283] Queipo N, Haftka R Shyy W, Goel T, Vaidyanathan R, and Tucker P. Surrogatebased analysis and optimisation. Prog. Aerospace Sciences, 41(1), pp. 1-28, 2005. 10.1016/j.paerosci.2005.02.001.

[284] Erkelens LJJ. Advanced noise abatement procedures for approach and departure. In AIAA Guidance, Navigation, and Control Conference and Exhibit, AIAA 2002-4858, Monterey, CA, Aug. 2002.

[285] Visser HG and Wijnen RAA. Optimization of noise abatement departure trajectories. $J$. Aircraft, 38(4), pp. 620-627, Jul. 2001. doi: 10.2514/2.2838.

[286] Visser HG and Wijnen RAA. Optimisation of noise abatement arrival trajectories. Aeronautical J., 107(1076), pp. 607-615, 2003. 
[287] Prats X, Puig V, and Quevedo J. Equitable aircraft noise-abatement departure procedures. J. Guidance, Control ES Dynamics, 34(1), pp. 192-203, Jan. 2011. doi: 10.2514/1.49530.

[288] Clarke JP. A System Analysis Methodology for Developing Single Event Noise Abatement Procedures. PhD thesis, MIT, Aero \& Astronautical Engineering, Cambridge, MA, Feb. 1997.

[289] Oliveira RF and Büskens C. Benefits of optimal flight planning on noise and emissions abatement at the Frankfurt airport. In AIAA Guigance, Navigation $\&$ Control Conf., AIAA 2012-4482, Minneapolis, MN, Aug. 2012.

[290] Koenig R and Macke O. Evaluation of simulator and flight tested noise abatement approach procedures. In 26th ICAS Congress. Braunschweig, Germany, 2008.

[291] Clarke JP, Ho NH, Ren L, Brown JA, Elmer KR, Tong KO, and Wat JW. Continuous descent approach: Design and flight test for Louisville international airport. J. Aircraft, 41(5), pp. 1054-1066, Sept. 2004. doi:10.2514/1.5572.

[292] Filippone A. Steep-descent manoeuvre of transport aircraft. J. Aircraft, 44(5), pp. 17271739, Sept. 2007. doi:10.2514/1.28980.

[293] Shah P, Mobed D, and Spakovszky Z. Engine air-brakes for quiet air transport. In 45th AIAA Aerospace Sciences Meeting, AIAA 2007-1033. Reno, NV, Jan. 2007.

[294] Bertsch L, Looye G, Anton E, and Schwanke S. Flyover noise measurements of a spiraling noise abatement approach procedure. J. Aircraft, 48(2), pp. 436-448, Mar. 2011. doi: 10.2514/1.C001005.

[295] Wijnen RAA and Visser HG. Optimal departure trajectories with respect to sleep disturbance. Aero. Sci.\& Technology, 7(1), pp. 81-91, Jan. 2003.

[296] de Oliveira RF and Büskens C. Benefits of optimal flight planning on noise and emissions abatement at the Frankfurt airport. In AIAA Guidance, Navigation $\& 5$ Control Conf., AIAA 2012-4482, Minneapolis, MN, Aug. 2012.

[297] Torres R, Chaptal J, Bes C, and Hiriart-Urruty JB. Optimal environmentally friendly departure procedures for civil aircraft. J. Aircraft, 48(1), pp. 1-22, Jan. 2011. doi:10.2514/1.C031012. 
[298] Antoine NE and Kroo I. A framework for aircraft conceptual design and environmental performance studies. AIAA J., 43(10), pp. 2100-2109, Oct. 2005. doi:10.2514/1.13017. 